\title{
Groei en productie van Corsicaanse den in Nederland
}

J.J. Jansen ${ }^{1}$, A. Oosterbaan ${ }^{2}$, G.M.J. Mohren ${ }^{1}$ en J. den Ouden $^{1}$

FEM Groei en Productie Rapport 2018 - 6

WAGENINGEN

UNIVERSITY \& RESEARᄃH

1 Forest Ecology and Forest Management group, Wageningen University, Department of Environmental Sciences

2 Nature and Society, Wageningen Environmental Research (WENR) 
Jansen, J.J., A. Oosterbaan, G.M.J. Mohren en J. den Ouden, 2018. Groei en productie van Corsicaanse den in Nederland. FEM Groei en Productie Rapport 2018 - 6, 109 blz.

Synopsis: Van 1925 tot 1990 is in Nederland op zeer grote schaal groei- en productieonderzoek bij de Corsicaanse den uitgevoerd. Dat betreft de studies van Becking en van de Dorschkamp/IBN. Samen met de permanente steekproeven uit de HOSP zijn 193 proefperken met 869 opnamen beschikbaar. Voor de ontwikkeling van de opperhoogte $\left(h_{t o p}\right)$ met de leeftijd $(t)$ werd het heteromorfe model van Jansen \& Hildebrand gekozen, met asymptoot en 3 andere parameters. Als maat voor de boniteit is de opperhoogte bij 50 jaar $\left(h_{50}\right)$ gekozen. De diameterontwikkeling tot een hoogte van $7 \mathrm{~m}$ werd het best verklaard met een Gompertz-functie in $h_{\text {top }}$, het stamtal na zuivering $\left(N_{R}\right)$, en $h_{50}$. Met het model van Jansen et al. (2016) werd de grondvlakbijgroei $\left(i_{G}\right)$ verklaard. Dat is een powerfunctie met $h_{\text {top }}, t$ en standruimte index van Hart $(S \%)$. Voor $S \%>22.4$ daalt de grondvlakbijgroei met een lineaire functie in $S \%$. Ook het opnamejaar in relatie tot het optreden van Brunchorstia taksterven speelde een rol. Het effect van de dunning op de diameter na dunning is gemodelleerd met een gemodificeerd La Bastide-Faber model. Met alle modellen is een opstand projectie model gemaakt, waarmee de gemeten opstandontwikkeling redelijk voorspeld werd. Er zijn opbrengsttabellen gemaakt met zeven boniteiten en zes verschillende dunninggraden.

Abstract: In the Netherlands, growth and yield research on Corsican pine was done from 1925 to 1990. This includes studies by Becking and by the Dorschkamp/IBN research institute. Together with the permanent sample plots from the timber prognosis system HOSP, all this comprises a dataset of 193 plots with 869 recordings. For the development of top height $h_{\text {top }}$ over age $(t)$, Jansen \& Hildebrand's model with asymptote and 3 additional parameters fitted best. As site index, top height at 50 year $\left(h_{50}\right)$ was chosen. The diameter development up to stand height of $7 \mathrm{~m}$ was best described with a Gompertz function based on $h_{\text {top }}$, the density after refinements $\left(N_{R}\right)$, and $h_{50}$. From a stand height of $7 \mathrm{~m}$ and up, the basal area increment $\left(i_{G}\right)$ was best described by a power function based on $h_{\text {top }}, t$, and the stand density index of Hart (S\%). For $S \%>22.4$ the basal area increment drops with increasing $S \%$. The year of recording in relation with Brunchorstia dieback was also included in the model. The effect of thinning on diameter after thinning was modelled with a modified La Bastide-Faber model. With all models together, a stand projection model was constructed, which follows the measured stand development reasonably well. The model was used to construct yield tables with seven site classes and six thinning intensities.

Keywords: Corsican pine, Pinus nigra subsp. salzmannii var. corsicana, Netherlands, yield tables, different thinning grade, Becking-Hart spacing index, height growth models, power model for basal area increment, Reineke's law and La Bastide-Faber model for thinning effect, stand projection model.

Dit rapport is gratis te downloaden op: https://doi.org/10.18174/444095

Dit rapport is gebaseerd op de database: Oosterbaan, A., J.J. Jansen, J.F. Oldenburger, G.M.J. Mohren \& J. den Ouden, 2016. FEM growth and yield data Monocultures - Corsican pine. DANS. http://dx.doi.org/10.17026/dans-zwm-kpmu 


\section{Voorwoord}

In Nederland zijn er zeer veel waarnemingen verricht in permanente proefperken van de Corsicaanse den (Pinus nigra subsp. salzmannii var. corsicana). Dit betreffen 685 opnamen in 139 proefperken tussen 1925 en 1990.

Becking \& De Vries (1959) nemen in hun set opbrengsttabellen een bewerking van de Britse tabel van Hummel \& Christie uit 1952 op. Jansen et al. (1996) kiezen in tabellenboek voor tabel van Faber (1987). Bartelink et al. (2001) geven een uitgebreid overzicht van de context en publicaties van het groei- en productieonderzoek aan deze en andere boomsoorten in Nederland.

Samen met de permanente steekproefpunten van de HOSP is er de huidige studie de beschikking over de gegevens van 193 plots met 869 opnamen.

In dit rapport wordt de ontwikkeling van opstanden van Corsicaanse den met verschillende dunninggraden geanalyseerd met het doel een groeimodel te maken bij een ruim scala aan beheerstrategieën. Deze studie is de achtste in een serie, waarin de groei en productie van douglas (Jansen et al., 2016), Japanse lariks (Jansen et al., 2018a), fijnspar (Jansen et al., 2018b), grove den (Jansen et al., 2018c), zomereik (Jansen et al., 2018d) en beuk (Jansen et al., 2018e) werden bestudeerd.

De studie volgt waar mogelijk dezelfde werkwijze als de voorgaande studies en vaak zijn delen van de tekst uit deze rapporten (soms ook zonder bronvermelding) overgenomen. Om de toegankelijkheid voor niet Nederlandse lezer te verhogen zijn alle figuren, en formules en veel tabellen van Engelse tekst voorzien.

Hans Jansen,

Wageningen, 2018 


\section{Inhoud}

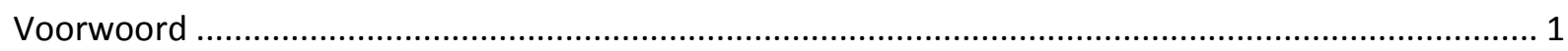

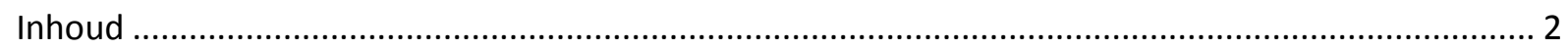

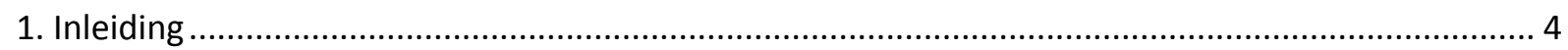

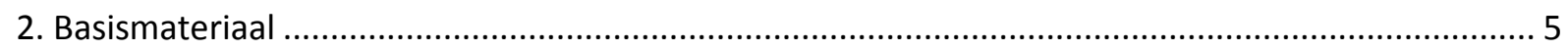

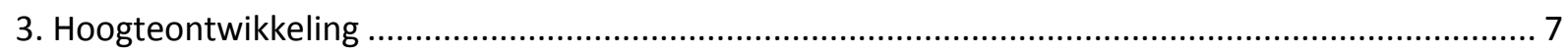

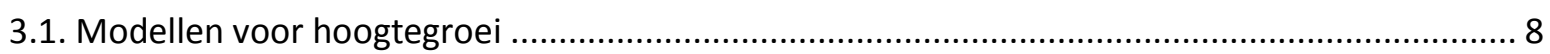

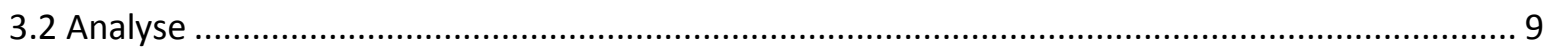

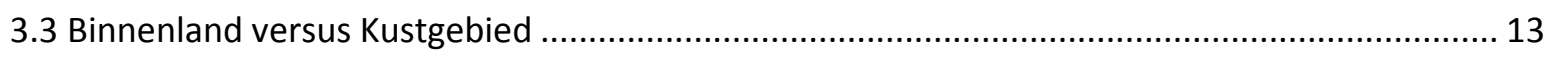

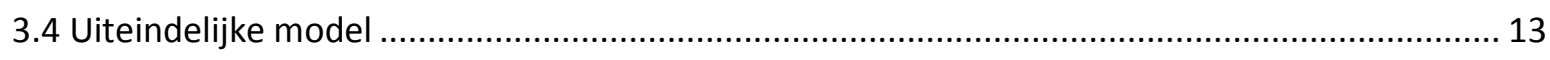

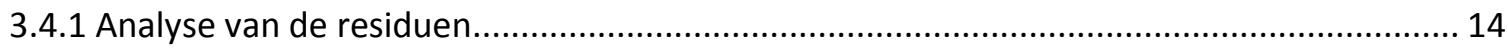

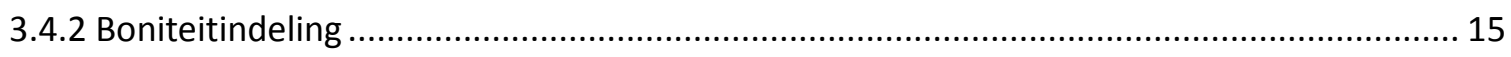

3.4.3 Modeltest met de controle plots .................................................................... 17

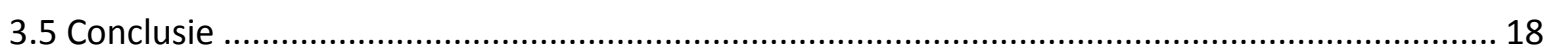

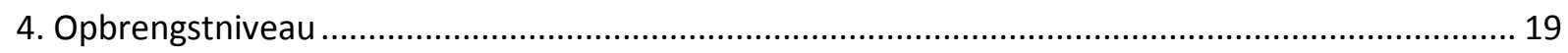

4.1 Diameter- en grondvlakontwikkeling tot een hoogte van $7 \mathrm{~m}$........................................ 19

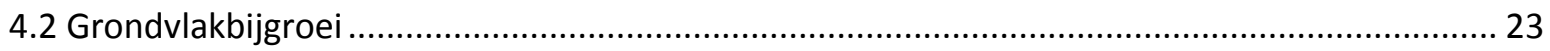

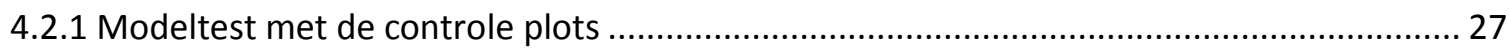

4.2.2 Aanpassing Model (16) met de controle plots en periode-index......................................28

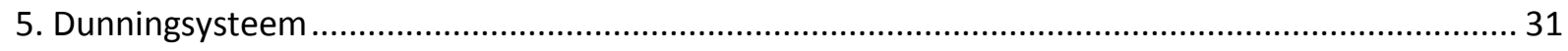

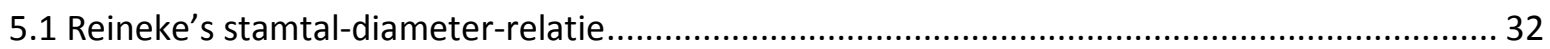

5.2 Model van La Bastide-Faber voor voorspelling diameter na dunning ................................... 33

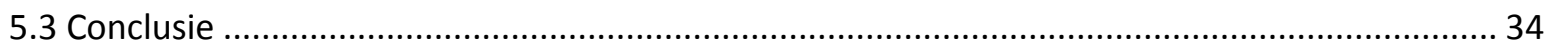

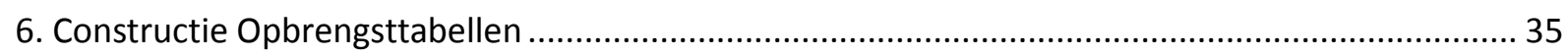

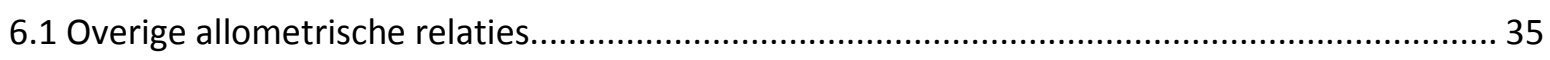

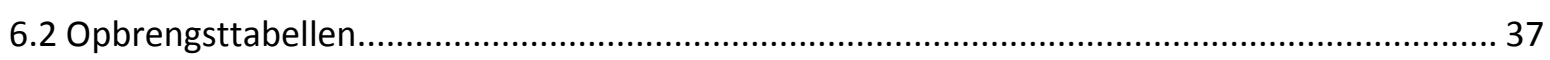

6.2.1 Keuze voor berekende opbrengsttabellen ........................................................... 37

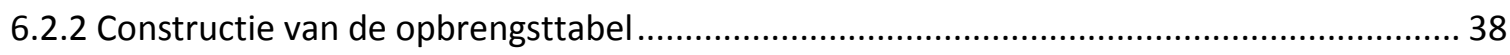

6.3 Kwaliteit van de voorspelling ................................................................................. 41

6.4 Vergelijking met andere opbrengsttabellen ................................................................... 42

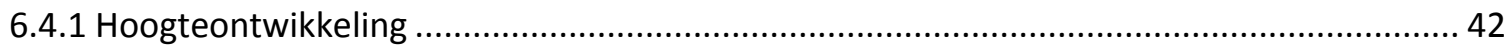

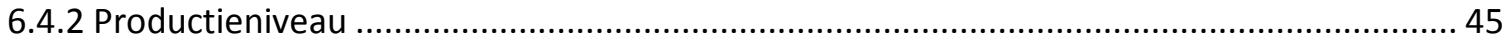

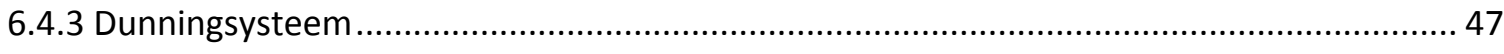

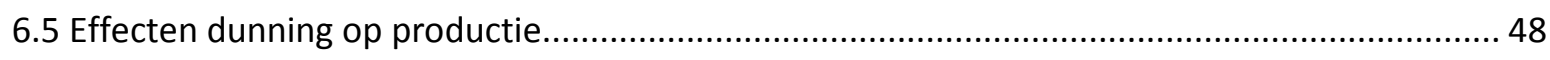




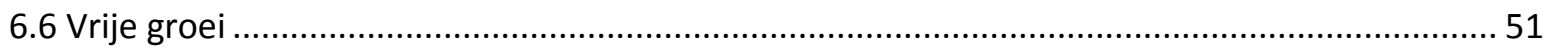

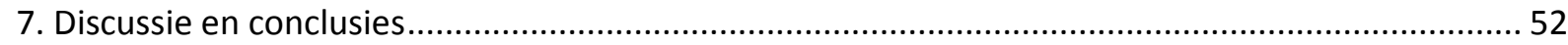

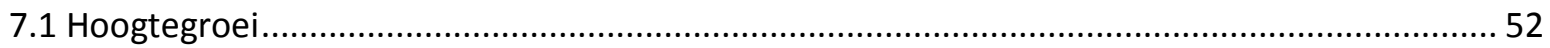

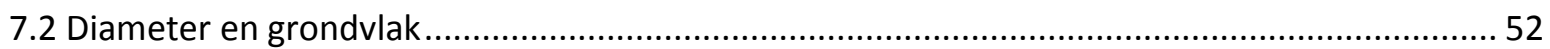

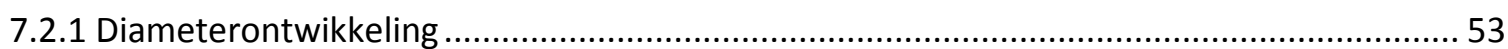

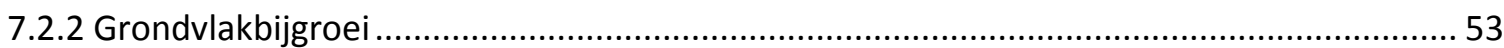

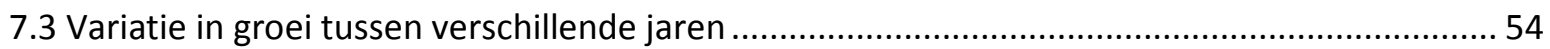

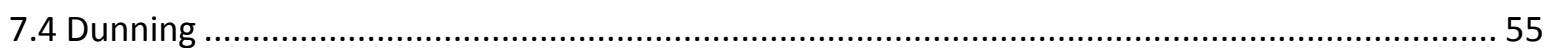

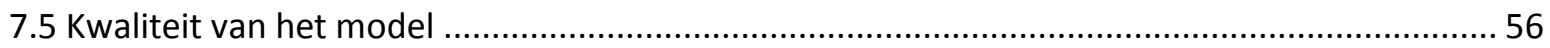

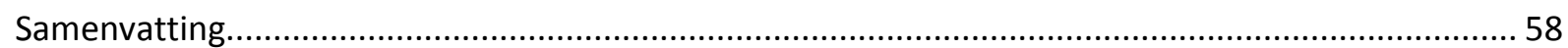

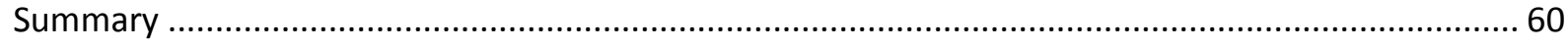

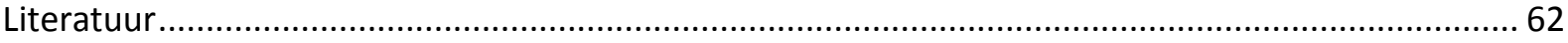

Bijlage 1. Opbrengsttabellen voor Corsicaanse den Nederland 2018.............................................. 65

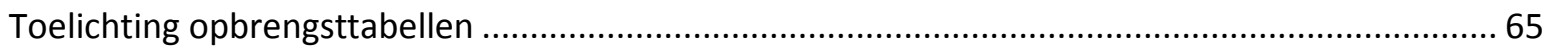

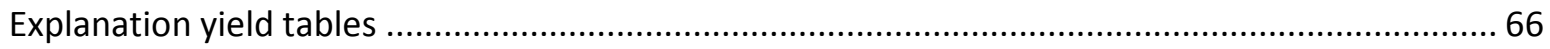

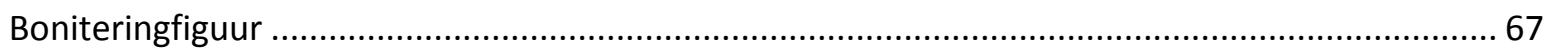

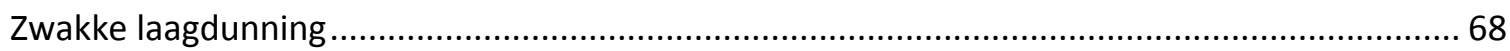

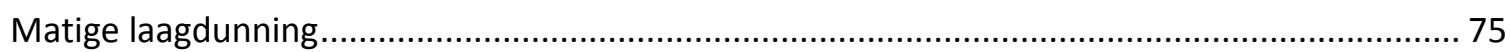

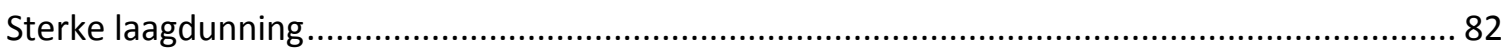

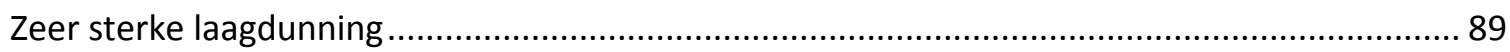

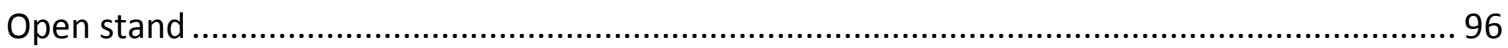

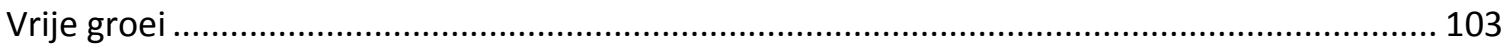




\section{Inleiding}

Tussen 1925 en 1990 zijn er gegevens verzameld over de groei van Corsicaanse den bij verschillende dunninggraden. Met deze gegevens is het mogelijk modellen te maken die de ontwikkeling van Corsicaanse dennenopstanden bij een variatie aan beheerstrategieën verklaren en mogelijk voorspellen. Eén van de gebruikelijke modellen is een opbrengsttabel. Faber (1987) heeft een opbrengsttabel voor de Corsicaanse den met één dunningregime gemaakt, welk geclassificeerd kan worden als een sterke tot zeer sterke laagdunning. Voor de tabel zelf zie Jansen et al. (1996). Een opbrengsttabel is een model waarmee de opstandontwikkeling in de tijd wordt beschreven en het bestaat meestal uit drie submodellen:

1. Model voor de hoogteontwikkeling, dit wordt In Hoofdstuk 3 besproken;

2. Model voor de grondvlakbijgroei in de tijd of relatief ten opzichte van de hoogte, waarmee het productieniveau van opstanden kan worden voorspeld, dit wordt In Hoofdstuk 4 besproken;

3. Model voor de dunning. Dit model moet een definitie geven van de dunninggraden, daarnaast is het de vraag wat de interactie is met model ad 2 bij verschillende dunninggraden. In Hoofdstuk 5 komen deze vragen aan de orde.

In Hoofdstuk 2 worden de basisgegevens besproken. In Hoofdstuk 6 worden de 3 submodellen geïntegreerd tot een serie opbrengsttabellen. Deze worden vergeleken met andere tabellen en voorspellende kwaliteit van de modellen wordt gekwantificeerd. De tabellen zijn te vinden in Bijlage 1. 


\section{Basismateriaal}

Sinds 1925 is in Nederland onderzoek gedaan naar de ontwikkeling van Corsicaanse dennenopstanden. In dit onderzoek gaat het om de volgende gebruikte studies:

1. Dunningonderzoek Becking 1951-1984 met 4 proefperken met in totaal 78 opnamen. De behandeling betreft een laagdunning met een vaste dunninggraad;

2. Groei- en productieonderzoek Dorschkamp/IBN 1925 - 1990 ten behoeve van opbrengsttabellen. Er zijn 106 proefperken met 443 opnamen;

3. Plantafstandproeven IBN 1960-1986 met 29 proefperken en 164 opnamen;

4. HOSP 1984-2000, in beheer bij Probos. Dit zijn ca. 3000 permanente steekproefpunten uit de 4 e bosstatistiek. Hieruit zijn 54 monocultures met Corsicaanse geselecteerd met in totaal 184 opnamen.

In totaal gaat het om 869 opnamen in 193 proefperken.

De proefvelden van studie 1, 2 en 3 betreffen proefvakken met een vaste oppervlakte. Soms wordt die oppervlakte kleiner door stormschade. De gegevens zijn daarna opnieuw berekend over de kleinste oppervlakte. In studie 4 gaat het om vaste steekproefpunten met een variërende straal zodanig dat er minimaal 25 bomen in de steekproef liggen. Door kap of ingroei kan deze wijzigen. Alleen dat deel wat in alle opnamen aanwezig was is bij het onderzoek betrokken.

Voor het bepalen van de dunninggraad is het S-procent van Hart (1928) (ook bekend als de Hart-Becking Spacing Index) van alle perken en opnamen berekend met formule (1):

$$
S \%=\frac{a_{a t}}{h_{\text {top }}} \cdot 100=\frac{100}{h_{\text {top }}} \cdot \sqrt{\frac{10000}{N_{a t}} \cdot \frac{2}{\sqrt{3}}} \approx \frac{10745.7}{h_{\text {top }} \cdot \sqrt{N_{a t}}}
$$

In deze definitie is de gemiddelde boomafstand na dunning $\left(a_{a t}\right)$ bepaald met een regelmatig driehoekverband. Het symbool $h_{\text {top }}$ staat voor de opperhoogte.

Van alle proefperken zijn basisgegevens als oppervlakte, kiemjaar en ligging bekend. Bij de ligging is onderscheid gemaakt tussen de regio's Noord (Drenthe, Friesland en Groningen, kop van Overijssel) met 2 proefperken, Midden (rest Overijssel, Gelderland, Utrecht en het Gooi) met 57 proefperken, Zuid (Noord-Brabant en Limburg) met 77 proefperken, Kustgebied (Waddeneilanden en duinstrook in Noord-Holland, Zuid-Holland en Zeeland) met 52 proefperken en West (Flevoland en de rest van Noord-Holland, Zuid-Holland en Zeeland) met 5 proefperken. In de vigerende opbrengsttabel voor Corsicaanse den (Faber 1987) is onderscheid gemaakt tussen het Kustgebied (52 proefperken) en het Binnenland (de rest met 141 proefperken)

De afzonderlijke metingen en berekeningen aan de bomen in de proefperken vormen de basisgegevens. Deze zijn daarna geaggregeerd tot kenmerken per ha per proefperk van voor, na, en van de dunning. De boomgegevens spelen in deze studie alleen een rol om de opstandkenmerken te genereren.

Per proefperk en opname zijn de gegevens beschikbaar, zoals vermeld in Tabel 1. 
Voor een volledige beschrijving van gemeten en berekende gegevens zie de file "Read me FEM growth and yield data Monocultures - Corsican pine.pdf" in de database FEM growth and yield data Monocultures - Corsican pine (Oosterbaan et al., 2016).

Tabel 1. Basisgegevens per plot en opname.

Table 1. Base information per plot and recording

\begin{tabular}{|c|c|c|}
\hline Naam & Symbool & Betekenis \\
\hline plotnr & & Plotnummer \\
\hline study & & Studienummer \\
\hline region & & Regio \\
\hline area & & Plotoppervlakte in ha \\
\hline yog & & Kiemjaar \\
\hline NO & $N_{0}$ & Beginstamtal \\
\hline sperc & $S \%$ & gemiddelde Hart-Becking Spacing Index in plot \\
\hline sperc0 & $S_{0} \%$ & Actuele Hart-Becking Spacing Index in de opname \\
\hline nrec & & Aantal opnamen \\
\hline rec & & Opname nummer \\
\hline DOR & & Datum van de opname \\
\hline age & $t$ & Leeftijd in jr \\
\hline htop & $h_{\text {top }}$ & Opperhoogte in m \\
\hline hdom & $h_{\text {dom }}$ & Dominante hoogte in $\mathrm{m}$ \\
\hline ddom & $d_{d o m}$ & Diameter van de dominante hoogte boom in $\mathrm{cm}$ \\
\hline N_bt & $N_{b t}$ & Stamtal per ha voor dunning \\
\hline G_bt & $G_{b t}$ & Grondvlak voor dunning in $\mathrm{m}^{2} / \mathrm{ha}$ \\
\hline h_bt & $h_{b t}$ & Hoogte van de grondvlak-middenstam in $\mathrm{m}$ voor dunning \\
\hline dg_bt & $d_{b t}$ & Diameter van de grondvlak-middenstam in $\mathrm{cm}$ voor dunning \\
\hline V_bt & $V_{b t}$ & Volume voor dunning in $\mathrm{m}^{3} / \mathrm{ha}$ \\
\hline N_th & $N_{t h}$ & Stamtal per ha van de dunning \\
\hline G_th & $G_{t h}$ & Grondvlak van de dunning in $\mathrm{m}^{2} / \mathrm{ha}$ \\
\hline h_th & $h_{t h}$ & Hoogte van de grondvlak-middenstam in $\mathrm{m}$ van de dunning \\
\hline dg_th & $d_{t h}$ & Diameter van de grondvlak-middenstam in $\mathrm{cm}$ van de dunning \\
\hline V_th & $V_{t h}$ & Volume van de dunning in $\mathrm{m}^{3} / \mathrm{ha}$ \\
\hline N_at & $N_{a t}$ & Stamtal per ha na dunning \\
\hline G_at & $G_{a t}$ & Grondvlak na dunning in $\mathrm{m}^{2} / \mathrm{ha}$ \\
\hline h_at & $h_{a t}$ & Hoogte van de grondvlak-middenstam in m na dunning \\
\hline dg_at & $d_{a t}$ & Diameter van de grondvlak-middenstam in $\mathrm{cm}$ na dunning \\
\hline V_at & $V_{a t}$ & Volume na dunning in $\mathrm{m}^{3} / \mathrm{ha}$ \\
\hline
\end{tabular}




\section{Hoogteontwikkeling}

In deze studie zijn de 54 HOSP plots als controle gebruik. Van de 139 overige proefperken liggen er 97 met 478 opnamen in het Binnenland en 42 met 168 opnamen in het Kustgebied. In Figuur 1 is de hoogteontwikkeling per plot weergegeven.

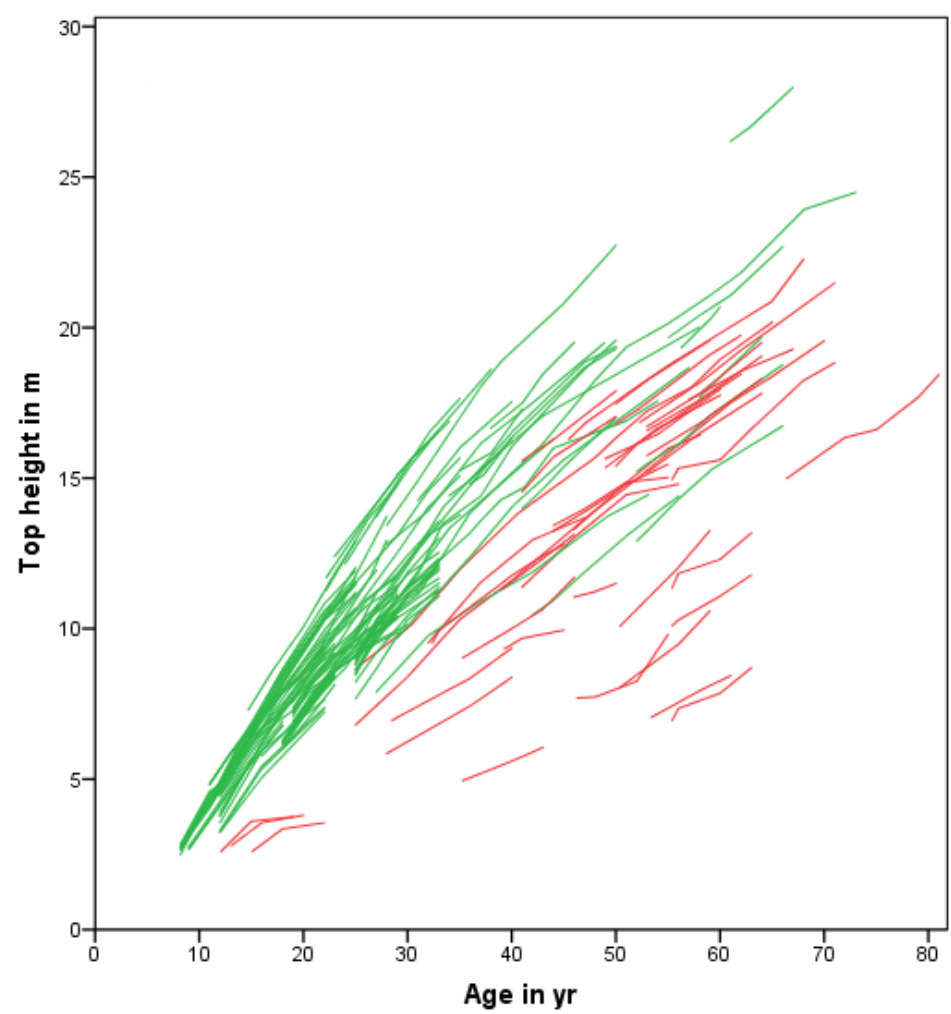

Figuur 1. Hoogteontwikkeling in de Corsicaanse dennenproefperken in Nederland, in groen voor het Binnenland en in rood voor het Kustgebied.

Figure 1. Development of tree height in the Corsican pine plots in the Inland part of the Netherlands (green lines) and in the Coastal part (red lines).

Er is nog geen sprake van een afplattingshoogte, in de controle plots blijkt dat wel voor te komen, maar daar rijkt de leeftijd tot 135 jaar.

Het is overduidelijke dat er een groot verschil is in groei tussen de beide Klimaatzones, de vraag is echter of dat alleen verschillen in boniteit betreft of ook vormverschillen in de curves. Eerst zal de beste groeifunctie voor de gezamenlijke klimaatzones worden bepaald, daar wordt onderzocht of er verschil is tussen de beide klimaatzones. In de klimaatzone Kustgebied vond de beste hoogtegroei plaats in plot 24 in het Robbenoordsbos in de Wieringermeerpolder. Omdat het oorspronkelijke eiland Wieringen tot het Kustgebied gerekend werd is hier destijds voor gekozen, maar in deze studie is dit plot tot het Binnenland gerekend. 


\subsection{Modellen voor hoogtegroei}

In de opbrengsttabellen tot ongeveer 1970 is de hoogteontwikkeling meestal handmatig gefit. Vanaf 1970 worden over het algemeen niet-lineaire groeifuncties gebruikt om de hoogteontwikkeling te fitten. In de huidige Nederlandse opbrengsttabel voor de Corsicaanse den (Faber, 1987) is het Chapman-Richards model gebruikt:

$$
h_{\text {top }}=S \cdot\left(1-e^{-a \cdot t}\right)^{b}
$$

In Formule (2) is S de zogenaamde "site index" de proefperkspecifieke constante en de asymptoot in het model. Deze $S$ kan gezien worden als de afplattingshoogte en het is tevens een maat voor de boniteit, in dit geval een absolute hoogteboniteit. Daarnaast wordt ook de hoogte bij een vaste leeftijd als maat voor de boniteit gebruikt. Voor de Corsicaanse den zal de $h_{50}$ worden gebruikt

Jansen et al. (2018a) testten 8 modellen voor de Japanse lariks, drie daarvan scoorden zo laag dat deze niet meer onderzocht zullen worden. De te onderzoeken modellen zijn Chapman-Richards, Burkhart \& Tennent, Jansen \& Hildebrand, Jansen et al., Cieszewski, zie Paragraaf 3.2 voor formules en referenties.

Jansen et al. (2018a) ontwikkelde een selectiemethode voor een model in 3 stappen. Als eerste een werd een MCA (Multi criteria-analyse) gebruik met 7 criteria. Daarna een visuele test met de data van de $4^{\mathrm{e}}$ bosstatistiek en vervolgens werd de voorspellende werking van de modellen vergeleken. De 7 criteria betreffen:

1. De algemene maat voor de verklaring, hiervoor is $R^{2}$ adj gebruikt;

2. De kwaliteit van de schatter van boniteit-parameters door naar de variatiecoëfficiënt $C V$ ervan te kijken. Indien het model voor alle proefperken geschikt is, zal het $95 \%$ betrouwbaarheidsinterval van CV klein zijn;

3. De $h_{50}$ met de gemiddelde waarde en interval, volgens Figuur 1 moet dat gemiddelde ongeveer $17 \mathrm{~m}$ zijn en tussen de 7 en $24 \mathrm{~m}$ liggen;

4. De model-parameter $S$ en een $95 \%$ betrouwbaarheidsinterval ervan, en getoetst of deze overeenkomt met de te verwachten maximale afplattingshoogte. De hoogst gemeten opperhoogte bleek $28 \mathrm{~m}$ bij een leeftijd van $98 \mathrm{jr}$. Bij de opname voor de 4e bosstatistiek (CBS, 1985) is de opperhoogte per opstand geschat. De hoogste waarde voor Corsicaanse den bedroeg 27 meter. Volgens https://www.monumentaltrees.com/nl/nld-zwarteden/hd1 (geraadpleegd op 03-08-2017) is de hoogste Corsicaanse den in Nederland echter $34.2 \mathrm{~m}$ en staat in het kleine Pinetum op Schovenhorst. De maximale S-waarde voor de beste boniteit voor de Corsicaanse den zal daarom ongeveer $35 \mathrm{~m}$ mogen bedragen;

5. De leeftijd waarop de borsthoogte wordt bereikt. Op het tijdstip 0 moet de hoogte ook 0 zijn, daarna moet de groei in de jeugd langzaam op gang komen. Een gemiddelde boniteit doet er ongeveer 5 jaar over om borsthoogte te bereiken met een range van 3 tot 8 jaar, maar het kan onder extreme omstandigheden ook veel langer duren. De mate waarin de door het model voorspelde waarde $t_{130}$ en een $95 \%$ betrouwbaarheidsinterval ervan, overeenkomt met deze verwachting;

6. De groei versnelt tot de hoogte ongeveer 4 à $7 \mathrm{~m}$, dat moet dus het buigpunt van de curve zijn, dus het maximum van de afgeleide functie in Figuur 2. De mate waarin de door 
het model voorspelde waarde voor de hoogte van het buigpunt $h_{\text {if }}$ en een $95 \%$ betrouwbaarheidsinterval ervan overeenkomt met die uit Figuur 2, dus ongeveer bij 5.6 jaar;

7. Het al dan significant en relevant zijn van alle parameterschattingen.

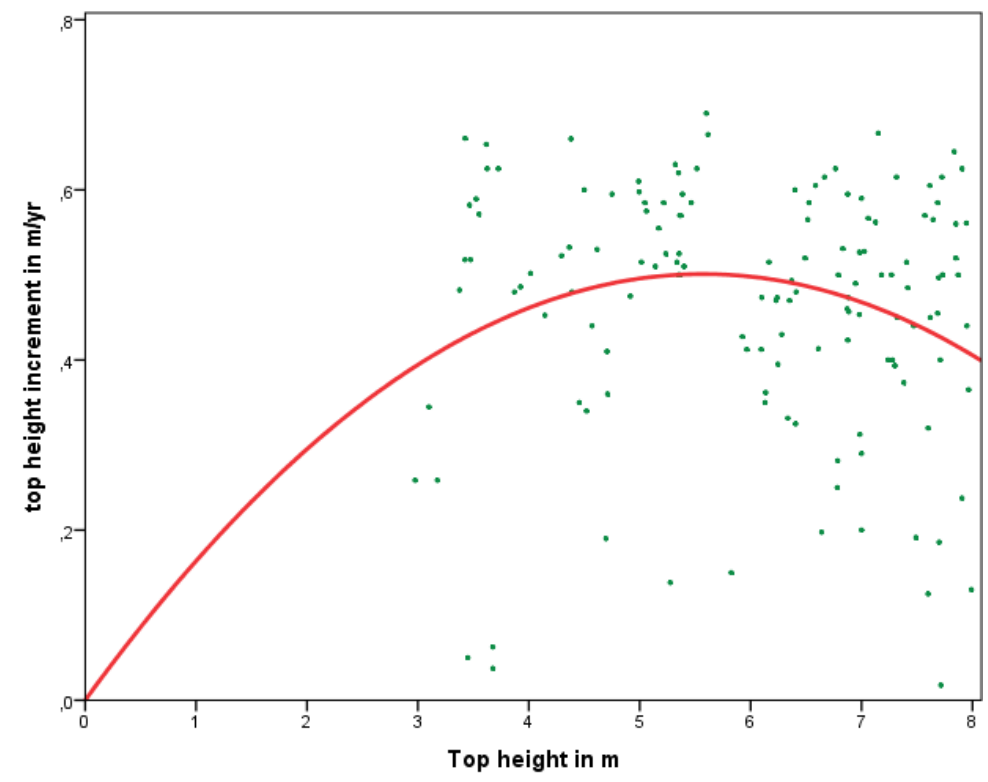

Figuur 2 . Hoogtebijgroei als functie van opperhoogte voor $h_{\text {top }} \leq 8 \mathrm{~m}$. Met rode lijn is de kwadratische fit door de puntenwolk en door de oorsprong, een maximum bij $5.6 \mathrm{~m}$.

Figure 2. Height increment as a function of the height for $h_{\text {top }} \leq 8 \mathrm{~m}$. The red line shows the cubic fit through the measured points and through the origin, with a maximum at htop $=5.6 \mathrm{~m}$.

\subsection{Analyse}

De volgende vijf modellen zijn onderzocht.

1. Het homomorfe model van Chapman-Richards (zie Pienaar \& Turnbull, 1973):

$$
h_{\text {top }}=S \cdot\left(1-e^{-a \cdot t}\right)^{b}
$$

2. Burkhart \& Tennent (1977) paste het Chapman-Richard model aan door de parameter $a$ als functie van $S$ uit te drukken waardoor een heteromorf model ontstaat:

$$
h_{\text {top }}=S \cdot\left(1-e^{-\left(a_{0}+a_{1} \cdot S\right) \cdot t}\right)^{b}
$$

3. Jansen \& Hildebrand (1986) pasten de werkwijze van Burkhart \& Tennent toe op de $b$-parameter, hierdoor ontstaat eveneens een heteromorf model:

$$
h_{\text {top }}=S \cdot\left(1-e^{-\alpha \cdot t}\right)^{\left(b_{0}-b_{1} \cdot S\right)}
$$

4. Jansen et al. (2016) pasten model (5) aan door een jeugdgroei-component toe te voegen gebaseerd op het model van Korf (1939): 


$$
\begin{aligned}
& h_{\text {top }}= \begin{cases}f_{1}(t)=x \cdot \frac{e^{-a_{k} \cdot t^{-b_{k}}}}{e^{-a_{k} \cdot t_{x}^{-b_{k}}}} \quad \text { for } t \leq t_{x} \\
f_{2}(t)=S \cdot\left(1-e^{-a \cdot t}\right)^{\left(b_{0}-b_{1} \cdot S\right)} & \text { for } t>t_{x}\end{cases} \\
& \text { where } t_{x}=-\frac{\ln \left(1-(x / S)^{1 / b}\right)}{a} \text { for } h_{\text {top }}=x \text { and } a_{k}=\frac{a \cdot b \cdot(S / x) \cdot e^{-a \cdot t_{x}} \cdot\left(1-e^{-a \cdot t_{x}}\right)^{b-1}}{b_{k} \cdot t_{x}^{-b_{k}-1}}
\end{aligned}
$$

Voor de grenswaarde voor de jeugdgroei is $x=5.6$ meter aangehouden

5. Het Cieszewski model (2001) gebruikt een referentieleeftijd, voor $t=50$ jaar luidt het:

$$
h_{\text {top }}=h_{50} \cdot \frac{t^{a} \cdot\left(50^{a} \cdot R+b\right)}{50^{a} \cdot\left(t^{a} \cdot R+b\right)}, \text { where } R=Z+\sqrt{Z^{2}+\frac{2 \cdot b \cdot h_{50}}{50^{a}}} \text { and } Z=h_{50}-c
$$

Dit heteromorfe model heeft wel een asymptoot, maar de oplossing moet gevonden worden met formule (7).

Een probleem bij het schatten van de parameters van de modellen is dat naast de 2 tot 4 parameters van het model ook de boniteit (de 139 proefperkparameters $S$ of $h_{\text {ref }}$ ) moeten worden geschat. "Zo wordt bijvoorbeeld het Chapman-Richards model (3) herschreven tot

$$
h_{\text {top }, i j}=\left(\sum_{i=1}^{139} S_{i} \cdot x_{i}\right) \cdot\left(1-e^{-a \cdot t_{i j}}\right)^{b} \text { for the } j^{\text {th }} \text { recording in the } i^{\text {th }} \text { plot }
$$

Hierin is $x_{i}$ een variabele die 1 is in het $i^{\text {de }}$ perk en 0 elders.

Om dit probleem te vermijden geven La Bastide \& Faber (1972) een oplossing, door niet $h_{\text {top }}$ te schatten maar de relatieve groei ervan:

$$
y=\frac{d h_{\text {top }}}{d t} \cdot \frac{1}{h_{\text {top }}}=\frac{\left(h_{\text {top } 2}-h_{\text {top } 1}\right)}{\left(t_{2}-t_{1}\right) \cdot\left(h_{\text {top } 1}+h_{\text {top } 2}\right) / 2}
$$

Met de huidige rekencapaciteit is dat niet meer nodig, maar hiermee kunnen wel goede beginschatters voor de modelparameters worden gevonden.

In Figuur 3 is deze relatieve groei tegen de leeftijd uitgezet, met de hier getoonde grote variatie zal een duidelijk beste model niet eenduidig te bepalen zijn. De waarnemingen met een opperhoogte beneden de $7 \mathrm{~m}$ hebben meestal een zeer grote invloed op keuze voor de groeicurve (Figuur 3 ). In de meeste opbrengsttabellen wordt de moeilijk te modelleren jeugdgroei dan ook weggelaten. 


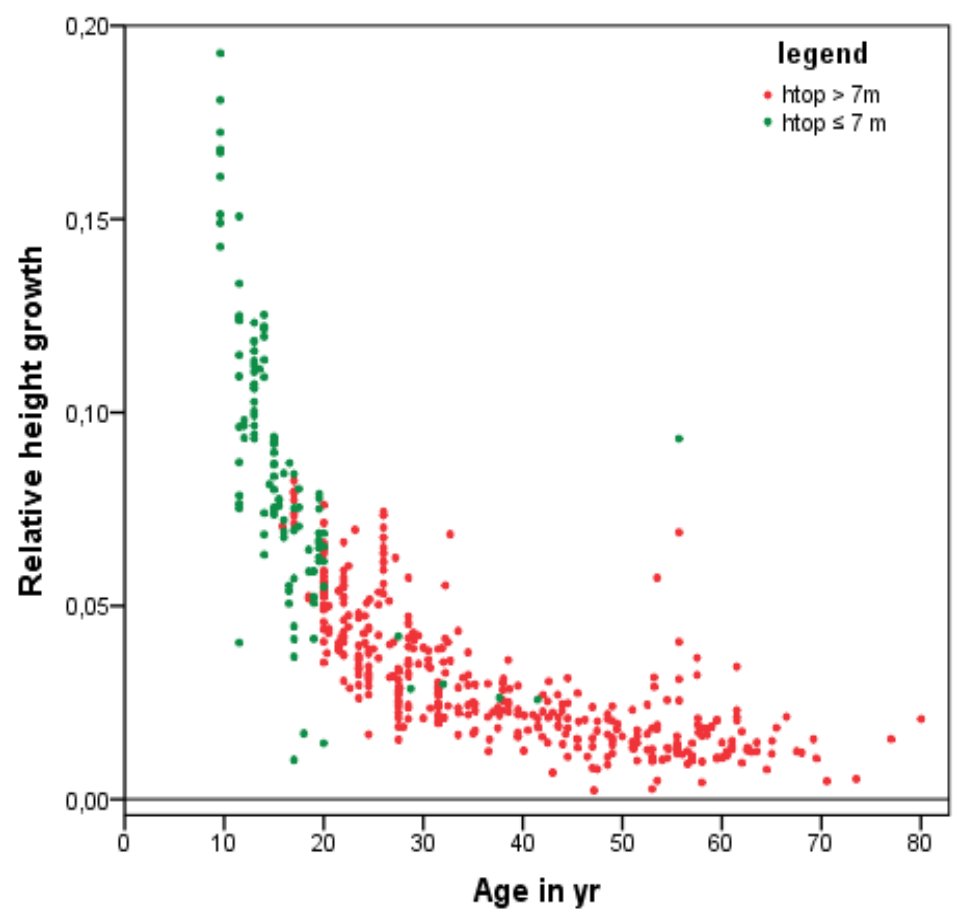

Figuur 3. Relatieve hoogtegroei als functie van de leeftijd.

Figure 3. Relative height increment as a function of age.

Jansen et al. (2018a) gebruikten een Multi criteria-analyse (MCA) met de criteria van Pagina 8 met gelijk gewicht meegenomen, om vervolgens nog een paar testen te doen.

In Tabel 2 zijn de resultaten weergegeven van de regressieanalyse van de opperhoogte met de besproken modellen. In de bovenste helft van de Tabel 2 de absolute waarde voor de criteria opgenomen. In het onderste deel van de tabel is de volgorde van resultaat (beste=1 en slechtste is 5 ) gegeven ( 2.5 betekent gedeelde $2^{\mathrm{e}}$ en $3^{\mathrm{e}}$ plaats).

Tabel 2. Resultaten van niet-lineaire regressie met de geselecteerde modellen in MCA.

Table 2. Results of nonlinear regression for the selected models in MCA.

\begin{tabular}{|c|c|c|c|c|c|c|c|c|c|c|}
\hline & model & npar & $R^{2} \mathrm{adj}^{*}$ & $C V$ & $\mathbf{h}_{50}$ & $S$ & $t_{130}$ & $h_{i f}$ & s/ns & result \\
\hline \multirow{5}{*}{$\frac{\check{d}}{\frac{\pi}{5}}$} & Chapman-Richards & 2 & 0.995 & $4\{3 ; 5\}$ & $18\{7 ; 25\}$ & $36\{14 ; 52\}$ & $5\{4 ; 8\}$ & $6\{3 ; 8\}$ & $\mathrm{s}$ & 5 \\
\hline & Burkhart \& Tennent & 3 & 0.995 & $4\{3 ; 8\}$ & $18\{7 ; 24\}$ & $34\{20 ; 41\}$ & $6\{4 ; 9\}$ & $6\{4 ; 7\}$ & ns & 4 \\
\hline & Jansen \& Hildebrand & 3 & 0.995 & $3\{2 ; 4\}$ & $18\{7 ; 24\}$ & $33\{14 ; 42\}$ & $6\{3 ; 10\}$ & $6\{4 ; 6\}$ & s & 2 \\
\hline & Jansen et al. & 4 & 0.995 & $4\{3 ; 5\}$ & $18\{7 ; 24\}$ & $35\{15 ; 45\}$ & $5\{3 ; 7\}$ & $6(5 ; 6\}$ & s & 1 \\
\hline & Cieszewski & 3 & 0.995 & $1\{1 ; 3\}$ & $17\{6 ; 24\}$ & $43\{39 ; 46\}$ & $6\{4 ; 9\}$ & $7(6 ; 7\}$ & ns & 3 \\
\hline \multirow{6}{*}{ 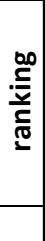 } & Chapman-Richards & 2 & 5 & 3.5 & 3 & 5 & 1 & 5 & 2 & 24.5 \\
\hline & Burkhart \& Tennent & 3 & 2 & 5 & 3 & 1 & 3.5 & 2.5 & 4.5 & 21.5 \\
\hline & Jansen \& Hildebrand & 3 & 4 & 2 & 3 & 2 & 5 & 2.5 & 2 & 20.5 \\
\hline & Jansen et al. & 4 & 3 & 3.5 & 3 & 3 & 2 & 1 & 2 & 17.5 \\
\hline & Cieszewski & 3 & 1 & 1 & 3 & 4 & 3.5 & 4 & 4.5 & 21.0 \\
\hline & best score & & $\max$ & $\min$ & $18\{7 ; 24\}$ & $<35$ & $4\{3 ; 7\}$ & 5.6 & $\mathrm{~s}$ & \\
\hline
\end{tabular}

*) Aantal model parameters exclusief de 139 boniteit parameters voor ieder proefperk.

Vervolgens zijn in Figuur 4 alle hoogte waarnemingen uitgezet met de modellijnen van perken met de beste en slechtste boniteit. 

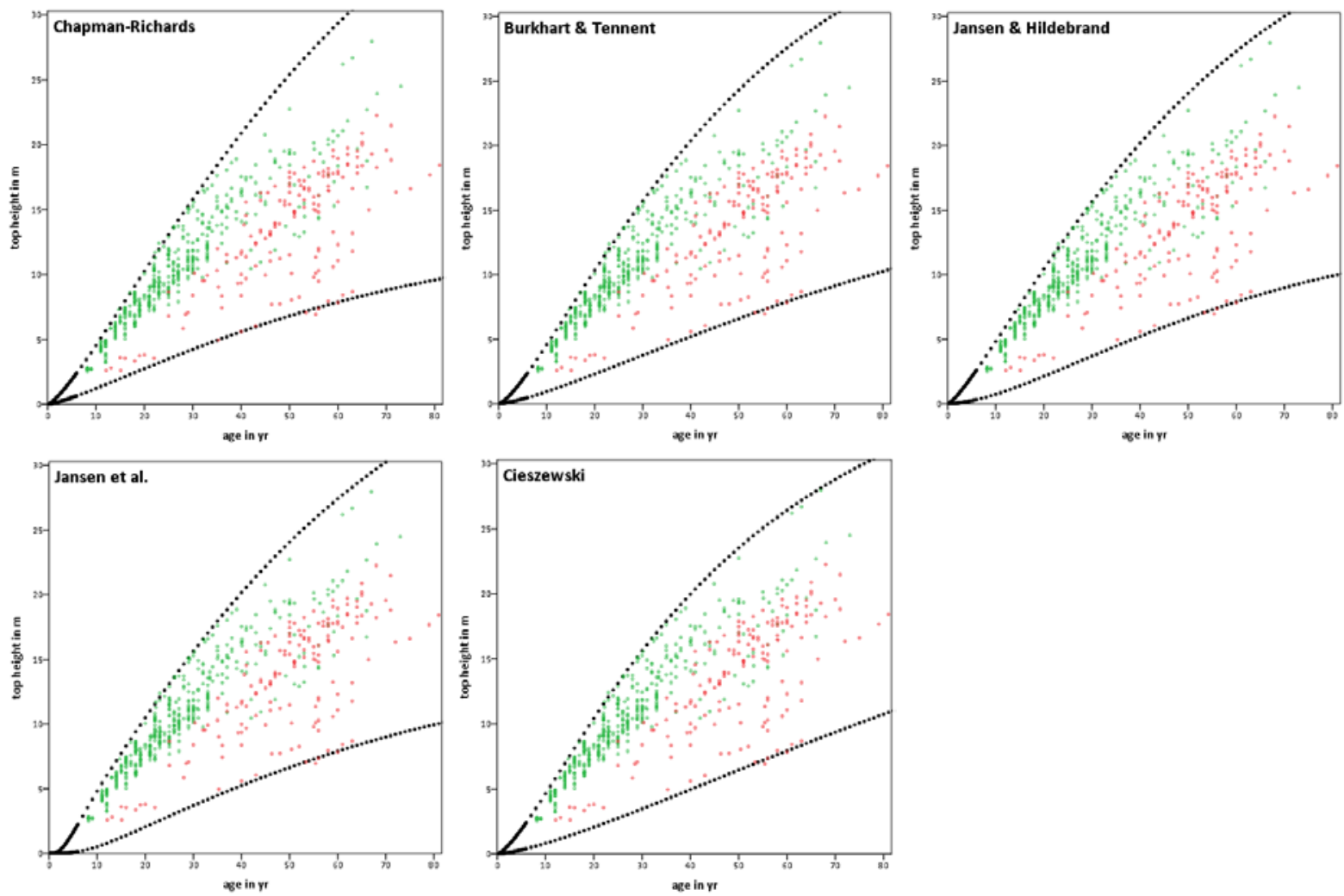

Figuur 4. Hoogtewaarnemingen (groen Binnenland en rood Kustgebied) en in zwart de curven van de laagste en hoogste boniteit per model.

Figure 4. Top height observations (green for inland plots and red for coastal plots) and in black the lowest and highest site curves per model.

Voor de drie beste modellen Jansen \& Hildebrand (1986), Jansen et al. (2016) en het model van Cieszewski (2001) is in Figuur 5 bekeken hoe de waarnemingen uit de $4^{\mathrm{e}}$ bosstatistiek hierin vallen. Het tweede model uit de test van Tabel 2 van Jansen \& Hildebrand (1986) is overigens nagenoeg gelijkwaardig aan de eerste keus zoals ook uit Figuur 4 blijkt. Het aantal waarnemingen buiten de lijnen bedraagt $4.7 \%$ bij Jansen \& Hildebrand, $4.3 \%$ bij Jansen et al., 2016. En $4.7 \%$ bij Cieszewski
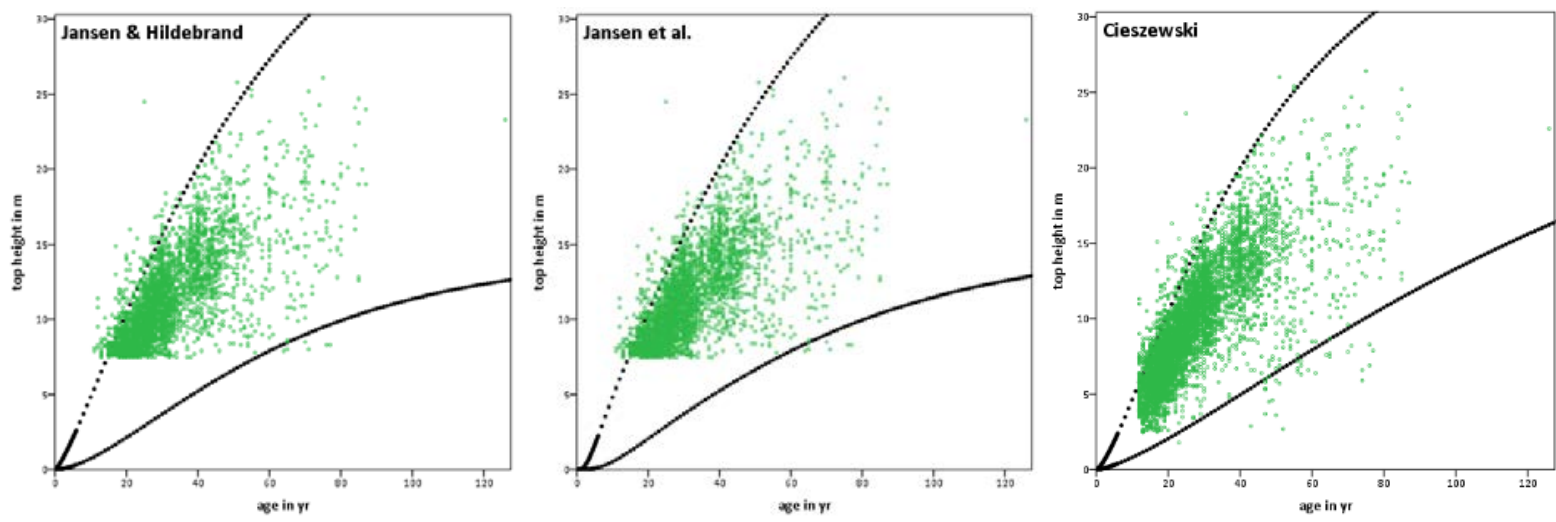

Figuur 5. Hoogtewaarnemingen in $4^{e}$ Bosstatistiek en curven van de laagste en hoogste boniteit per model.

Figure 5. Top height observations in Fourth Dutch Forest Inventory with lowest and highest site curves per model. 
Het model van Jansen et al. 2016 is in eerste instantie gekozen, omdat het over de twee toetsen gezamenlijk het best voldoet. Maar bij het boniteren van de opstanden uit de $4^{\mathrm{e}}$ Bosstatistiek (CBS, 1981) in Paragraaf 3.4.2 werden we met een onverwacht probleem geconfronteerd, de iteratieve berekening van $S$ liep vast bij zeer lage opperhoogten van redelijk oude opstanden. Zo komt er een opstand in het Kustgebied van 50 jaar met een hoogte van $4 \mathrm{~m}$ voor. Voor de praktijk is dit model met het gekozen aansluitpunt $x=7 \mathrm{~m}$ in Formule (6) onbruikbaar. Het probleem is oplosbaar door het aansluitpunt bij $x=3 \mathrm{~m}$ te leggen, maar dat is onrealistisch. Er is daarom uiteindelijk gekozen voor het model van Jansen \& Hildebrand.

\subsection{Binnenland versus Kustgebied}

Van de drie parameters $a, b_{0}$ en $b_{1}$ van model (5) is vervolgens onderzocht of deze afhankelijk zijn de klimaatgebieden op de volgende wijze:

$$
\begin{aligned}
a= & a_{0}+a_{c} \cdot x_{c} \\
b_{0}= & b_{00}+b_{0 c} \cdot x_{c} \\
b_{1}= & b_{10}+b_{1 c} \cdot x_{c} \\
& \text { where } x_{c}= \begin{cases}0 & \text { if data in Inland Area } \\
1 & \text { if data in Coastal Area }\end{cases}
\end{aligned}
$$

Geen van parameters bleek significant verschillende waarden te hebben tussen de klimaatgebieden. Wel bleken er verschillen in range en gemiddelde van de boniteit-parameters.

\subsection{Uiteindelijke model}

In formule (11) en alle volgende vergelijkingen die een onderdeel van het opbrengstmodel vormen worden de parameters genummerd als $c_{1}, c_{2}$ enzovoorts.

$$
\begin{aligned}
h_{\text {top }}= & S \cdot\left(1-e^{-c_{1} \cdot t}\right)^{b} \\
& \text { where } b=c_{2}-c_{3} \cdot S
\end{aligned}
$$

\begin{tabular}{|c|c|c|c|c|c|c|c|c|c|c|}
\hline$R^{2}$ & $R^{2}$ adj & RMSE & Region & Parameter & Estimate & Std. Error & $s$ & $h_{50}$ & $t_{130}$ & $h_{\text {if }}$ \\
\hline \multirow[b]{2}{*}{0.996} & \multirow[b]{2}{*}{0.995} & \multirow[b]{2}{*}{0.33} & $\begin{array}{l}\bar{D} \\
\stackrel{\bar{T}}{0} \\
\underline{\underline{0}}\end{array}$ & \multirow{2}{*}{$\begin{array}{l}c_{1} \\
c_{2} \\
c_{3}\end{array}$} & \multirow{2}{*}{$\begin{array}{l}0.0209 \\
2.0262 \\
0.0171\end{array}$} & \multirow{2}{*}{$\begin{array}{l}0.001 \\
0.182 \\
0.005\end{array}$} & $36\{25 ; 42\}$ & $20\{13 ; 25\}$ & $5\{3 ; 8\}$ & $6\{5 ; 6\}$ \\
\hline & & & $\begin{array}{l}\bar{\pi} \\
\tilde{\omega} \\
\tilde{0} \\
0\end{array}$ & & & & $26\{14 ; 38\}$ & $14\{7 ; 22\}$ & $8\{4 ; 14\}$ & $5\{3 ; 6\}$ \\
\hline
\end{tabular}

Met een $R^{2}$ adj van 0.995 werd de parameterschatting van Tabel 3 gevonden

Tabel 3. Parameters voor hoogteontwikkelingsmodel (11) en andere eigenschappen.

Table 3. Parameters for height development model (11) and other characteristics. 
In Figuur 6 is de met Formule (11) voorspelde opperhoogte uitgezet tegen de gemeten opperhoogte. De gearceerde rode lijn betreft de lineaire fit, deze ligt nagenoeg geheel op de perfecte fit lijn met een hoek onder $45^{\circ}$.

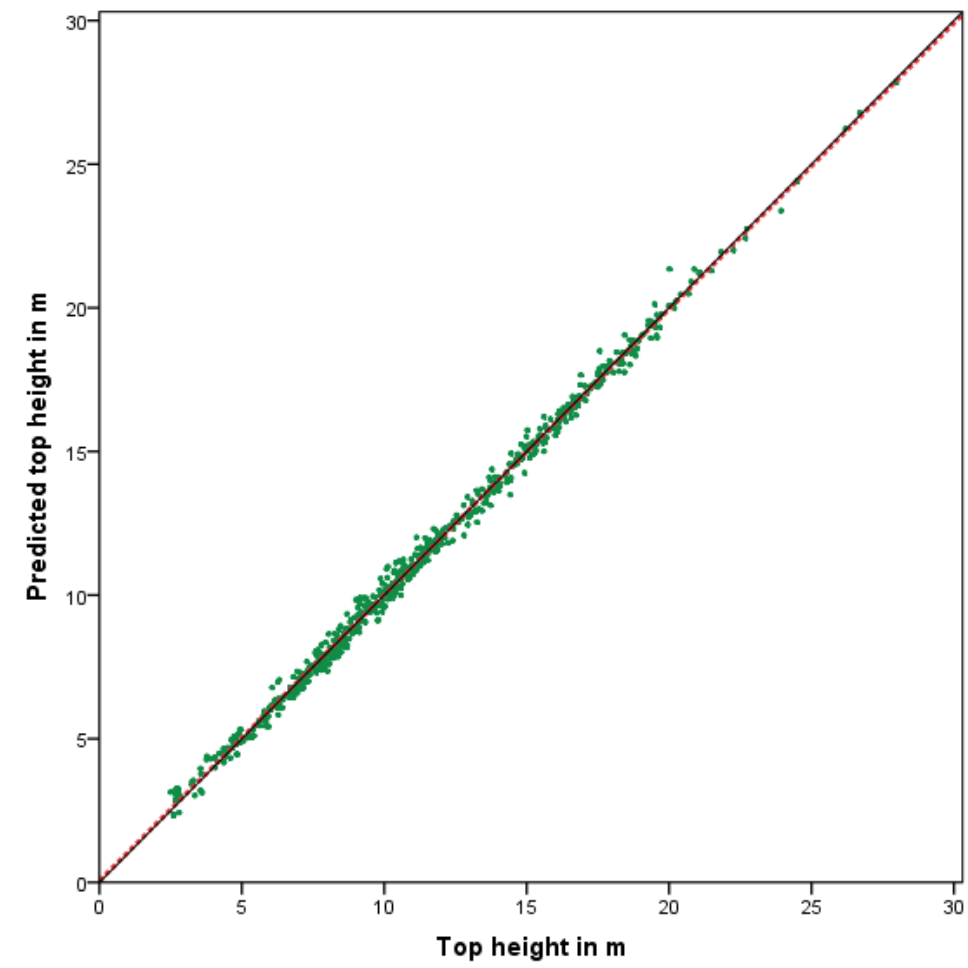

Figuur 6. Voorspelde opperhoogte met Formule (11) in relatie met gemeten opperhoogte op tijdstip van de waarneming. De rode lijn geeft lineaire fit weer, de zwarte lijn geeft de perfecte fit met een hoek van $45^{\circ}$ weer.

Figure 6. Predicted top height with model (11) in relation with observed top height at recording time. The red line represents the linear fit, the black line the perfect fit with an angle of $45^{\circ}$.

\subsubsection{Analyse van de residuen}

Bij lineaire regressie is het gebruikelijk naar uitbijters te kijken om fouten op te sporen. De residuen van de NLR met Formule (11) zijn uitgezet tegen de systeemvariabelen leeftijd en $h_{50}$ (Figuur 7). 

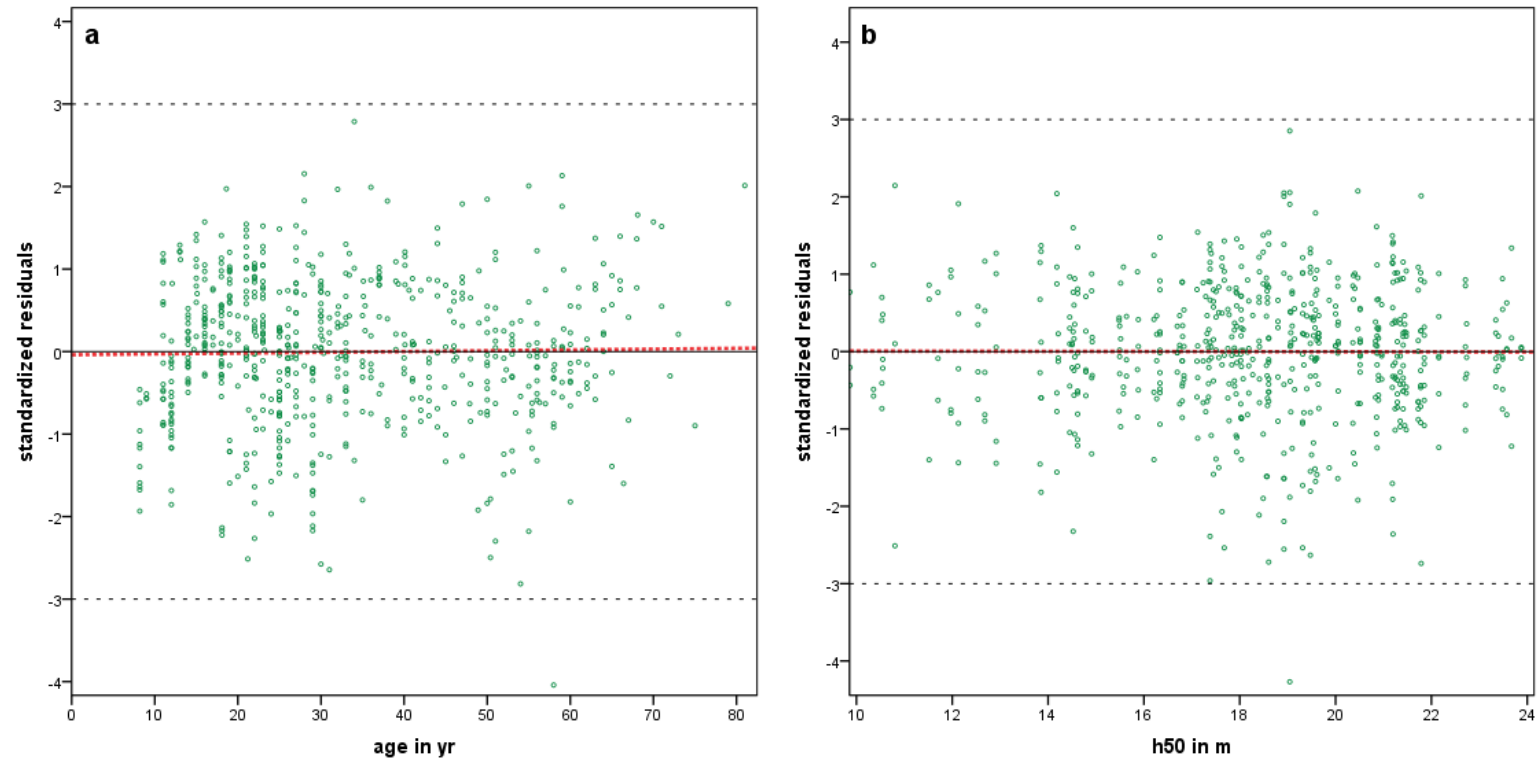

Figuur 7. Gestandaardiseerde residuen in relatie tot leeftijd (a) en $h_{50}(b)$, de rode lijn geeft de lineaire fit weer.

Figure 7. Standardized residuals in relation to top height (a) and $h_{50}(b)$, the red line is the linear fit.

In Figuur 7 is te zien dat er geen onzuiverheid is in het model ten opzichte van beide modelvariabelen en er is één uitbijter aanwezig, die niet verklaard kon worden.

\subsubsection{Boniteitindeling}

De met Formule (11) gevonden waarden van $h_{50}$ zijn nogal verschillend tussen beide klimaatzones, zie Tabel 3. Met de gegevens van de $4^{\mathrm{e}}$ Bosstatistiek (CBS, 1985) is van 5248 monocultures met Corsicaanse den de $h_{50}$ bepaald volgens de methode van Jansen et al. (2016). Dit leidt tot de verdeling over de $h_{50}$ zoals weergegeven in Figuur 8.
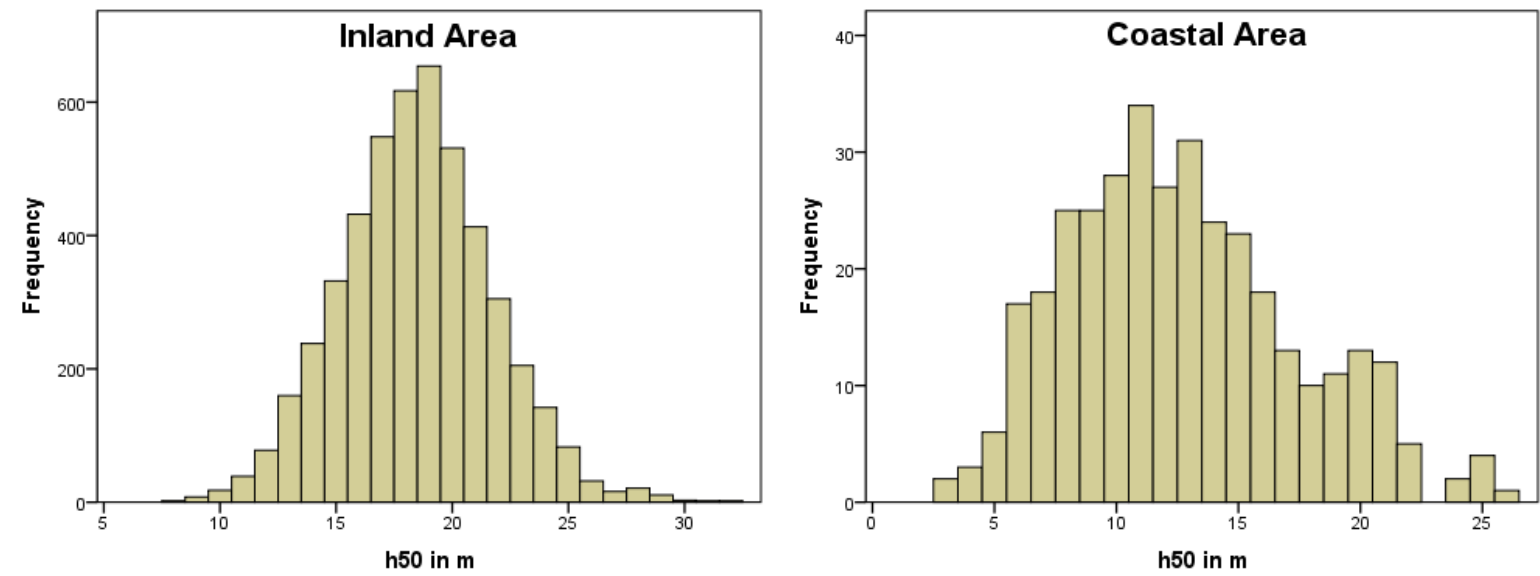

Figuur 8. Frequentiehistogrammen per bosgebied van $h_{50}$ in $4 e$ bosstatistiek.

Figure 8. Frequency histograms of $h_{50}$ per forest region in the Fourth Dutch Forest Inventory.

De grenzen voor een boniteitindeling zijn zo gekozen dat 95 tot $99 \%$ van de opstanden in de klassen I tot en met V valt. Zie Tabel 4 voor het resultaat. Met deze indeling heeft $1.0 \%$ van 
alle opstanden van de Corsicaanse den een betere boniteit dan de $\mathrm{I}^{\mathrm{e}}$ en $0.4 \%$ heeft een slechtere boniteit dan de VII .

Tabel 4. Indeling in boniteiten gebaseerd op de $\boldsymbol{h}_{50}$.

Table 4. Classification in site classes based on the $h_{50}$.

\begin{tabular}{|c|c|c|r|rrr|}
\cline { 4 - 6 } $\begin{array}{c}\text { Boniteit } \\
\text { site class }\end{array}$ & $\boldsymbol{h}_{\mathbf{5 0}}$ & $\begin{array}{c}\text { Bereik } \boldsymbol{h}_{\mathbf{5 0}} \\
\text { range } \boldsymbol{h}_{\mathbf{5 0}}\end{array}$ & $\begin{array}{r}\text { \% in data set } \\
\text { \% in data set }\end{array}$ & $\begin{array}{r}\text { Totaal } \\
\text { total }\end{array}$ & $\begin{array}{r}\text { Binnenland } \\
\text { Inland area }\end{array}$ & $\begin{array}{r}\text { Kustgebied } \\
\text { Coastal area }\end{array}$ \\
\hline$<$ I & & $>27$ & & 1.0 & 1.1 & \\
I & 25.5 & $(24-27)$ & 0.5 & 3.3 & 3.5 & 1.7 \\
II & 22.5 & $(21-24)$ & 21.5 & 15.5 & 16.3 & 4.0 \\
III & 19.5 & $(18-21)$ & 35.9 & 33.1 & 34.8 & 9.4 \\
IV & 16.5 & $(15-18)$ & 21.8 & 29.1 & 30.2 & 13.1 \\
V & 13.5 & $(12-15)$ & 13.5 & 12.8 & 12.1 & 22.7 \\
VI & 10.5 & $(9-12)$ & 4.2 & 3.6 & 2.0 & 25.6 \\
VII & 7.5 & $(6-9)$ & 2.6 & 1.3 & 0.1 & 17.6 \\
$>$ VII & & $<6$ & & 0.4 & & 6.0 \\
\hline
\end{tabular}

In de dataset blijken de betere boniteiten oververtegenwoordigd, wat ook bij de eerder geanalyseerde datasets het geval was.

In Figuur 9 is de hoogteontwikkeling per boniteit samen met die van de proefperken weergegeven.

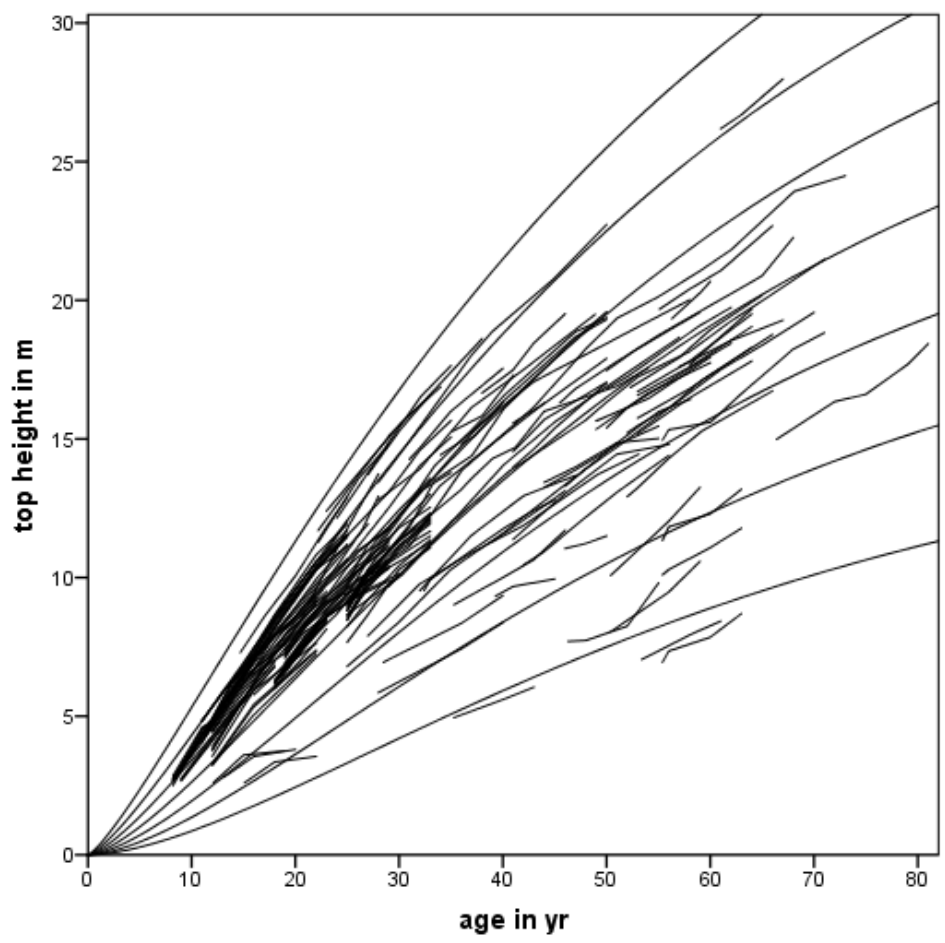

Figuur 9. Hoogteontwikkeling van de proefperken en boniteitcurven voor de Corsicaanse den in Nederland.

Figure 9. Top height development of the plots with site curves for Corsican pine in the Netherlands. 


\subsubsection{Modeltest met de controle plots}

Door de gevonden parameters van Tabel 3 te fixeren in model (11) zijn daarna voor de 54 monocultures HOSP-plots van de controle-set de $h_{50}$-waarden geschat. Daarmee zijn de residuen berekend, in formule:

$$
\begin{aligned}
y_{i j}= & h_{\text {top }_{i j}}-\hat{h}_{11_{i j}} \\
& \text { where } \hat{h}_{11_{i j}} \text { the predicted } h_{\text {top }} \text { with Formula } 11 \text { for the } j^{\text {th }} \text { record in the } i^{\text {th }} \text { plot }
\end{aligned}
$$

In Figuur 10a is te zien dat die residuen niet verschillen per opname tussen de analyse plots en de HOSP-controle plots. Wel bleek er geheel volgens de verwachting een HOSP-effect op de standaarddeviatie van die afwijkingen (in figuur 10a te zien aan het veel ruimere betrouwbaarheidsinterval bij de controle plots). De opnamen van de HOSP-controle plots zijn immers niet meegenomen in de analyse omdat door enerzijds de kleine oppervlakte en anderzijds het meten van de hoogte in meters in plaats van decimeters een grotere variantie werd verondersteld.
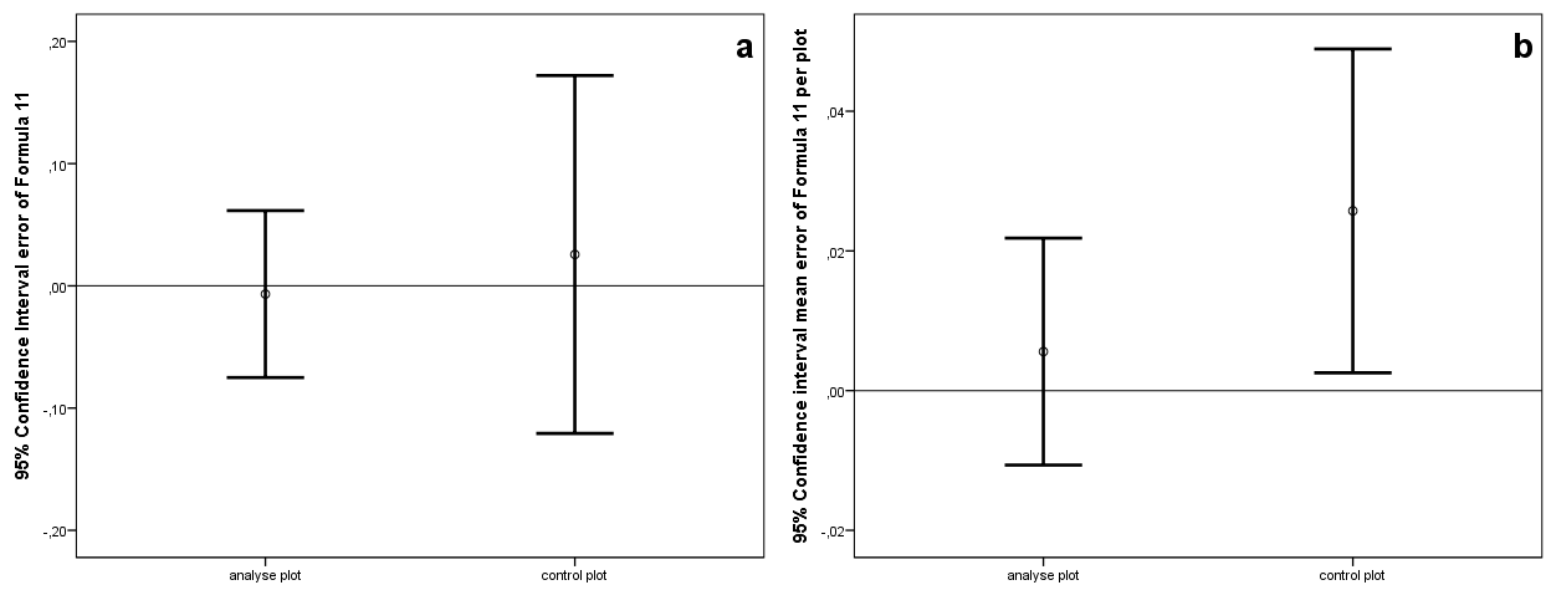

Figuur 10. Betrouwbaarheidsinterval residuen van model (11) voor de groepen analyse plots en controle plots (a) en het $95 \%$ betrouwbaarheidsinterval van het gemiddelde van die residuen per plot (b).

Figure 10. Confidence interval of the residuals from model (11) for both groups analysis plots and control plots (a) and the $95 \%$ confidence interval of the average of those residuals per plot (b).

Ook de gemiddelden van de residuen per plot bleken niet significant te verschillen in een variatieanalyse, zie figuur $10 \mathrm{~b}$ en tabel 5 . Dit betekent dat de controleplots goed aansluiten bij het gevonden model. Uit figuur $10 \mathrm{~b}$ blijkt dat het niet-significante verschil ongeveer twee centimeter bedraagt. De controleplots van de HOSP-studie sluiten dus zeer goed aan bij het gevonden model.

Tabel 5. ANOVA van HOSP-effect op de gemiddelde residuen per plot.

Table 5. ANOVA of HOSP effect on the average residuals per plot.

\begin{tabular}{|l|r|r|r|r|c|}
\hline & \multicolumn{1}{|c|}{ Sum of Squares } & \multicolumn{1}{c|}{ df } & Mean Square & F & Sig. \\
\hline Between Groups & 0.016 & 1 & 0.016 & 1.798 & 0.182 \\
Within Groups & 1.677 & 191 & 0.009 & & \\
Total & 1.693 & 192 & & & \\
\hline
\end{tabular}




\subsection{Conclusie}

De hoogtegroei van de Corsicaanse den is onderzocht. Geen van de modellen voldeden volledig aan de voorwaarden en het model van Jansen \& Hildebrand werd de hoogtegroei gemodelleerd. Hiermee is een indeling in 7 boniteiten gemaakt. Ongeveer $1 \%$ van de Corsicaanse dennenbossen in Nederland heeft een betere boniteit dan de hier gepresenteerde boniteit I, en $0.4 \%$ heeft een lagere boniteit dan boniteit VII. De boniteiten in het Binnenland zijn gemiddeld veel hoger dan in het Kustgebied, maar de parameters van het model zijn hetzelfde. 


\section{Opbrengstniveau}

Naast de hoogtegroei vindt ook diktegroei plaats. Dit resulteert in diameterbijgroei $i_{d}=\left(d_{2}-d_{1}\right) /\left(t_{2}-t_{1}\right)$ en grondvlakbijgroei $i_{G}=\left(G_{2}-G_{1}\right) /\left(t_{2}-t_{1}\right)$. Hoogtegroei en diktegroei tezamen resulteren in een volumebijgroei. In opbrengsttabellen is een belangrijk doel juist de volumebijgroei te bepalen. Aangezien het boomvolume in de dataset een afgeleide, berekende variabele is en niet berust op een primaire waarneming, zal ook de volumebijgroei indirect worden berekend. Diameter en het totale grondvlak zullen in de loop van de tijd toenemen, maar gelijktijdig neemt ook de hoogte toe.

Jansen et al. (2016) onderzochten voor douglas een aantal groeimodellen en vonden dat de opstandontwikkeling tot een opstandhoogte van $7 \mathrm{~m}$ het best verklaard werd met een voorspelling van de diameter voor dunning. Vanaf een hoogte van $7 \mathrm{~m}$ werd de opstandontwikkeling beter verklaard door de grondvlakbijgroei. In Paragraaf 4.1 zal de diameterontwikkeling en daaraan gekoppeld de grondvlakontwikkeling worden geanalyseerd en gemodelleerd. In Paragraaf 4.2 zal de grondvlakbijgroei vanaf een hoogte van $7 \mathrm{~m}$ worden geanalyseerd en gemodelleerd.

\subsection{Diameter- en grondvlakontwikkeling tot een hoogte van $7 \mathrm{~m}$}

Als maat voor de diameter is gekozen voor de "gemiddelde" diameter van de opstand voor dunning $\left(d_{b t}\right)$. Onder "gemiddelde" wordt hier verstaan het kwadratische gemiddelde. Het gaat dus om de $d_{g}$, maar de toevoeging $g$ (van gemiddeld grondvlak) is weggelaten. Uit Figuur 11 blijkt dat de diameter voor dunning zowel met behulp van de opperhoogte als de leeftijd is te voorspellen. De eerste stap het selecteren van een goed groeimodel.
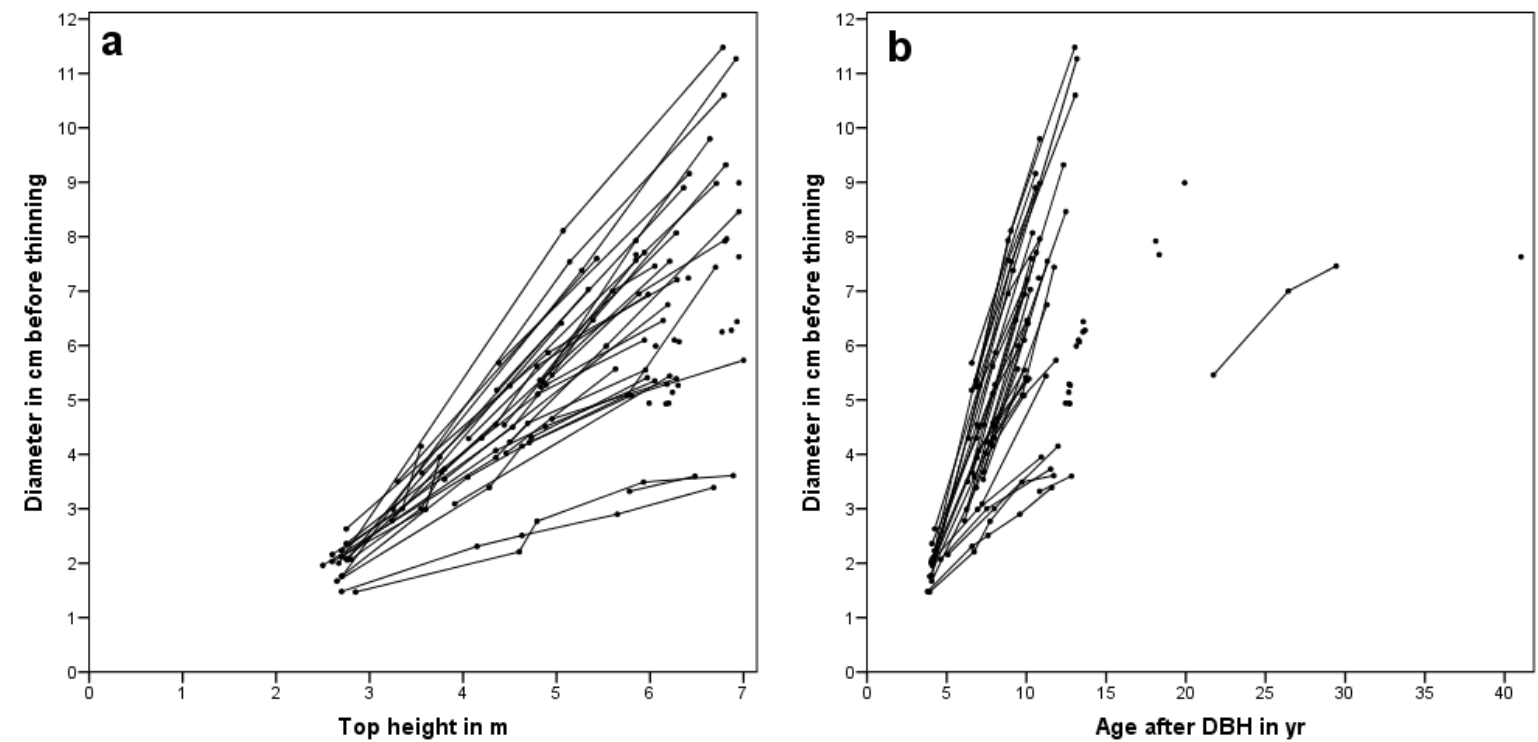

Figuur 11. Verloop diameterontwikkeling tot een hoogte van 7 meter als functie van opperhoogte (a) en leeftijd na bereiken borsthoogte (b).

Figure 11. Course of the diameter development as a function of top height (a) and of age since reaching breast height (b). 
Stap 1. Het bepalen van een groeimodel

Het model dat Jansen et al. (2016) voor de diameterontwikkeling van douglas gebruikte bestaat uit een component voor de jeugdgroei tot een hoogte van $7 \mathrm{~m}$ zonder dunning, en een component voor de ontwikkeling daarna, met een Gompertz-functie (1832) voor jeugdgroei en een powerfunctie daarna. Jansen et al. (2018a) vereenvoudigden het model en transformeerden het naar een schatter voor het gemiddelde boomgrondvlak voor dunning:

$$
g_{b t}=\pi \cdot\left(\frac{d_{b t}}{200}\right)^{2}=\pi \cdot\left(\frac{d_{7}}{200}\right)^{2} \cdot\left\{\frac{\exp \left(-c_{4} \cdot e^{-c_{5} \cdot\left(h_{\text {top }}-1.30\right)}\right)}{\exp \left(-c_{4} \cdot e^{-c_{5} \cdot(7-1.30)}\right)}\right\}^{2} \text { for } h_{\text {top }} \leq 7 \mathrm{~m}
$$

where $d_{7}=c_{6}+c_{7} / \sqrt{N_{0}}$

Indien niet beide parameters van de Gompertz-functie significant zijn kan deze vervangen worden door een power-functie. Soms wordt er al gezuiverd of gedund voor het bereiken van een hoogte van $7 \mathrm{~m}$. In vorige studies zijn die waarnemingen dan meestal uitgesloten, maar voor de grove den betrof dat bijna alle waarnemingen en kozen Jansen et al. (2018c) om $N_{0}$ in Formule (13) te vervangen door $N_{R}$ het stamtal voordat de zuivering/dunning wordt uitgevoerd. Omdat het voor de Corsicaanse den ook om veel waarnemingen (zie Tabel 6) gaat is hier ook voor $N_{R}$ gekozen.

Tabel 6. Waarnemingen met en zonder dunning per regio met $\boldsymbol{h}_{\text {top }} \leq 7 \mathrm{~m}$.

\begin{tabular}{|l|rr|r|}
\hline & zonder dunning & met dunning & totaal \\
\hline Binnenland & 52 & 57 & 109 \\
Kustgebied & 3 & 13 & 16 \\
\hline Totaal & 55 & 70 & 125 \\
\hline
\end{tabular}

Met de 125 waarnemingen en $N_{R}$ in plaats van $N_{0}$ werd Model (13) opgelost met een $R^{2}$ adj van 0.883 .

\section{Stap 2. Regressiediagnose}

De standaardafwijking van model (13) bedraagt $0.00070 \mathrm{~m}^{2}$. In Figuur $12 \mathrm{~b}, 12 \mathrm{c}$ en $12 \mathrm{~d}$ is te zien dat er één uitbijter aanwezig zijn. De gestandaardiseerde residuen zijn in de Figuren 12a en $12 c$ tegen de beide modelvariabelen $h_{\text {top }}$ en $N_{R}$ uitgezet, en in de Figuren $12 \mathrm{~b}$ en $12 \mathrm{~d}$ tegen de niet-modelvariabelen leeftijd en $h_{50}$. In de figuren zijn de lineaire regressielijnen door de puntenwolk met een gestreepte rode lijn weergegeven.

Ondanks dat geen van deze lijnen significant verschilt van de $\mathrm{x}$-as, zijn er twee problemen die opgelost dienen te worden:

1. Er zijn 12 waarnemingen met zowel een $N_{R}$ als $N_{0}$ waarde van 20000 of meer, waarbij de diameter onderschat lijkt te worden. Omdat dergelijke waarden bij de te ontwikkelen opbrengsttabellen niet voorkomen kunnen ze daarom worden weggelaten;

2. De wat oudere proefperken betreffen alle een $\mathrm{VI}^{\mathrm{e}}$ of $\mathrm{VII}$ boniteit in de duinen, hier lijkt de diameter te worden overschat. Toevoeging van de leeftijd of $h_{50}$ is een optie. 

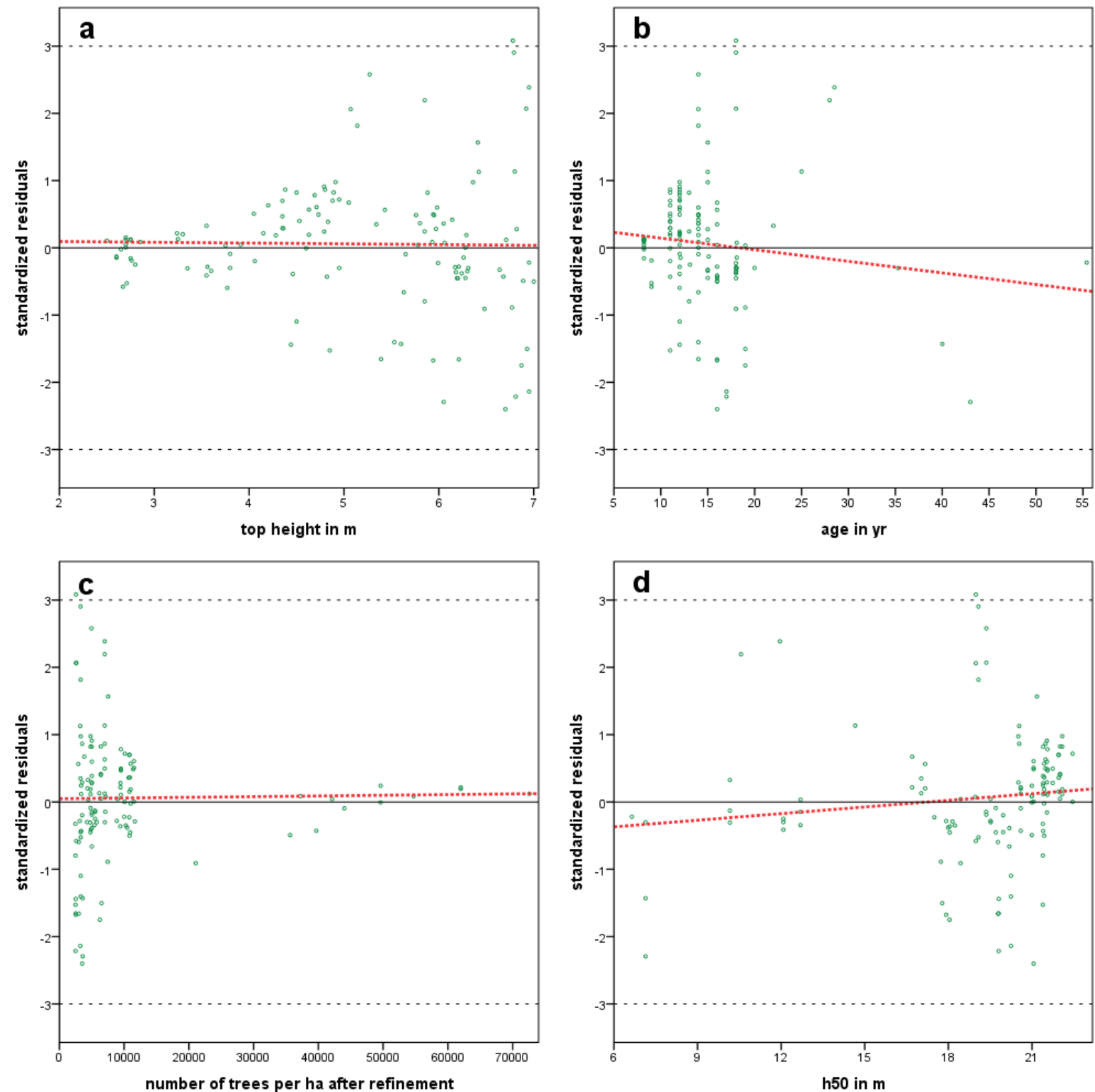

Figuur 12. Gestandaardiseerde residuen van model (13) in relatie tot opperhoogte (a), leeftijd (b), stamtal na zuivering (c) en $h_{50}(d)$ met rode lijn is lineaire fit door de residuen.

Figuur 12. Standardized residuals of model (13) in relation to top height (a), age (b), density after refinements (c) and $\mathrm{h} 50$ (d) and the red lines represent linear fit.

\section{Stap 3. Modelverbetering}

Het weglaten van de 12 waarnemingen met de zeer hoge stamtallen leverde slechts een marginale daling op van $R^{2}$ adj naar 0.875 op en is daarom niet doorgevoerd.

Na wat andere opties te hebben onderzocht werd model (13) met de toevoeging van $h_{50}$ als volgt verbeterd: 


$$
g_{b t}=\pi \cdot\left(\frac{d_{b t}}{200}\right)^{2}=\pi \cdot\left(\frac{d_{7}}{200}\right)^{2} \cdot\left\{\frac{\exp \left(-c_{4} \cdot e^{-c_{5} \cdot\left(h_{\text {top }}-1.30\right)}\right)}{\exp \left(-c_{4} \cdot e^{-c_{5} \cdot(7-1.30)}\right)}\right\}^{2} \text { for } h_{\text {top }} \leq 7 \mathrm{~m}
$$

$$
\text { where } d_{7}=c_{6} / \sqrt{\sqrt{h_{50}}}+c_{7} / \sqrt{N_{R}}
$$

Met 125 waarnemingen en een $R^{2}$ adj van 0.890 de oplossing van Tabel 7 gevonden. Er bleek geen verschil tussen beide klimaatzones.

Tabel 7. Parameters voor Model (14)

Table 7. Parameters for Model (14).

\begin{tabular}{|l|r|r|r|r|}
\hline \multirow{2}{*}{ Parameter } & & & \multicolumn{2}{|c|}{ 95\% Confidence Interval } \\
\cline { 4 - 5 } & Estimate & Std. Error & Lower Bound & Upper Bound \\
\hline$c_{4}$ & 2.8602 & 0.289 & 2.287 & 3.433 \\
$c_{5}$ & 0.1944 & 0.091 & 0.015 & 0.374 \\
$c_{6}$ & 5.2198 & 0.653 & 3.927 & 6.512 \\
$c_{7}$ & 407.0273 & 20.582 & 366.280 & 447.775 \\
\hline
\end{tabular}

In Tabel 8 is het effect van het beginstamtal op de ontwikkeling van de diameter gegeven, indien er tot een opperhoogte van $7 \mathrm{~m}$ niet gedund wordt.

Tabel 8. Diameter voor dunning bij $\boldsymbol{h}_{\text {top }}=\mathbf{7} \mathrm{m}$ per stamtal na zuivering/dunning.

Table 8. Diameter before thinning at $h_{\text {top }}=7 \mathrm{~m}$ and HD-ratio per density after refinements/thinning.

\begin{tabular}{|r|rrrrrrr|}
\hline & \multicolumn{7}{|c|}{$\boldsymbol{d}_{\boldsymbol{b t}}$ in cm voor boniteit: } \\
\cline { 2 - 8 } $\boldsymbol{N}_{\boldsymbol{R}}$ & $\mathbf{I}$ & II & III & IV & V & VI & VII \\
\hline 3000 & 8.5 & 8.5 & 8.6 & 8.7 & 8.9 & 9.0 & 9.3 \\
5000 & 6.8 & 6.9 & 6.9 & 7.0 & 7.2 & 7.4 & 7.7 \\
10000 & 5.1 & 5.2 & 5.3 & 5.4 & 5.5 & 5.7 & 6.0 \\
20000 & 3.9 & 4.0 & 4.1 & 4.2 & 4.3 & 4.5 & 4.8 \\
\hline
\end{tabular}

Model (14) schat het boomgrondvlak zuiver, de transformatie naar de diameter is dan niet meer zuiver. In Figuur 13a en $13 \mathrm{~b}$ is te zien dat deze afwijking nu ook voor leeftijd en $h_{50}$ verwaarloosbaar is. 

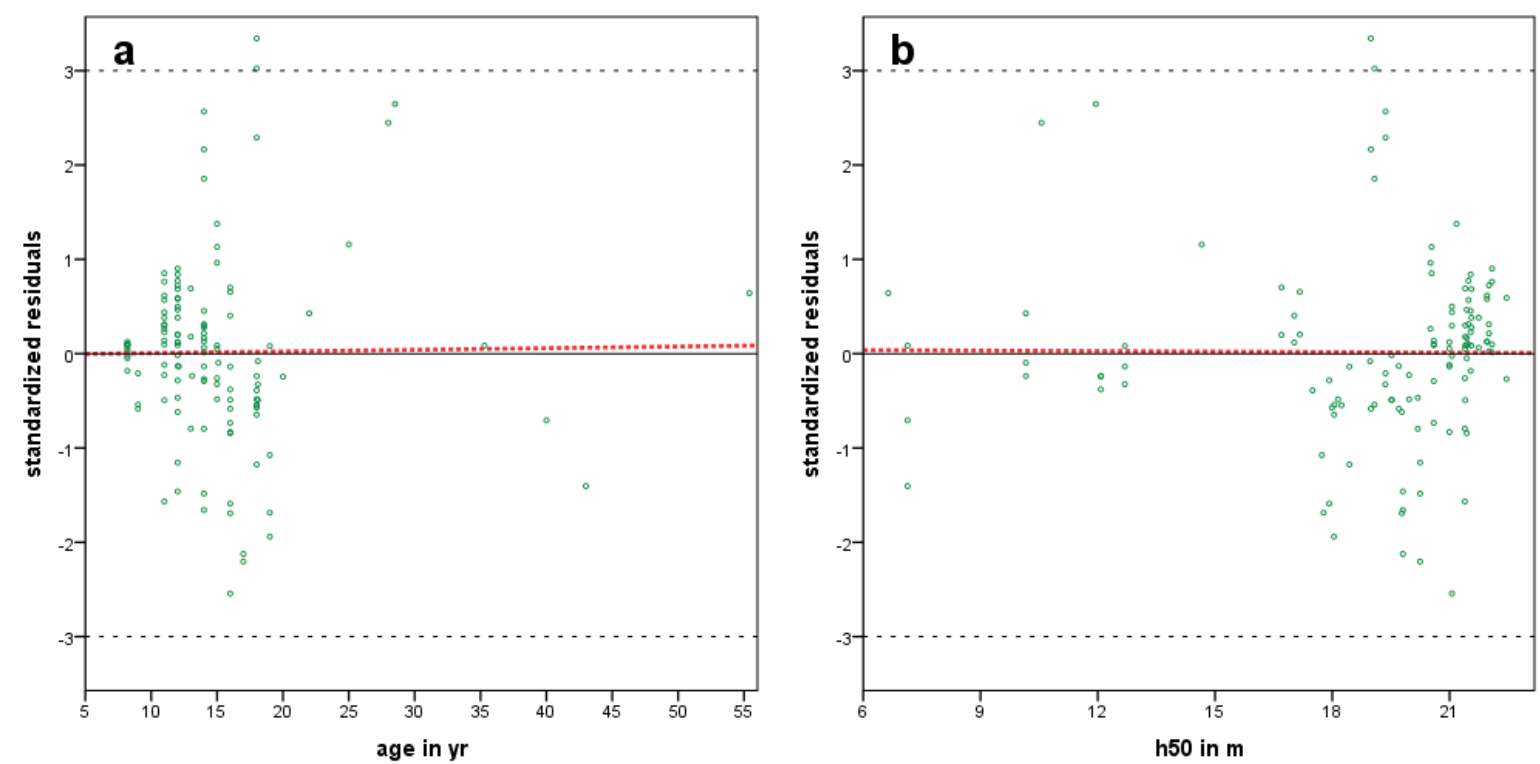

Figuur 13. Gestandaardiseerde residuen van model (14) in relatie tot leeftijd (a) en $h_{50}(b)$ met rode lijn is lineaire fit door de residuen.

Figure 13. Standardized residuals of Model (14) in relation to age (a) and $h_{50}(b)$, the red lines represent linear fit.

\section{Conclusie}

Het model dat Jansen et al. (2016) voor douglas vonden bleek met enige toevoeging ook toepasbaar voor Corsicaanse den.

$\mathrm{Er}$ is een nauwkeurige schatter voor de $d_{7}$ (de diameter bij een opperhoogte van $7 \mathrm{~m}$ ) gevonden. En ook de ontwikkeling van die diameter tot $d_{7}$ kan goed voorspeld worden.

\subsection{Grondvlakbijgroei}

Bij de analyse van de grondvlakbijgroei is als grens is een opperhoogte van $7 \mathrm{~m}$ aangehouden, ontwikkeling van het grondvlak tot die hoogte is in Paragraaf 4.1 al besproken. Hier wordt de groei vanaf een opperhoogte van $7 \mathrm{~m}$ behandeld. In de Figuren 14 is te zien dat de grondvlakbijgroei een nogal chaotisch verloop vertoond. Het lijkt erop of er sprake is van zowel naar leeftijd als hoogte een monotoon dalende functie, maar vooral voor de hoogte is er veel ruis. 

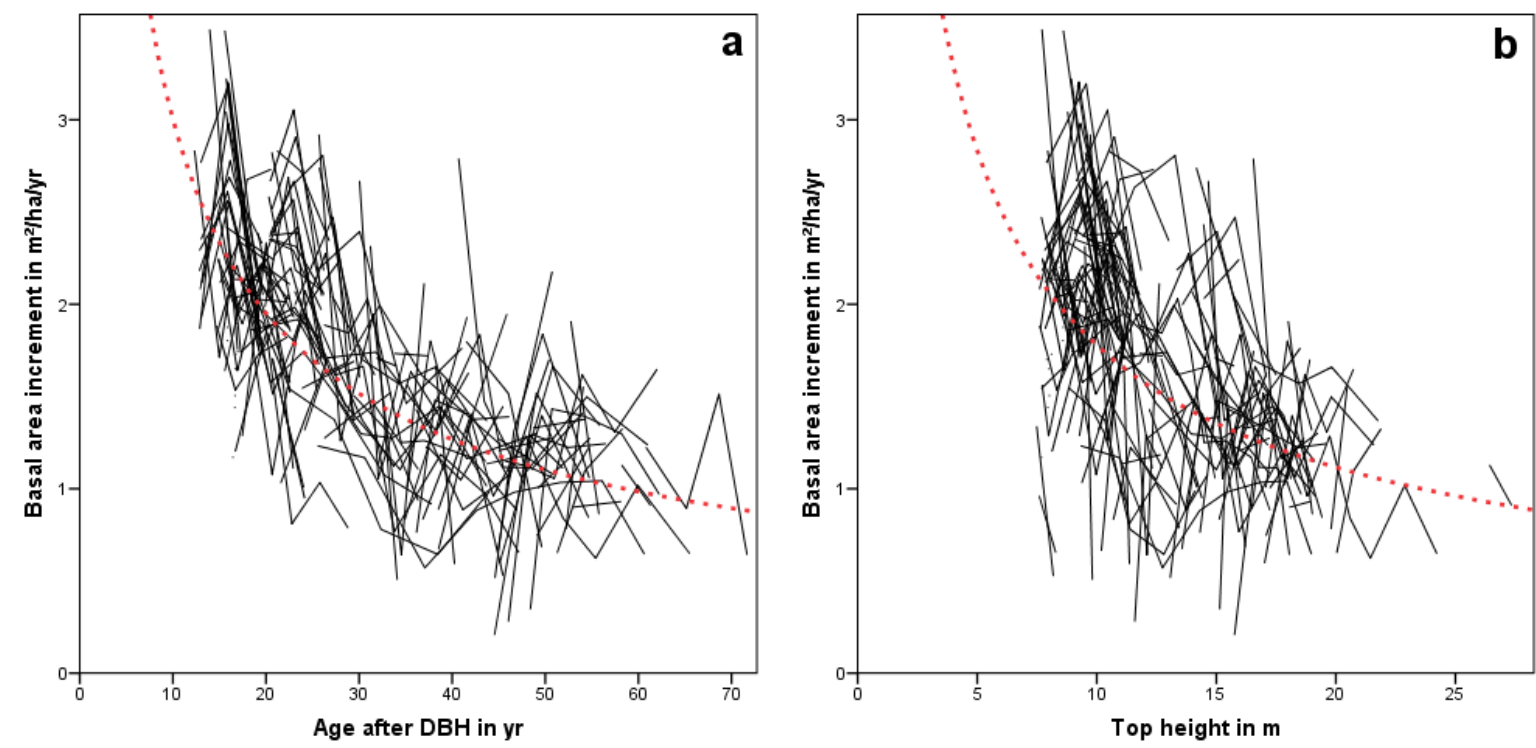

Figuur 14. Grondvlakbijgroei als functie van de leeftijd (a) en opperhoogte (b). De zwarte lijnen geven het verloop binnen één plot aan, de rode lijn de beste fit voor een power-functie over alle opnamen.

Figure 14. The basal area increment as a function of age (a) and top height (b). The black line represents the course within one plot, the red line represents the best fit with a power function.

De grondvlakbijgroei betreft een berekende waarneming tussen 2 opnamen, de leeftijd en opperhoogte betreffen dan het gemiddelde tussen beide opnamen.

Totaal zijn er 389 opnamen beschikbaar voor de analyse

Stap 1. Bijgroeimodel voor grondvlak bepalen.

Jansen et al. (2016) ontwikkelden voor de grondvlakbijgroei van douglas het volgende model:

$$
i_{G, j k}=Y I_{j} \cdot P L_{k} \cdot f_{1}(S \%) \cdot f_{2}\left(h_{\text {ref }}\right) \cdot\left\{\frac{F_{3}\left(h_{2}, t_{2}\right)-F_{3}\left(h_{1}, t_{1}\right)}{\Delta t}\right\}
$$

where $Y I=$ year index ans $P L=$ plot level

Voor de douglas bleek $f_{2}$ geen significante bijdrage te leveren.

Hierin is $F_{3}$ een power-functie. In de Figuren 14 a en $14 \mathrm{~b}$ zijn de afgeleiden van $F_{3}$ naar $t$ en $h_{\text {top }}$, in beide gevallen dus weer een powerfunctie, getekend. Op grond daarvan mag geconstateerd worden dat een powermodel zoals Jansen et al. (2016) gebruiken geschikt is om de grondvlakbijgroei te verklaren.

Stap 2. Verschilmodel voor grondvlakbijgroei.

Bij het fitten van vergelijking (15) kan de jaarindex $Y I$ voor het $j^{e}$ kalender niet worden geschat, maar Jansen et al. (2016) geven alternatieven met correctiefactoren voor bepaalde perioden, waaronder de $c f_{80}$ in Formule (16). $F_{3}$ is de functie voor de totale grondvlakproduc- 
tie, hier voldeed een powerfunctie die zowel naar de hoogte als de leeftijd kan worden gemodelleerd. Voor de douglas bleek de toevoeging van de leeftijd geen extra verklaring te geven, voor de Corsicaanse den is die wel van belang en $f_{2}$ speelt net als bij de douglas geen rol, voor $h_{1}>7 \mathrm{~m}$ geldt dan:

$$
\begin{gathered}
i_{G}=\text { cor }_{5 \%} \cdot c_{8} \cdot\left\{c_{12} \cdot \operatorname{Term}_{h}+\left(1-c_{12}\right) \cdot \text { Term }_{t}\right\} \cdot c f_{80} \\
\text { where } \text { Term }_{h}=\left\{\left(h_{2 c}-1.30\right)^{c_{11}}-\left(h_{1}-1.30\right)^{c_{11}}\right\} / d t \\
\text { Term }_{t}=\left\{\left(t_{2}-t_{130}\right)^{c_{11}}-\left(t_{1}-t_{130}\right)^{c_{11}}\right\} / d t \\
t_{1}=t_{i, j} \text { and } t_{2}=t_{i, j+1} \text { for the } j^{\text {th }} \text { record in the } i^{\text {th }} \text { plot } \\
h_{2 c}= \begin{cases}h_{2} \quad \text { for } h_{2}>h_{1} \\
h_{1}+\hat{h}_{2}-\hat{h}_{1} & \text { for } h_{2} \leq h_{1}\end{cases} \\
h_{1} \text { and } h_{2} \text { are the top heights at time } t_{1} \text { and } t_{2} \\
\text { cor }_{5 \%}= \begin{cases}1 & \text { for } S \%_{0} \leq c_{10} \\
1-c_{9} \cdot\left(S \%_{0}-c_{10}\right) & \text { for } S \%_{0}>c_{10}\end{cases} \\
S \% \%_{0}=\text { Hart-Becking spacing index after thinning at time } t_{1} \\
c f_{80}=\text { correction factors for growth till } 1980 \text { and after that year }
\end{gathered}
$$

Met $R^{2}$ adj $=0.482$ en standaarddeviatie $0.43 \mathrm{~m}^{2} \mathrm{jr}^{-1} \mathrm{ha}^{-1}$ werden de parameters van Tabel 9 gevonden. Omdat er slechts 3 waarnemingen vanaf 1981 zijn, bleek de $c f_{80}$ in Formule (16) niet schatbaar.

Tabel 9. Parameterschatting met Model (16)

Table 9. Parameter estimation with Model (16)

\begin{tabular}{|l|rrrr|}
\hline & \multicolumn{3}{c}{ 95\% Confidence Interval } \\
Parameter & \multicolumn{1}{|c}{ Estimate } & \multicolumn{1}{c|}{ Std. Error } & Lower Bound & Upper Bound \\
\hline$c_{8}$ & 22.6694 & 4.151 & 14.509 & 30.830 \\
$c_{9}$ & 0.0132 & 0.006 & 0.002 & 0.025 \\
$c_{10}$ & 22.7868 & 2.599 & 17.676 & 27.897 \\
$c_{11}$ & 0.4695 & 0.037 & 0.396 & 0.543 \\
$c_{12}$ & 0.1948 & 0.064 & 0.069 & 0.320 \\
\hline
\end{tabular}




\section{Stap 3. Kwaliteit van Model (16)}

Figuur 15a is te zien is dat het model lage waarden van de grondvlakbijgroei overschat en de hoge waarden onderschat. Dit heeft te maken met het ontbreken van een verfijnde jaarindex. Figuur 15b betreft dezelfde weergave maar dan met model (18) uit Paragraaf 4.2.2.

In Figuur 16 is te zien dat er twee uitbijters meer zijn die meer dan $3 \sigma$ afwijken, een verklaring werd niet gevonden.

In Figuur 16 is voorts te zien dat het model voor de modelvariabelen opperhoogte (16a), leeftijd (16b) en dunninggraad (16c) een nagenoeg zuivere schatter geeft, dat geldt ook voor de niet-model variabele boniteit $h_{50}(16 \mathrm{~d})$, de geringe hellinghoeken van de lineaire fit zijn in geen van de figuren voor de modelvariabelen significant. Voor de niet-model variabele boniteit $h_{50}$ is de kans slechts 0.04 dat deze niet-significant is.
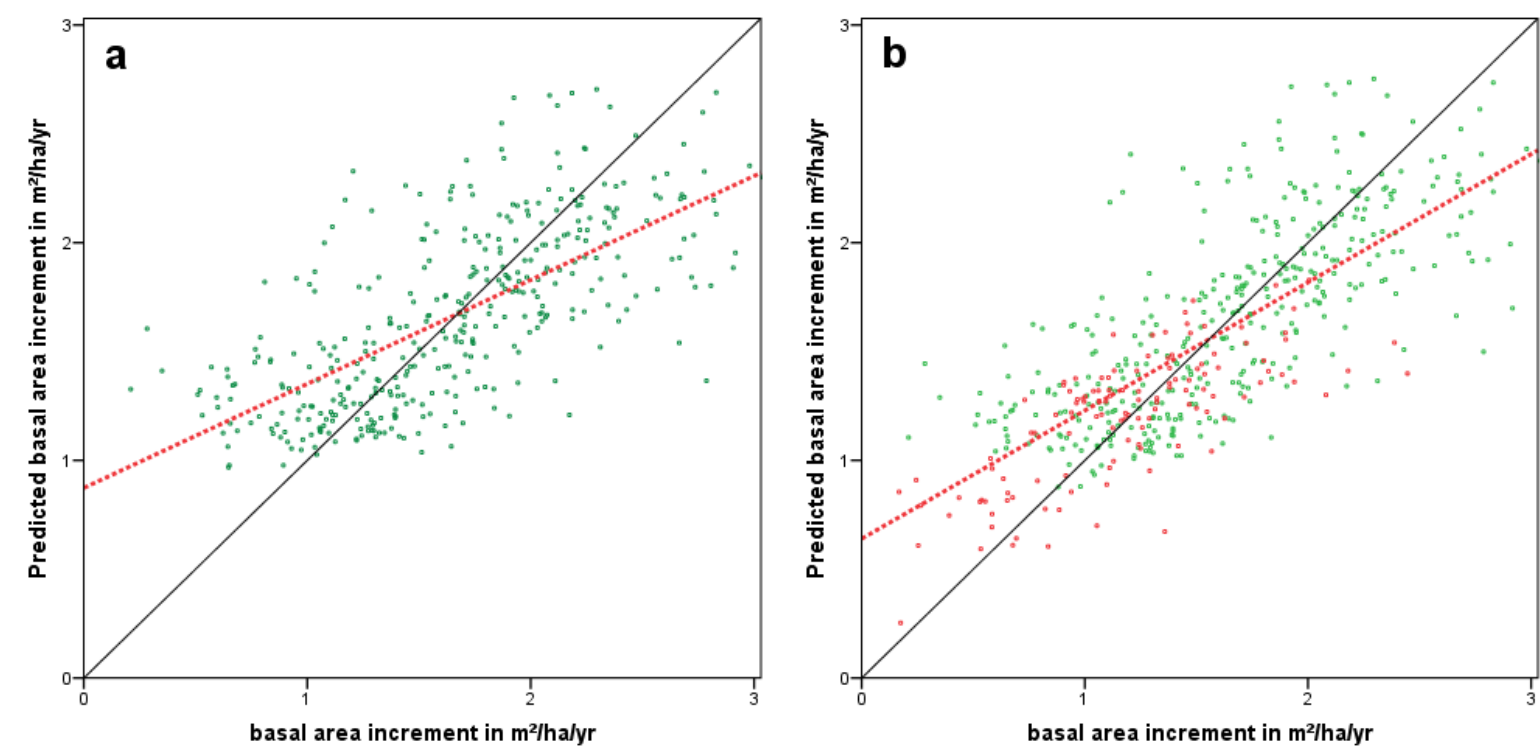

Figuur 15. In 15a de voorspelde grondvlakbijgroei met Model (16) als functie van de gemeten grondvlakbijgroei en dezelfde weergave maar dan met Model (18) in 15b waarbij de rode punten de data van de controle plots betreffen. De zwarte lijn geeft een 1 op 1 verhouding aan; de rode lijn is de lineaire fit door de puntenwolk.

Figure 15. Predicted basal area increment with Model (16) as a function of the measured basal area increment (a). And the same graph with Model (18), where the red dots represent data from control plots (b). The black line represents a 1 to 1 relation; the red line is the linear fit through the point cloud. 

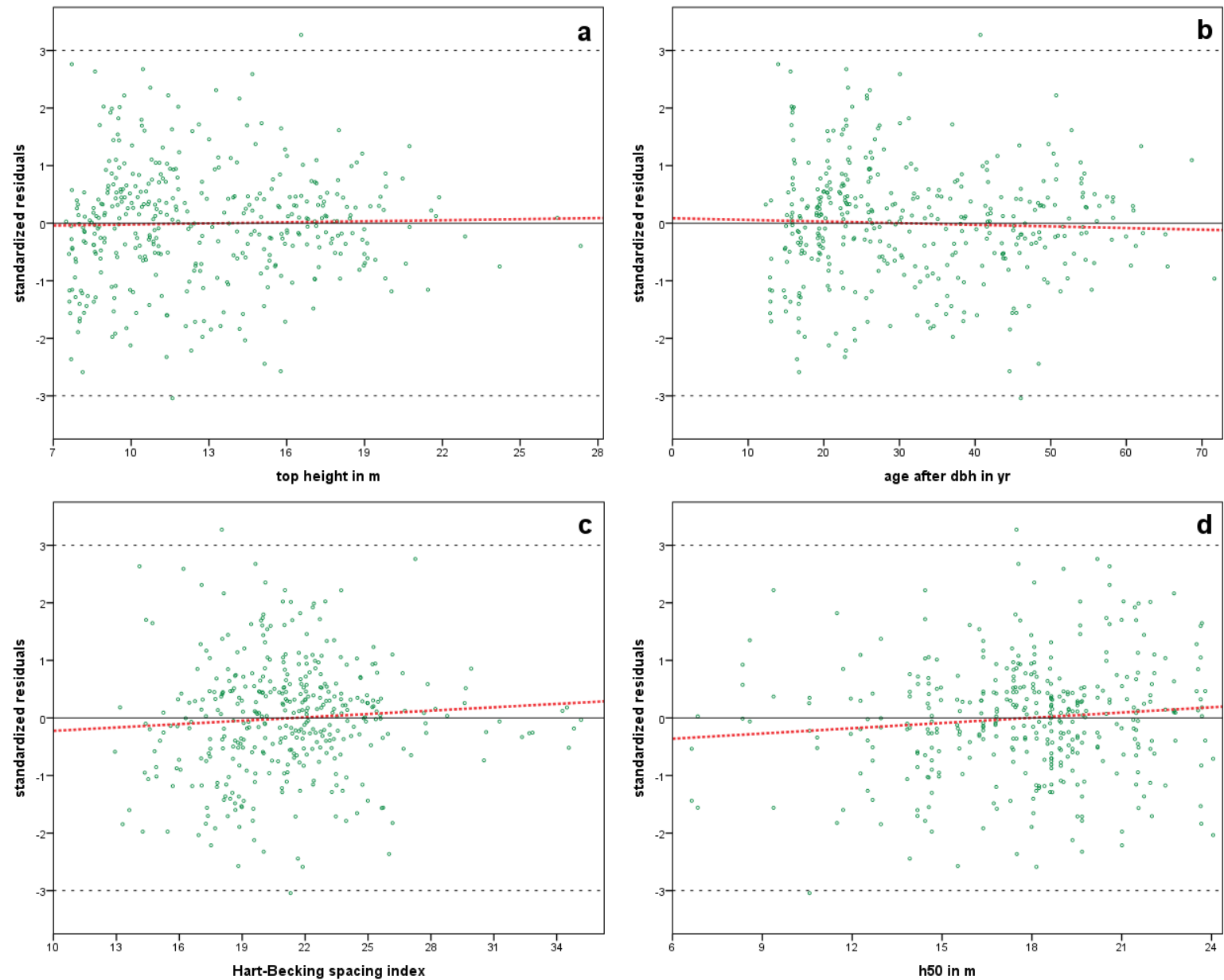

Figuur 16. Gestandaardiseerde residuen van Model (16) in relatie tot de modelvariabelen opperhoogte (a), leeftijd (b) en S\% (c) en de niet-model variabele $h_{50}(d)$. De rode lijn geeft de lineaire regressielijn weer door de residuen.

Figure 16. Standardized residuals of Model (16) in relation to the model variables top height (a), age (b), $5 \%$ (c) and the non-model variable $h_{50}(d)$. The red line shows the linear regression line through the residuals.

\subsubsection{Modeltest met de controle plots}

Door de gevonden parameters van Tabel 9 te fixeren in model (16) is daarna voor de HOSPplots van de controle-set de grondvlakbijgroei $i_{G}$ geschat. Daarmee zijn de residuen berekend, in formule (17):

$$
\begin{aligned}
y_{i j}= & i_{G i j}-\hat{i}_{G 16_{i j}} \\
& \text { where } \hat{i}_{G 16_{i j}} \text { the predicted } i_{G} \text { with Formula } 16 \text { for the } j^{\text {th }} \text { record in the } i^{\text {th }} \text { plot }
\end{aligned}
$$

In Figuur 17 is te zien dat die residuen aanzienlijk verschillen per opname tussen de analyse plots en de HOSP-controle plots. 


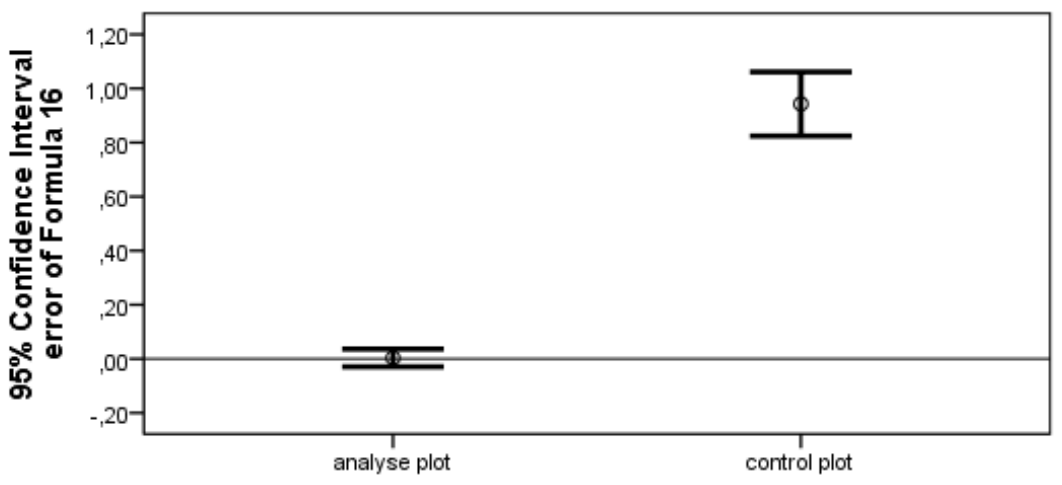

Figuur 17. Betrouwbaarheidsinterval residuen van model (16) voor de groepen analyse plots en controle plots.

Figure 17. Confidence interval for the residuals of model (16) for the groups analyse versus control plots.

\subsubsection{Aanpassing Model (16) met de controle plots en periode-index}

In Formule (15) is in eerste instantie sprake van een jaarindex voor de grondvlakbijgroei. In Formule (16) is deze vervangen door $c f_{80}$ en deze bleek niet schatbaar. Omdat alle controle plots In de periode na 1980 liggen is besloten model (16) opnieuw te onderzoeken met de analyse en controle plots samen. Hierbij is in plaats van de $c f_{80}$ en gebruikt gemaakt van een periode-index. Met $P I_{50}$ voor de periode tot $1955, P I_{60}$ voor de periode 1955 tot $1965, P I_{70}$ voor de periode 1965 tot 1975, $P l_{80}$ voor de periode 1975 tot 1985, $P l_{90}$ voor de periode 1985 tot 1995 en $P / 00$ voor de periode vanaf 1995. De keuze voor de periode-index in plaats van de $c f_{80}$ is gebaseerd twee overwegingen:

1. Hiermee wordt voorkomen dat de bias uit Figuur 17 automatisch met een correctie wordt aangepast voor alle HOSP plots;

2. Zwarte dennen blijken in de praktijk in Nederland periodiek zwaar productieverlies te lijden door aantasting van Brunchorstia taksterven (Gremmen, 1966; Van Gerwen, 1983 en De Kam, 1987)

Het model luidt nu:

$$
\begin{aligned}
& i_{G}=\operatorname{cor}_{\text {tgr }} \cdot c_{8} \cdot\left\{c_{12} \cdot \operatorname{Term}_{h}+\left(1-c_{12}\right) \cdot \text { Term }_{t}\right\} \cdot P I_{x x} \\
& \text { where } \operatorname{Term}_{h}=\left\{\left(h_{2 c}-1.30\right)^{c_{11}}-\left(h_{1}-1.30\right)^{c_{11}}\right\} / d t \\
& \operatorname{Term}_{t}=\left\{\left(t_{2}-t_{130}\right)^{c_{11}}-\left(t_{1}-t_{130}\right)^{c_{11}}\right\} / d t \\
& h_{1}, h_{2}, t_{1}, t_{2}, h_{2 c} \text { and } \text { cor }_{\text {tgr }} \text { the as in Formula } 16 \\
& \text { with the condition } P I_{50}+P I_{60}+P I_{70}+P I_{80}+P I_{90}+P I_{00}=6
\end{aligned}
$$

Met 513 waarnemingen $R^{2} \mathrm{adj}=0.590$ en standaarddeviatie $0.39 \mathrm{~m}^{2} \mathrm{jr}^{-1} \mathrm{ha}^{-1}$ werden de parameters van Tabel 10 gevonden. 
Tabel 10. Parameterschatting met Model (18)

Table 10. Parameter estimation with Model (18).

\begin{tabular}{|l|rrrr|}
\hline & \multicolumn{3}{c}{ 95\% Confidence Interval } \\
Parameter & \multicolumn{1}{|c}{ Estimate } & \multicolumn{1}{c|}{ Std. Error } & Lower Bound & Upper Bound \\
\hline$c_{8}$ & 15.3930 & 2.367 & 10.743 & 20.043 \\
$c_{9}$ & 0.0160 & 0.003 & 0.009 & 0.023 \\
$c_{10}$ & 22.3679 & 1.626 & 19.174 & 25.562 \\
$c_{11}$ & 0.5341 & 0.031 & 0.473 & 0.595 \\
$c_{12}$ & 0.1928 & 0.048 & 0.098 & 0.287 \\
\hline$P I_{50}$ & 0.8514 & 0.041 & 0.771 & 0.931 \\
$P I_{60}$ & 0.9368 & 0.028 & 0.882 & 0.991 \\
$P I_{70}$ & 1.1259 & 0.026 & 1.075 & 1.177 \\
$P l_{80}$ & 1.1258 & 0.030 & 1.067 & 1.185 \\
$P l_{90}$ & 0.9372 & 0.030 & 0.878 & 0.996 \\
$P l_{00}$ & 1.0230 & 0.057 & 0.911 & 1.135 \\
\hline
\end{tabular}

De verschillen met de eerder gevonden waarden voor de parameters zijn betrekkelijk gering en liggen onderling in elkaars betrouwbaarheidsintervallen. De betrouwbaarheidsintervallen van de periode-indices overlappen elkaar gedeeltelijk, maar zijn verder niet van belang en dienen alleen om het effect van periodieke klimaatomstandigheden op groei en aantasting weg te filteren.

Bij de bespreking van Figuur 14a is verondersteld dat het overschatten van lage waarden van de grondvlakbijgroei en het onderschatten van lage waarden ervan te verklaren was door het ontbreken van een jaarindex in Formule (16). Met het invoeren van een periode-index in Formule (18) verbetert het iets (vergelijk Figuur 15b met Figuur 15a).

In Figuur 18 is te zien dat er nu vier uitbijters zijn die meer dan $3 \sigma$ afwijken, een verklaring werd niet gevonden. Verder is te zien dat het model voor de modelvariabelen opperhoogte (18a), leeftijd (18b) en dunninggraad (18c) een nagenoeg zuivere schatter geeft, dat geldt ook voor de niet-modelvariabele boniteit $h_{50}(18 \mathrm{~d})$, de geringe hellinghoeken van de lineaire fit zijn in geen van de figuren significant.

Ook de gemiddelden van de residuen per plot bleken niet significant te verschillen in een variatieanalyse, zie tabel 11 . Dit betekent dat de HOSP plots nu goed met de overige analyse plots aansluiten bij het gevonden model.

Tabel 11. ANOVA van HOSP-effect op de gemiddelde residuen per plot.

Table 11. ANOVA of HOSP effect on the average residuals per plot.

\begin{tabular}{|l|r|r|r|r|c|}
\hline & Sum of Squares & \multicolumn{1}{|c|}{ df } & Mean Square & F & Sig. \\
\hline Between Groups & 0.0015 & 1 & 0.001 & 0.022 & 0.884 \\
Within Groups & 12.1353 & 176 & 0.069 & & \\
Total & 12.1368 & 177 & & & \\
\hline
\end{tabular}



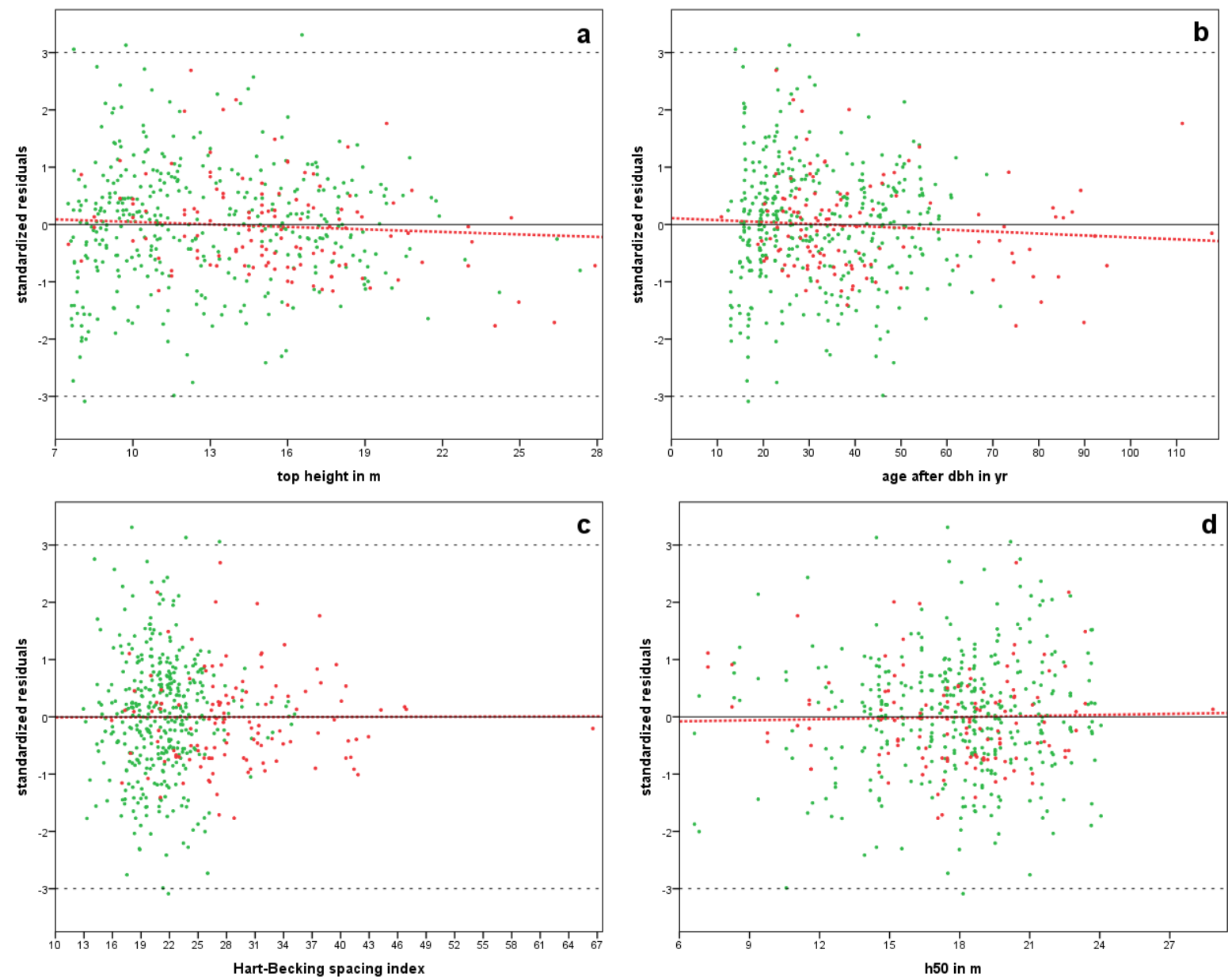

Figuur 18. Gestandaardiseerde residuen van Model (18) in relatie tot de modelvariabelen opperhoogte (a), leeftijd (b), $S \%$ (c)en de niet-modelvariabele $h_{50}(d)$. De rode lijn geeft de lineaire regressielijn weer door de residuen. De groene punten zijn de waarnemingen van de analyse plots de rode die van de controle plots

Figure 18. Standardized residuals of Model (18) in relation to the model variables top height (a), age (b), $5 \%$ (c) and the non-model variable $h_{50}(d)$. The red lines shows the linear regression lines through the residuals. Green dots represent data from analyse plots and red ones those from control plots.

\section{Conclusie}

Met het model van Jansen et al. (2016) is de grondvlakbijgroei te voorspellen, niet alle elementen van het model bleken toepasbaar. Het model voldoet niet aan de verbeterde wet van Eichhorn.

Het plotniveau zou volgens Formule (15) als volgt kunnen worden bepaald:

$$
i_{G}=\hat{i}_{G_{-} f 18} \cdot P L_{k} \quad \text { for the } k^{\text {th }} \text { plot number }
$$

Maar aangezien van de 177 plots met een opperhoogte boven de 7 meter er slechts 17 zijn met meer dan 4 waarnemingen is een redelijke schatting niet mogelijk. 


\section{Dunningsysteem}

In de dunningproeven van studie 1 en 2 zijn verschillende vaste dunninggraden nagestreefd (zie Tabel 12).

Tabel 12. Dunninggraden

Table 12 . Thinning grades

\begin{tabular}{|c|c|l|}
\hline Tgr $_{\mathbf{0}}$ & S\% bij $\mathbf{3 5} \mathbf{~ j r}$ & Omschrijving \\
\hline 1 & 13 & zonder dunning \\
2 & 16 & zwakke laagdunning \\
3 & 19 & matige laagdunning \\
4 & 22 & sterke laagdunning \\
5 & 25 & zeer sterke laagdunning \\
6 & 28 & open stand \\
\hline
\end{tabular}

Er is reden om aan te nemen dat de dunninggraad, zoals hier gedefinieerd via het $S \%$, op latere leeftijd moet stijgen omdat de vorm wijzigt zodra topsterfte optreedt. Maar bij Corsicaanse den moet ter voorkoming van Brunchorstia taksterven al veel eerder een wijdere stand worden aangehouden op basis van Figuur 19b is gekozen voor een grensleeftijd van 35 jaar, met een constant $S \%$ daarbeneden.
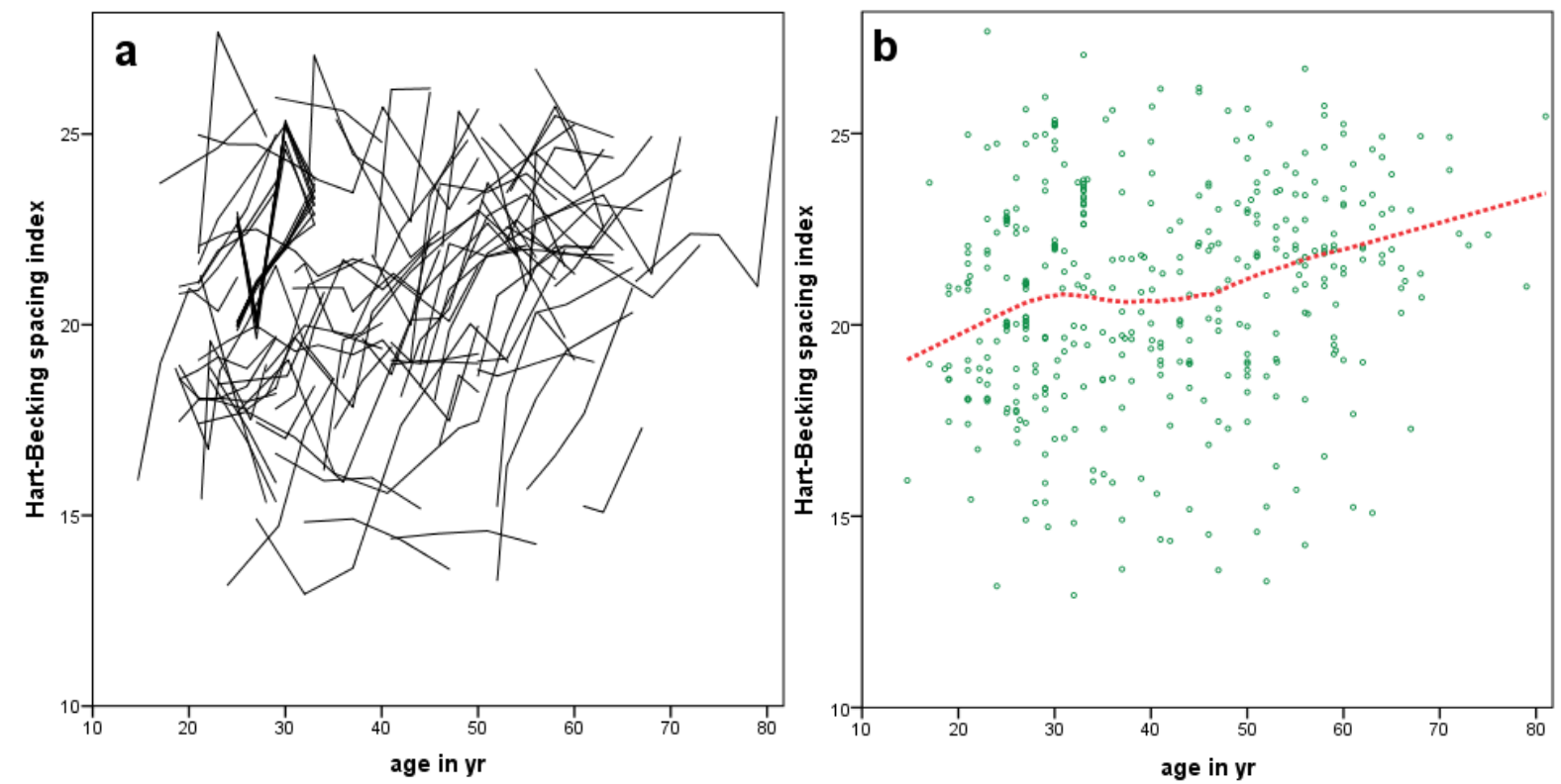

Figuur 19. Schommeling van het $S \%$ in de tijd in per plot (a) en met alleen de waarnemingen waarbij de rode lijn het voortschrijdend gemiddelde representeert (b).

Figure 19. Fluctuations in thinning grade in the separate plots (a) and with only the observation and the red line shows the moving average (b).

Het model luidt dan:

$$
S \%= \begin{cases}13+3 \cdot\left(\operatorname{Tgr}_{0}-1\right) & \text { age } \leq 35 \\ 13+3 \cdot\left(\operatorname{Tgr}_{0}-1\right)+c_{13} \cdot(\text { age }-35) & \text { age }>35\end{cases}
$$


Vanaf de eerste dunning of sterfte tot een leeftijd van 35 jaar komt het $S \%$, behorend bij de in te stellen dunninggraad $\operatorname{Tgr}_{0}$, overeen met die uit de tweede kolom van de tabel, daarna loopt het $S \%$ langzaam op.

Een model om $c_{13}$ te schatten luidt:

$$
S \%_{i j}=\left\{\begin{array}{ll}
S \%_{j} & \text { age } \leq 35 \text { and } h_{\text {top }}>7 \\
S \%_{j}+c_{13} \cdot\left(a g e_{i j}-35\right) & \text { age }>35 \text { and } h_{\text {top }}>7
\end{array} \text { for the } i^{\text {th }} \text { record in the } j^{\text {th }}\right. \text { plot }
$$

Met $R^{2}$ adj $=0.709$ werd gevonden $c_{13}=0.1459$ in een 95\% betrouwbaarheidsinterval $\{0.1144 ; 0.1774\}$, de gemiddelde $S \%$ waarde per plot is 19 met een range $\{12 ; 25\}$.

In de beschikbare opbrengsttabellen voor Frankrijk, het Verenigd Koninkrijk en Nederland blijkt geen enkele overeenkomst in dunningstrategie.

De dunninggraden hebben dus niet langer een vast maar een variabel $S \%$.

$\mathrm{Er}$ is een verband gedefinieerd tussen het stamtal en de diameter na sterfte door Reineke (1933), dit komt in Paragraaf 5.1 aan de orde. La Bastide \& Faber (1972) ontwikkelden een model om de diameter na dunning te bereken, dit model wordt in Paragraaf 5.2 besproken. Bij de analyse in Hoofdstuk 5 zijn opnamen uitgesloten die meer dan 2 dunninggraden van voorgaande afwijken (dit is meestal stormschade) en waarbij de diameter van de dunning hoger is dan die voor dunning (dat betreft soms stormschade en soms hoogdunning).

\subsection{Reineke's stamtal-diameter-relatie}

Reineke (1933) formuleerde een allometrische relatie tussen stamtal en diameter voor ongedunde opstanden voor diverse soorten in Oregon en Washington (USA) als volgt:

$$
\log N=K+c \cdot \log d_{m}
$$

Jansen et al. (2016) breidde dit model voor geplante en gedunde opstanden uit tot:

$$
\begin{aligned}
& \log N_{a t}=K_{0}-u-\sqrt{u^{2}+c_{17}^{2}} \\
& \text { where } u=-\frac{1}{2} \cdot\left\{c_{14}-c_{15} \cdot \log d_{a t}-c_{16} \cdot(T g r-1)-K_{0}\right\}
\end{aligned}
$$

Met een $R^{2}$ adj van 0.963 werd de volgende oplossing gevonden (zie Tabel 13).

De parameter $c_{17}$ is niet significant. 
Tabel 13. De geschatte parameters met Model (23).

Table 13. The estimated parameters with Model (23).

\begin{tabular}{|l|r|r|r|r|}
\hline & & & \multicolumn{2}{|c|}{$95 \%$ Confidence Interval } \\
\cline { 4 - 5 } Parameter & Estimate & Std. Error & Lower Bound & Upper Bound \\
\hline$c_{14}$ & 5.2266 & 0.018 & 5.191 & 5.262 \\
$c_{15}$ & 1.6231 & 0.015 & 1.594 & 1.652 \\
$c_{16}$ & 0.0470 & 0.002 & 0.044 & 0.050 \\
$c_{17}$ & 0 & & & \\
\hline
\end{tabular}

In Figuur 20 is het stamtal na dunning uitgezet tegen de diameter na dunning, beide in een logaritmische schaal. De hellinghoek $c_{15}$ komt overeen met die van Reineke (ongeveer 1.6).

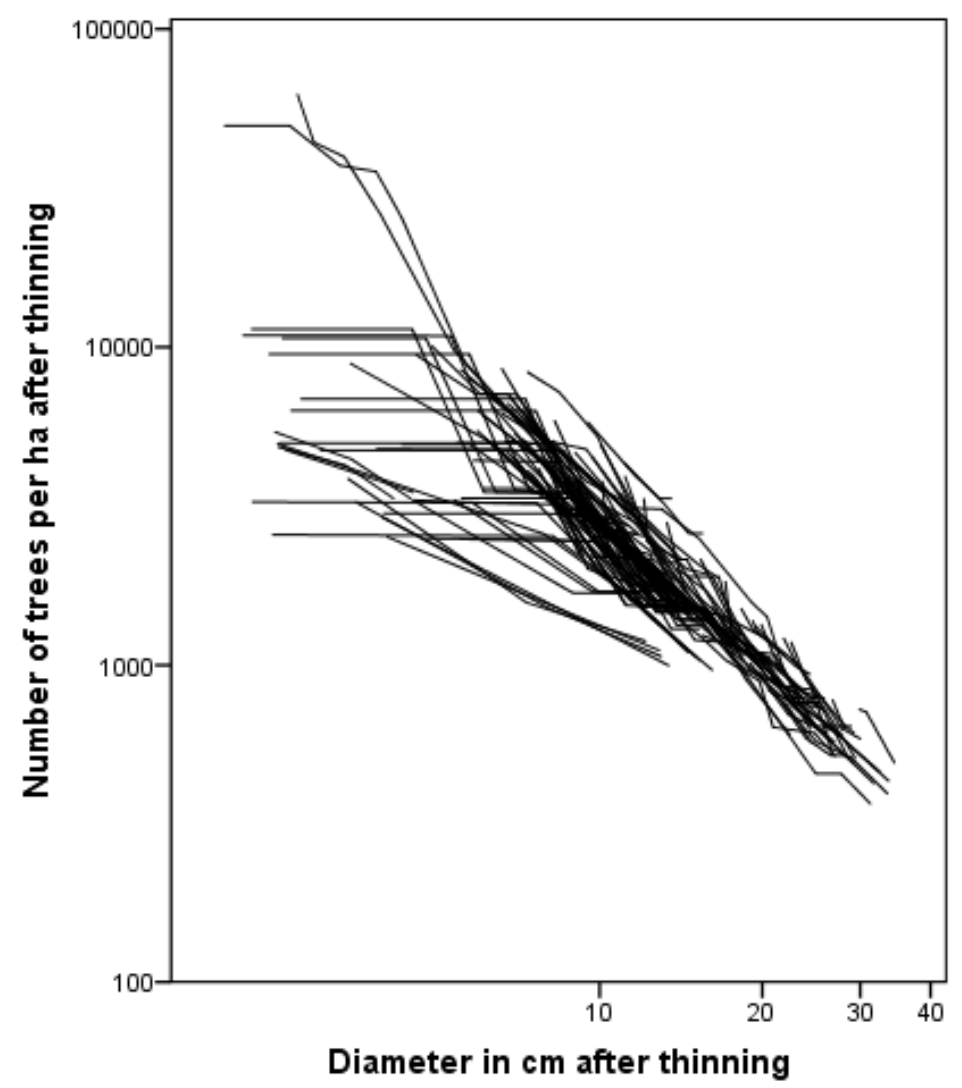

Figuur 20. Relatie stamtal en diameter na dunning.

Figure 20. Relation between stem density and diameter after thinning.

\subsection{Model van La Bastide-Faber voor voorspelling diameter na dunning}

Het stamtal na dunning wordt bepaald met het S-procent van Hart.

Jansen et al. (2016) voorspellen de diameter na dunning met een modificatie van het model van La Bastide \& Faber (1972): 


$$
\begin{aligned}
d_{a t}= & d_{b t} \cdot\left\{R \cdot \frac{a_{a t}}{a_{b t}}+1-R\right\} \\
& \text { where } R=c_{18}+c_{19} \cdot h_{50}+c_{20} \cdot \sqrt{T g r}+c_{21} \cdot t
\end{aligned}
$$

Met een $R^{2}$ adj van 0.999 werden de volgende constanten gevonden:

Tabel 14. Parameterschatting met Model (24).

Table 14. Parameter estimation with Model (24).

\begin{tabular}{|l|r|r|r|r|}
\hline & & & \multicolumn{2}{|c|}{ 95\% Confidence Interval } \\
\cline { 4 - 5 } Parameter & Estimate & Std. Error & Lower Bound & Upper Bound \\
\hline$c_{18}$ & 0.5597 & 0.027 & 0.506 & 0.614 \\
$c_{19}$ & 0 & & & -0.077 \\
$c_{20}$ & -0.0977 & 0.010 & -0.118 & -0.000 \\
$c_{21}$ & -0.0009 & 0.000 & -0.001 & \\
\hline
\end{tabular}

De parameters $c_{19}$ bleek niet significant. Bij de analyse zijn alle opnamen uitgesloten waarbij er minder dan 4 bomen uit het proefperk waren verdwenen, omdat dit meestal geen dunning maar sterfte betreft. Ook opnamen waarbij de diameter voor dunning hoger was dan die na dunning zijn uitgesloten, omdat dit geen normale laagdunning betreft. Door die selectie zijn er 431 waarnemingen beschikbaar.

Bij het maken van de opbrengsttabellen zal extrapolatie naar gebieden die niet gedekt zijn door data noodzakelijk zijn. Daarom is ook het originele model van La Bastide \& Faber gefit:

$$
d_{a t}=d_{b t} \cdot\left\{c_{22} \cdot \frac{a_{a t}}{a_{b t}}+1-c_{22}\right\}
$$

Met een $R^{2}$ adj van 0.998 werd voor de parameter gevonden $c_{22}=0.3228$ in een $95 \%$ betrouwbaarheidsinterval $\{0.313 ; 0.332\}$. Achteraf bleek het niet nodig model (25) te gebruiken.

\subsection{Conclusie}

In de inleiding is aangegeven hoeveel stammen er afhankelijk van de dunninggraad bij een zekere hoogte gedund worden. Hieruit volgt het stamtal na dunning. Met de inverse van Formule (23) is dan de diameter na dunning te voorspellen. Het probleem daarbij is dat vanwege die logaritmische transformatie de diameter zelf niet zuiver geschat wordt. De andere schatter van de diameter na dunning met de Formule (24) uit Paragraaf 5.2 heeft een hogere $R^{2}$ adj en is zuiver en geniet daarom de voorkeur. 


\section{Constructie Opbrengsttabellen}

Met de in deze studie gevonden relaties zullen nu nieuwe opbrengsttabellen worden gemaakt met verschillende dunninggraden.

Al eerder is besloten een indeling in relatieve boniteiten te maken, met daaraan gekoppeld de "hoogte" op 50 jaar. Er is gekozen voor de volgende presentatie van gegevens op dezelfde wijze als voor de douglas door Jansen et al. (2016).

Voor een groot aantal van deze gegevens kunnen de gevonden relaties in de voorafgaande hoofdstukken worden gebruikt. Maar er zullen nog wat allometrische relaties gefit moeten worden, voor variabelen die tot nu toe nog niet voorkwamen.

\subsection{Overige allometrische relaties}

Dominante hoogte

Het model van Jansen et al. (2016) is gekozen:

$$
h_{d o m}= \begin{cases}h_{\text {top }}-c_{23} \cdot h_{\text {top }}^{c_{24}} & \text { voor } N_{a t}>250 \\ \frac{N_{a t}-100}{250-100} \cdot\left(h_{t o p}-c_{23} \cdot h_{t o p}^{c_{24}}\right)+\frac{250-N_{a t}}{250-100} \cdot h_{\text {top }} & \text { voor } 100<N_{a t} \leq 250 \\ h_{\text {top }} & \text { voor } N_{a t} \leq 100\end{cases}
$$

Met een $R^{2}$ adj van 0.991 werd gevonden voor 223 waarnemingen in 58 proefperken: $c_{23}=$ 0.3093 en $c_{24}=-0.0640$.

Dominante diameter

Voor de dominante diameter werd het model van Jansen et al. (2018c) voor de grove den gefit:

$$
\begin{aligned}
& d_{d o m}= \begin{cases}d_{d o m 2} & \text { for } h_{\text {top }} \leq 7 \mathrm{~m} \\
\left(2 \cdot d_{d o m 2}+d_{d o m 1}\right) / 3 & \text { for } 7<h_{\text {top }} \leq 9 \mathrm{~m} \\
\left(d_{d o m 2}+2 \cdot d_{d o m 1}\right) / 3 & \text { for } 9<h_{\text {top }} \leq 11 \mathrm{~m} \\
d_{d o m 1} & \text { for } h_{\text {top }}>11 \mathrm{~m}\end{cases} \\
& \text { where } d_{d o m 1}=d_{a t}+\left\{c_{25} \cdot h_{50}^{c_{26}} \cdot\left(d_{a t} / c_{27}\right)^{c_{28}-1} \cdot \exp \left(-\left(d_{a t} / c_{27}\right)^{c_{28}}\right)\right\} \cdot\left(1-c_{29} \cdot T g r_{0}\right) \\
& d_{\text {dom } 2}=c_{30} \cdot d_{a t} \\
& T g r_{0} \text { is the actual thinning grade from Formula } 20 \text { with } \max T g r_{0}=7
\end{aligned}
$$

Met een $R^{2}$ adj van 0.967 werd gevonden $c_{25}=6.2590, c_{26}=0.3524, c_{27}=45, c_{28}=1.6427, c_{29}$ $=0.0501$ en $c_{30}=1.4844$. Bij de residuen zijn geen belangrijke afwijkingen te vinden, geconcludeerd is dat Formule (27) geschikt is.

Gemiddelde opstandhoogte

Jansen et al. (2016) vonden voor de gemiddelde hoogte $\left(h_{g}\right)$ na dunning een powerfunctie gevonden met in de loop van de ontwikkeling wijzigende parameters: 


$$
\begin{aligned}
& h_{a t}= \begin{cases}h_{a t(2)} & \text { for } h_{\text {top }} \leq 1.30 \mathrm{~m} \\
h_{a t(2)} & \text { for } h_{a t(1)} \leq h_{a t(2)} \\
h_{a t(1)} & \text { else }\end{cases} \\
& \text { where } h_{a t(1)}=\left(c_{31}+c_{32} \cdot a g e\right) \cdot h_{\text {top }}^{\left(c_{33}-c_{34} \cdot h_{\text {top }}\right)} \\
& h_{a t(2)}=c_{45} \cdot h_{\text {top }} \text { and } c_{45}=0.8 \text { (a set value) }
\end{aligned}
$$

Met een $R^{2}$ adj van 0.970 werden de volgende parameters gevonden: $c_{31}=0.6020, c_{32}=$ $0.0005872, c_{33}=1.1641$ en $c_{34}=0.001838$. De begrenzing met de $c_{45}$ parameter is achteraf ingesteld omdat de basisformule voor lage leeftijden onrealistische waarden opleverde.

Voor de hoogte voor dunning volgde:

$$
h_{b t}=c_{35} \cdot h_{a t} \quad \text { with } R^{2} \text { adj }=0.999 \text { and } c_{35}=0.9907
$$

\section{Opstandvolume}

In de data zijn de boomvolumes bepaald met de Formule (30), zie Dik (1984). Ze gebruikte het Schumacher-Hall-model (1933):

$$
v=d^{c_{35}} \cdot h^{c_{36}} \cdot e^{c_{37}} \text { met } d \text { in } \mathrm{cm}, h \text { in } \mathrm{m} \text { en } v \text { in } \mathrm{dm}^{3}
$$

Voor Corsicaanse den geldt in het Binnenland: $c_{36}=1.89192, c_{37}=0.95374$ en $c_{38}=-2.72505$ en voor het Kustgebied $c_{36}=1.89118, c_{37}=1.13859$ en $c_{38}=-3.22112$.

Van de perken van de Dorschkamp zijn geen boomgegevens meer beschikbaar, maar alleen opstandgegevens. Deze zijn vermoedelijk met een eerdere versie van (30) berekend met iets afwijkende parameters. Daarom is met de data waar wel boomgegevens beschikbaar zijn de functie opnieuw gefit zonder verschil tussen Binnenland en Kustgebied. Met een $R^{2}$ van 0.992 is gevonden: $c_{36}=1.89155, c_{37}=0.87470$ en $c_{38}=-2.48350$.

Formule (30) is niet geschikt om het opstandvolume te bepalen. In het verleden werd gebruik gemaakt van de gemodificeerde opstandvolumefunctie van Heisterkamp (1981), de functie luidt:

$$
\begin{aligned}
V= & c_{39} \cdot G^{c_{40}} \cdot h_{\text {top }}^{\left(c_{41}+c_{42} \cdot t_{0}\right)} \text { met } G \text { in } \mathrm{m}^{2} / \text { ha, } h_{\text {top }} \text { in } \mathrm{men} V \text { in } \mathrm{m}^{3} / \mathrm{ha} \\
& \text { met } t_{0}=t-t_{1.30}
\end{aligned}
$$

Deze is opnieuw gefit met:

$$
y=V_{b t}+V_{a t}=c_{39} \cdot h_{t o p}^{\left(c_{41}+c_{42} \cdot t_{0}\right)} \cdot\left(G_{b t}^{c_{40}}+G_{a t}^{c_{40}}\right)
$$

Met een $R^{2}$ van 0.989 is gevonden: $c_{39}=0.6226, c_{40}=0.9854, c_{41}=0.9306$ en $c_{42}=0$.

De formule van Heisterkamp is ontwikkeld voor opbrengsttabellen die een startwaarde hadden voor de opperhoogte, voor Corsicaanse den was die $7 \mathrm{~m}$. Daar beneden moet met de Formule (30) worden gewerkt. 
Beginstamtal

Als beginstamtal is gekozen voor $5000\left(=c_{43}\right)$ en 3000 bij een open stand.

\section{Grenswaarde}

De steeds terugkerende grenswaarde voor de opperhoogte van $7 \mathrm{~m}$ is de parameter $c_{44}$ in de modellen. En geeft daarbij de boven grens aan voor de jeugdgroei.

\subsection{Opbrengsttabellen}

\subsubsection{Keuze voor berekende opbrengsttabellen}

Allereerst is gekozen welke tabellen gepubliceerd zullen worden. Er is gekozen voor een opbrengsttabel voor Nederland met vijf dunninggraden en zeven boniteiten.

In Tabel 16 is de verdeling over boniteiten en leeftijdsklassen gegeven voor het aantal opstanden in de $4^{\mathrm{e}}$ Bosstatistiek met een leeftijd vanaf 12 jaar in Nederland. Dit geeft de behoefte aan tabellen weer, terwijl Tabel 15 een indicatie van de mogelijkheden geeft.

Tabel 15. Leeftijdsinterval in dataset per dunninggraad en boniteit.

Table 15. Age interval in the data set by thinning grade and site class.

\begin{tabular}{|l|ccccccc|}
\hline & \multicolumn{7}{|c|}{ data per boniteit } \\
\hline Dunninggraad & I & II & III & IV & V & VI & VII \\
\hline zonder dunning & & $61-67$ & $55-66$ & & $32-66$ & & \\
zwakke laagdunning & $22-29$ & $22-35$ & & $25-71$ & $27-81$ & $46-63$ & \\
matige laagdunning & & $12-50$ & $16-73$ & $18-68$ & $42-71$ & $50-63$ & $50-59$ \\
sterke laagdunning & & $8-35$ & $18-50$ & $19-64$ & $12-58$ & $15-22$ & $35-63$ \\
zeer sterke laagdunning & & $8-27$ & $18-50$ & & $25-70$ & $28-45$ & \\
open stand & & $11-22$ & $9-29$ & $12-23$ & & & \\
\hline
\end{tabular}

Tabel 16. Aantal opstanden per leeftijdsklassen en boniteit in $4^{\mathrm{e}}$ Bosstatistiek.

Table 16. Age classes per site class in $4^{\text {th }}$ National Forest Inventory (number of stands).

\begin{tabular}{|c|rrrrrrrr|r|}
\hline \multirow{2}{*}{$\begin{array}{c}\text { Leeftijdsklasse in } \\
\text { jaar }\end{array}$} & \multicolumn{7}{|c|}{ Boniteit } & \\
\cline { 2 - 9 } & 10 & II & III & IV & V & VI & $\geq$ VII & Totaal \\
\hline $20-30$ & 168 & 434 & 631 & 375 & 147 & 39 & & 1794 \\
$30-40$ & 52 & 288 & 721 & 587 & 195 & 27 & 9 & 1879 \\
$40-50$ & 6 & 63 & 273 & 312 & 128 & 24 & 4 & 810 \\
$50-60$ & & 24 & 88 & 193 & 116 & 38 & 22 & 481 \\
$60-70$ & 1 & 5 & 13 & 33 & 43 & 25 & 29 & 149 \\
$\geq 70$ & & & 6 & 15 & 21 & 14 & 15 & 71 \\
\hline Totaal & 227 & 814 & 1735 & 1525 & 672 & 187 & 88 & 5248 \\
\hline
\end{tabular}

Extrapolatie buiten het waarnemingsmateriaal moet in principe beperkt worden maar is onvermijdelijk (zie Tabel 15). De maximale leeftijd is op 80 jaar gesteld. Een tabel voor Corsicaanse den zonder dunning wordt niet gemaakt. 


\subsubsection{Constructie van de opbrengsttabel}

Voor de constructie worden eerst bij een gekozen waarde voor $h_{50}$ (zie Tabel 4 in Hoofdstuk 3) en een gekozen dunninggraad de $t_{130}$ en $t_{7}$ berekend met Formule (11) en het bij de dunninggraad behorende $S \%$ van Hart vastgesteld. Verder is het beginstamtal $N_{0}$ vastgesteld op 5000 , behalve voor de open stand, waar met een lager beginstamtal van 3000 wordt gewerkt. Daarna zijn per leeftijd $t$ op het interval $\left\{1, t_{\max }+1\right\}$ een aantal variabelen berekend. Allereerst wordt $h_{\text {top }}$ berekend met Formule (11), daarna $h_{\text {dom }}$ met (26).

Er worden drie situaties onderscheiden:

I. $h_{\text {top }}<7 \mathrm{~m}$. Geen dunning of zuivering.

Het stamtal is gelijk aan $N_{0}$ (in het model is deze $c_{43}$ ). De $G_{b t}$ wordt met Formule (14) berekend. De $h_{g}$ wordt met Formule (28) berekend. Voor $d_{b t}$ volgt $d_{b t}=200 \cdot \sqrt{\frac{G_{b t}}{\pi \cdot N_{0}}}$. Het volume wordt met Formule (31) berekend. Voor de grondvlak- en volumebijgroei is de berekening hetzelfde als bij situatie III.

Tot een hoogte van $1.30 \mathrm{~m}$ worden alleen het stamtal, de opperhoogte en de dominante hoogte vermeld;

II. $h_{\text {top }(t)} \leq 7 \mathrm{~m}$ en $h_{\text {top }(t+1)}>7 \mathrm{~m}$

Geen dunning maar wel start berekening van het grondvlak. Allereerst wordt de $t_{7}$ bepaald (de exacte leeftijd waarop een opperhoogte van $7 \mathrm{~m}$ wordt bereikt. Voor de diameter (voor dunning) geldt $d_{7}=c_{6} \cdot h_{50}^{-0.25}+c_{7} \cdot N_{0}^{-0.50}$ uit Formule (14).

Voor het grondvlak (voor dunning) volgt dan $G_{b t\left(t_{7}\right)}=N_{0} \cdot \frac{\pi}{40000} \cdot d_{7}^{2}$.

Het $S \%$ wordt met $N_{0}$ en $h_{\text {top }}=7$ met Formule (1) berekend, daaruit volgt de dunninggraad voor dunning volgt $\operatorname{Tg} r=(S \%-10) / 3$. De grondvlakbijgroei wordt nu met een aangepaste versie van Formule (16) berekend:

$$
\begin{array}{r}
i_{G}\left(t_{7}, t+1\right)=\operatorname{cor}_{S \%} \cdot\left\{c_{12} \cdot \operatorname{Term}_{h}+\left(1-c_{12}\right) \cdot \text { Term }_{t}\right\} \text { for } h_{\text {top }}>7 \\
\text { where } \operatorname{Term}_{h}=c_{8} \cdot \frac{\left(h_{\text {top }(t+1)}-1.30\right)^{c_{11}}-(7-1.30)^{c_{11}}}{t+1-t_{7}} \\
\operatorname{Term}_{t}=c_{8} \cdot \frac{\left(t+1-t_{130}\right)^{c_{11}}-\left(t_{7}-t_{130}\right)^{c_{11}}}{t+1-t_{7}} \\
\operatorname{cor}_{S \%} \text { as in Formula } 16
\end{array}
$$

$\mathrm{Na}$ het bepalen van $I_{G}$ wordt het grondvlak voor dunning op het tijdstip $t+1$ bepaald:

$$
G_{b t(t+1)}=G_{b t\left(t_{7}\right)}+i_{G}\left(t_{7}, t+1\right) \cdot\left(t+1-t_{7}\right)
$$

De berekening gaat nu verder als bij situatie III

III. $h_{\text {top }}>7 \mathrm{~m}$. Dit is de situatie waarin gedund kan worden.

Het stamtal voor dunning op tijdstip $t=t$ is gelijk aan het stamtal na dunning op het tijdstip $t=t-1$. Het grondvlak voor dunning is ook bekend, omdat dit op ieder tijdstip een jaar 
vooruit wordt berekend - de eerste keer met Formule (33) en (34), en later met (36) en (37). Met de opperhoogte op $t=t$ en $N_{b t}$ wordt actuele dunninggraad ( $\left.S \%\right)$ met formule (1) berekend.

Met de reciproke van de grondvlakdefinitie wordt de diameter voor dunning berekend.

$$
d_{b t}=200 \cdot \sqrt{\frac{G_{b t}}{\pi \cdot N_{b t}}}
$$

Op ieder tijdstip wordt verder het volume voor dunning $V_{b t}$ berekend met Formule (31). Alleen bij veelvouden van 5 jaar mag er gedund worden, daartussendoor vindt er wel bijgroei plaats, maar wordt er niet gedund en geldt "de situatie na dunning is gelijk aan die voor dunning". Bij die veelvouden van 5 jaar worden ook de dominante hoogte en de dominante diameter berekend met de Formules (26) en (27).

Het gewenste stamtal na dunning wordt berekend met $N_{a t}=\left(10746 /\left(S \% \cdot h_{d o m}\right)\right)^{2}$. Hierin wordt het gewenste $S \%$ berekend met Formule (20). N.B. tot 35 jaar zijn deze gewenste $S$-percentages ook in Tabel 12 vermeld.

Indien het gewenste stamtal $N_{a t}$ kleiner is dan $N_{b t}$ wordt er gedund. De diameter na dunning $d_{a t}$ wordt berekend met de Formules (24) en (25), dus $d_{a t}=d_{b t} \cdot\left\{R \cdot \frac{a_{a t}}{a_{b t}}+1-R\right\}$ waarbij geldt $R=c_{18}+c_{19} \cdot h_{50}+c_{20} \cdot \sqrt{T g r}+c_{21} \cdot t$. Voor het grondvlak na dunning volgt $G_{a t}=N_{a t} \cdot \pi \cdot\left(d_{a t} / 200\right)^{2}$, voor dat van de dunning geldt $G_{t h}=G_{b t}-G_{a t}$, evenzo $N_{t h}=N_{b t}-N_{a t}$ en $d_{t h}=200 \cdot \sqrt{G_{t h} /\left(\pi \cdot N_{t h}\right)}$.

Voor de gemiddelde hoogte na en voor dunning gelden respectievelijk de Formules (28) en (29). Het volume voor en na dunning wordt berekend met Formule (31) en het verschil tussen beide waarden is het volume van de dunning.

Alle relevante informatie van de situatie met en zonder dunning is nu bekend en alvorens naar een volgend jaar te gaan wordt de grondvlakbijgroei tot het volgende jaar $t=t+1$ met de uit Formule (16) afgeleide volgende formule berekend:

$$
\begin{gathered}
i_{G}(t, t+1)=\operatorname{cor}_{s \%} \cdot\left\{c_{12} \cdot \operatorname{Term}_{h}+\left(1-c_{12}\right) \cdot \text { Term }_{t}\right\} \text { for } h_{\text {top }}>7 \\
\text { where } \operatorname{Term}_{h}=c_{8} \cdot\left\{\left(h_{\text {top }(t+1)}-1.30\right)^{c_{11}}-\left(h_{\text {top }(t)}-1.30\right)^{c_{11}}\right\} \\
\operatorname{Term}_{t}=c_{8} \cdot\left\{\left(t+1-t_{130}\right)^{c_{11}}-\left(t-t_{130}\right)^{c_{11}}\right\} \\
\operatorname{cor}_{5 \%} \text { as in Formula 16 }
\end{gathered}
$$

De dunninggraad in formule (36) is de actuele dunninggraad na eventuele dunning. $\mathrm{Na}$ het bepalen van $I_{G}$ wordt het grondvlak voor dunning op $t=t+1$ bepaald:

$$
G_{b t(t+1)}=G_{a t(t)}+I_{G}(t, t+1)
$$

Verder wordt er een telwerk bijgehouden van het grondvlak en volume van de uitgevoerde dunningen en wordt het totaal geproduceerde volume berekenend met $V_{\text {tot }}=V_{a t}$ 
$+\Sigma V_{t h}$, evenzo $G_{t o t}=G_{a t}+\Sigma G_{t h}$. Alle resultaten worden per leeftijd opgeslagen, daarna worden de gemiddelde en lopende volumebijgroei berekend met

$\operatorname{Im} V=\frac{V_{t o t(t)}}{t} \quad$ and $\quad I c V=\frac{V_{t o t(t+1)}-V_{t o t(t-1)}}{2}$

Op vergelijkbare wijze worden de gemiddelde en de lopende bijgroei van het grondvlak berekend.

In tabel 17 is een lijst met de geschatte parameters opgenomen.

Tabel 17. Lijst met alle parameters

Table 17. List with all parameters

\begin{tabular}{|c|c|c|c|}
\hline Parameter & Formula number & Thinning from below & remarks \\
\hline$c_{1}$ & $(11)$ & 0.0208852 & \\
\hline$c_{2}$ & (11) & 2.0262175 & \\
\hline$c_{3}$ & (11) & 0.0171167 & \\
\hline$c_{4}$ & (14) & 2.9103217 & \\
\hline$c_{5}$ & (14) & 0.2213508 & \\
\hline$c_{6}$ & (14) & 5.3710673 & \\
\hline$c_{7}$ & (14) & 216.2289514 & \\
\hline$c_{8}$ & (18) & 15.3929716 & \\
\hline$c_{9}$ & (18) & 0.0159755 & \\
\hline$c_{10}$ & (18) & 22.3679204 & \\
\hline$c_{11}$ & (18) & 0.5340613 & \\
\hline$c_{12}$ & (18) & 0.1927750 & \\
\hline$c_{13}$ & (20) & 0.1459104 & \\
\hline$C_{14}$ & (23) & 5.2265761 & \\
\hline$c_{15}$ & (23) & 1.6230632 & \\
\hline$c_{16}$ & (23) & 0.0469713 & \\
\hline$c_{17}$ & (23) & 0 & \\
\hline$c_{18}$ & (24) & 0.5596955 & \\
\hline$c_{19}$ & (24) & 0 & \\
\hline$c_{20}$ & (24) & -0.0977475 & \\
\hline$c_{21}$ & (24) & -0.0009470 & \\
\hline$c_{22}$ & (25) & 0.3227561 & \\
\hline$c_{23}$ & (26) & 0.3092790 & \\
\hline$c_{24}$ & (26) & -0.0640379 & \\
\hline$C_{25}$ & (27) & 6.2590171 & \\
\hline$c_{26}$ & (27) & 0.3523817 & \\
\hline$c_{27}$ & (27) & 45 & \\
\hline$c_{28}$ & (27) & 1.6426912 & \\
\hline$c_{29}$ & (27) & 0.0501015 & \\
\hline$c_{30}$ & (27) & 1.4843830 & \\
\hline$c_{31}$ & (28) & 0.6019632 & \\
\hline$C_{32}$ & (28) & 0.0005872 & \\
\hline$C_{33}$ & (28) & 1.1640631 & \\
\hline$c_{34}$ & (28) & 0.0018374 & \\
\hline$c_{35}$ & (29) & 0.9906699 & \\
\hline$c_{37}$ & (30) & 1.8915500 & \\
\hline$c_{38}$ & (30) & 0.8747048 & \\
\hline$c_{39}$ & (31) & -2.4834990 & \\
\hline$c_{40}$ & (31) & 0.6225716 & \\
\hline$C_{41}$ & (31) & 0.9853904 & \\
\hline$C_{42}$ & (31) & 0 & \\
\hline$c_{43}$ & $N_{0}$ & 5000 & 3000 for $\operatorname{Tg} r=6$ and FG \\
\hline$c_{44}$ & & 7 & Border value for $h_{\text {top }}$ \\
\hline$C_{45}$ & (28) & 0.8 & \\
\hline
\end{tabular}


In Paragraaf 6.3 wordt de kwaliteit van het ontwikkelde model beoordeeld. In Paragraaf 6.4 worden enkele eigenschappen van de uiteindelijk tabellen vergeleken met andere opbrengsttabellen. In Bijlage 1 zijn de geproduceerde opbrengsttabellen weergegeven.

\subsection{Kwaliteit van de voorspelling}

Om de kwaliteit van het opbrengsttabelmodel te beoordelen moet de ontwikkeling van bestaande opstanden worden voorspeld en vergeleken met de gemeten verandering. Het ontwikkelde groeimodel van Paragraaf 6.2 om opbrengsttabellen te maken moet daartoe gemodificeerd worden tot een "stand projection model".

Van een bepaalde opstand moet de leeftijd, de opperhoogte, het stamtal en het grondvlak bekend zijn, waarmee alle andere toestandvariabelen kunnen worden berekend. Daarna kan de situatie over een aantal jaren voorspeld worden en een dunning worden gesimuleerd, en de veranderingen in de opstandkenmerken worden voorspeld. Door dit voor de proefperken te doen kan de modelvoorspelling worden vergeleken met de gemeten kenmerken. Het "stand projection model" werkt als volgt:

\section{Stap 1. Boniteit bepalen}

Allereerst moet de site index $S$ met de reciproke van Formule (11), de leeftijd en $h_{\text {top }}$ worden bepaald:

Er wordt begonnen met een startwaarde voor $S$, stel $S_{\text {old }}=33$ (het gemiddelde uit Hoofdstuk 3). Daarna een nieuwe waarde bepalen voor $S$ met Formule (39)

$$
\begin{aligned}
S_{\text {new }}= & h_{\text {top }} \cdot\left(1-e^{-c_{1} \cdot t}\right)^{-b} \\
& \text { where } b=c_{2}-c_{3} \cdot S_{\text {old }}
\end{aligned}
$$

Vervolgens een nieuwe beginwaarde bepalen met:

$$
S_{\text {old }}=\left(3 \cdot S_{\text {old }}+S_{\text {new }}\right) / 4
$$

Daarna Formule (39) en (40) herhalen tot $S=S_{\text {new }}=S_{\text {old }}$.

\section{$\underline{\text { Stap } 2 .}$}

Met de definitie van de Formules (1) en (20) wordt vervolgens de dunninggraad voor en na dunning bepaald. De grondvlakbijgroei per jaar worden berekend met de waarden voor $S \%$, $h_{\text {top }}$ en $t$ over het interval $\left\{t_{1} ; t_{2}\right\}$. In Paragraaf 6.2 is beschreven welke formules daartoe gebruikt worden. Hieruit volgt het grondvlak voor dunning op tijdstip $t_{2}$ en hieruit weer de diameter voor dunning $\left(\hat{d}_{b t 2}\right)$.

\section{$\underline{\text { Stap } 3 .}$}

Hierna wordt de opperhoogte berekend op het $2^{\mathrm{e}}$ tijdstip met Formule (11). De voorspelde diameterbijgroei op het interval $\left\{t_{1}, t_{2}\right\}$ bedraagt:

$$
\Delta_{d}=\hat{d}_{b t 2}-d_{a t 1}
$$


Er worden evenveel bomen gedund als in werkelijkheid maar de diameter na dunning $\left(\hat{d}_{\text {at2 }}\right)$ wordt berekend met Formule (24).

\section{Vervolg}

Stap 2 en 3 kunnen nu herhaald worden voor een $3^{e}$ tijdstip en eventuele vervolgtijdstippen. De stamtallen van de dunning en die voor en na dunning zijn bekend, hiermee en met de formules uit het opbrengsttabel model kunnen alle andere opstandkenmerken worden berekend.

Om de kwaliteit van het model te meten is deze procedure voor series van 4 opnamen doorgerekend (veel perken hebben echter maar 3 opnamen, daar is met 3 opnamen gewerkt). Voor bijvoorbeeld een perk met 6 opnamen ontstaan zo drie voorspellingseries op de intervallen $\left\{t_{1}, t_{4}\right\},\left\{t_{2}, t_{5}\right\}$ en $\left\{t_{3}, t_{6}\right\}$. Vervolgens is de zuiverheid en nauwkeurigheid van de voorspellingen van de bereikte opperhoogte, de diameter na dunning en het opstandgrondvlak na dunning in de laatste (dus de $3^{\mathrm{e}}$ of $4^{\mathrm{e}}$ ) opname bekeken. Het gemiddelde tijdvak bedroeg $9.3 \mathrm{jr}$. Ook werd de grondvlakbijgroei over 10 jaar bekeken (zie Tabel 18 voor de resultaten). De zuiverheid van alle berekende voorspellingen blijkt gering tot slecht, met $0.8 \%$ onderschatting van de diameter na dunning tot $8.1 \%$ onderschatting van de grondvlakbijgroei. De nauwkeurigheid van de schatting van de grondvlakbijgroei is zeer gering. De geringe nauwkeurigheid en zuiverheid blijkt veroorzaakt te worden door 21 uitbijters van de 444 records waarover schattingen beschikbaar zijn. Dit betroffen grotendeels opnamen uit de plantafstandproeven waarbij de grenswaarde van een hoogte van $7 \mathrm{~m}$ werd gepasseerd (zie het rechterdeel van Tabel 18).

Tabel 18. Eigenschappen van enige schatters.

Table 18. Properties of some predictions.

\begin{tabular}{|l|rrrrr|rrrrrrr|r|}
\hline & \multicolumn{4}{|c|}{ resultaten bij laatste opname met alles } & \multicolumn{5}{c|}{ resultaten zonder uitbijters } \\
\cline { 2 - 14 } & gemeten & geschat & bias & bias\% & stdev & VC & gemeten & geschat & bias & bias\% & stdev & VC \\
\hline$h_{\text {top }}$ & 13.71 & 13.85 & -0.140 & $-1.02 \%$ & 1.020 & $7.4 \%$ & 14.06 & 14.23 & -0.172 & $-1.22 \%$ & 1.033 & $7.4 \%$ \\
$d_{a t}$ & 18.26 & 18.11 & 0.153 & $0.84 \%$ & 1.187 & $6.5 \%$ & 18.80 & 18.78 & 0.028 & $0.15 \%$ & 1.017 & $5.4 \%$ \\
$G_{a t}$ & 28.40 & 27.70 & 0.695 & $2.45 \%$ & 3.840 & $13.5 \%$ & 28.77 & 28.58 & 0.190 & $0.66 \%$ & 2.652 & $9.2 \%$ \\
$i G_{10}$ & 18.32 & 16.83 & 1.486 & $8.11 \%$ & 6.678 & $36.5 \%$ & 17.54 & 17.13 & 0.409 & $2.33 \%$ & 3.354 & $19.1 \%$ \\
\hline
\end{tabular}

\subsection{Vergelijking met andere opbrengsttabellen}

Hierna zijn enkele andere opbrengsttabellen voor de Corsicaanse den in Europa vergeleken met het hier gevonden resultaat.

\subsubsection{Hoogteontwikkeling}

Er zijn 2 landen waarvoor tabellen vergeleken zijn, namelijk die van Decourt (1965) voor de Sologne in Frankrijk en die van Hamilton \& Christie (1971) voor Groot-Brittannië, daarnaast zijn de beide tabellen van Faber (1987) voor Nederland vergeleken.

De hoogten vanaf 30 jaar bij Decourt (1965) in die in de nieuwe tabel voor Nederland (zie Figuur 21) komen zeer goed overeen. Voor de leeftijd is de groei bij Decourt wat steiler. Bij Decourt komen allen de drie beste boniteiten voor. 


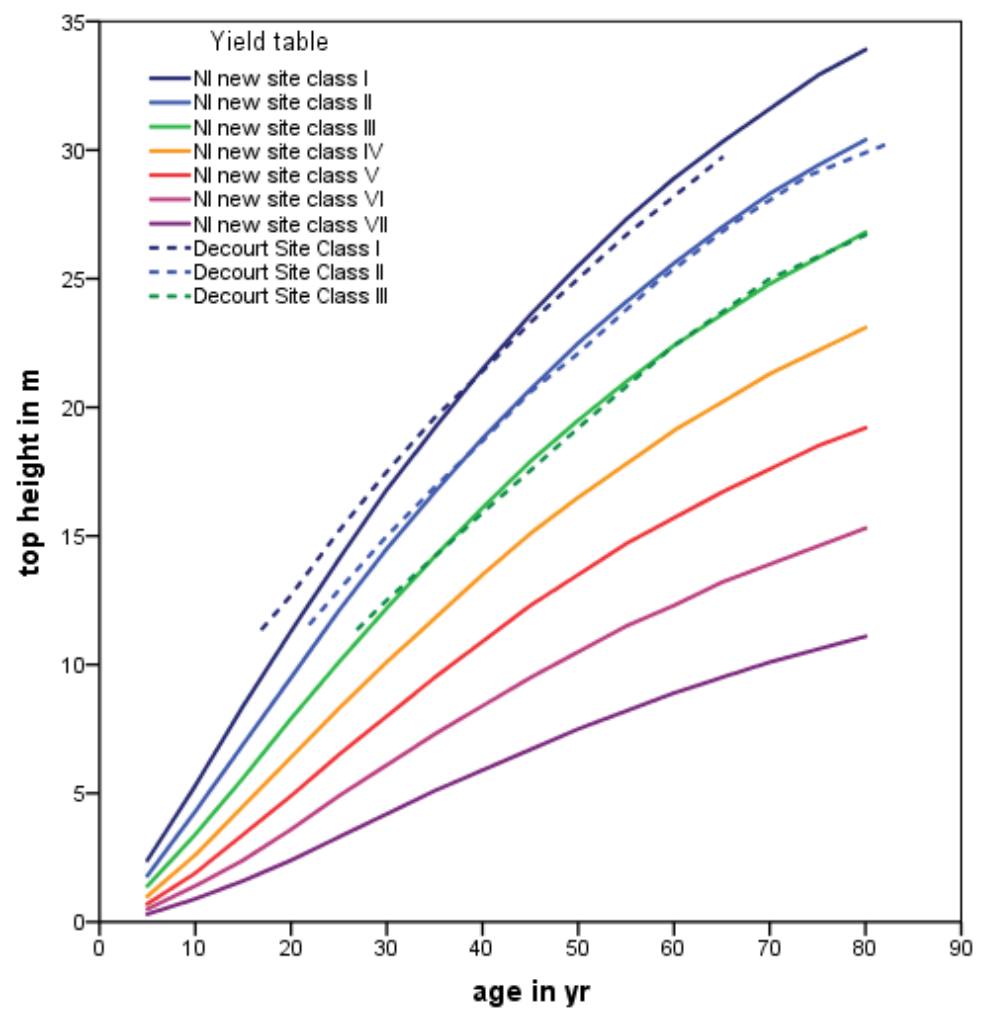

Figuur 21. Hoogteontwikkeling bij Decourt en het nieuwe model voor Nederland.

Figure 21. Height development at Decourt's yield table and the new model for Netherlands.

Bij de vergelijking met de tabel van Hamilton \& Christie (1971) blijkt de vorm van de curven tot een leeftijd van 50 à 60 jaar zeer goed overeen te komen met die van de nieuwe tabel voor Nederland. Hamilton \& Christie onderscheiden nog een betere boniteit dan in de nieuwe tabellen terwijl beide slechtste boniteiten er niet voorkomen (zie Figuur 22). Maar deze slechtste boniteiten zijn allen ontwikkeld voor het Kustgebied in Nederland. 


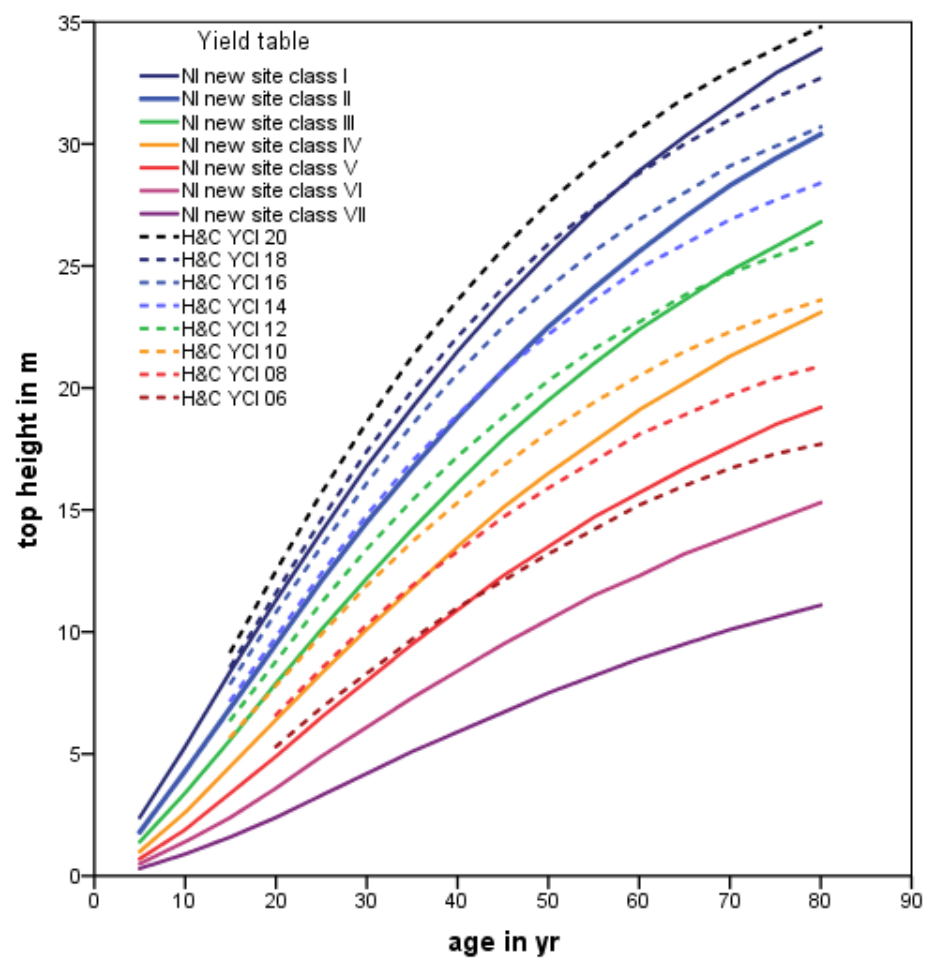

Figuur 22. Hoogteontwikkeling bij Hamilton \& Christie en het nieuwe model voor Nederland.

Figure 22. Height development at Hamilton \& Christie's yield table and the new model for Netherlands.

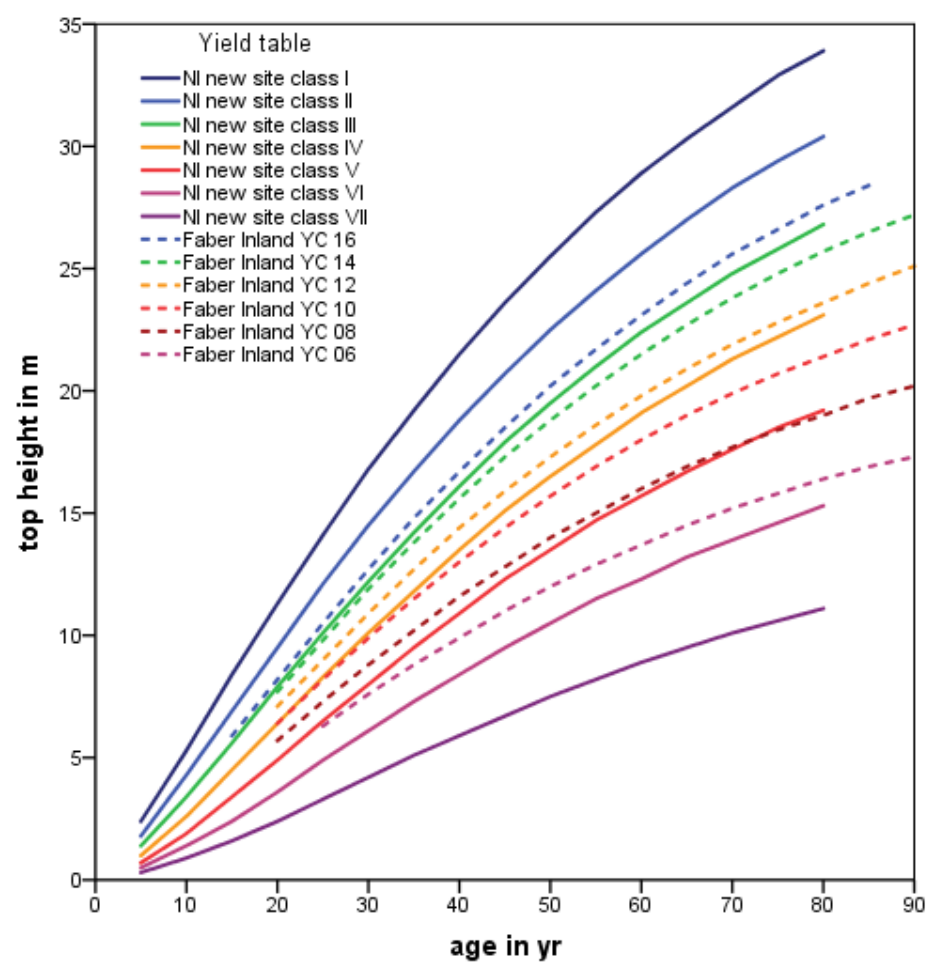

Figuur 23. Hoogteontwikkeling Faber in het Binnenland en het nieuwe model voor Nederland.

Figure 23. Height development at Faber's inland yield table and the new model for Netherlands. 
De hoogtecurven bij Faber (1987) komen zowel in het kustgebied voor de betere boniteiten zeer goed overeen met de nieuwe tabellen voor Nederland (zie Figuur 23 en Figuur 24). De slechtere boniteiten vlakken er eerder af. Wel is de range aan boniteiten veel ruimer in de nieuwe tabel voor Nederland.

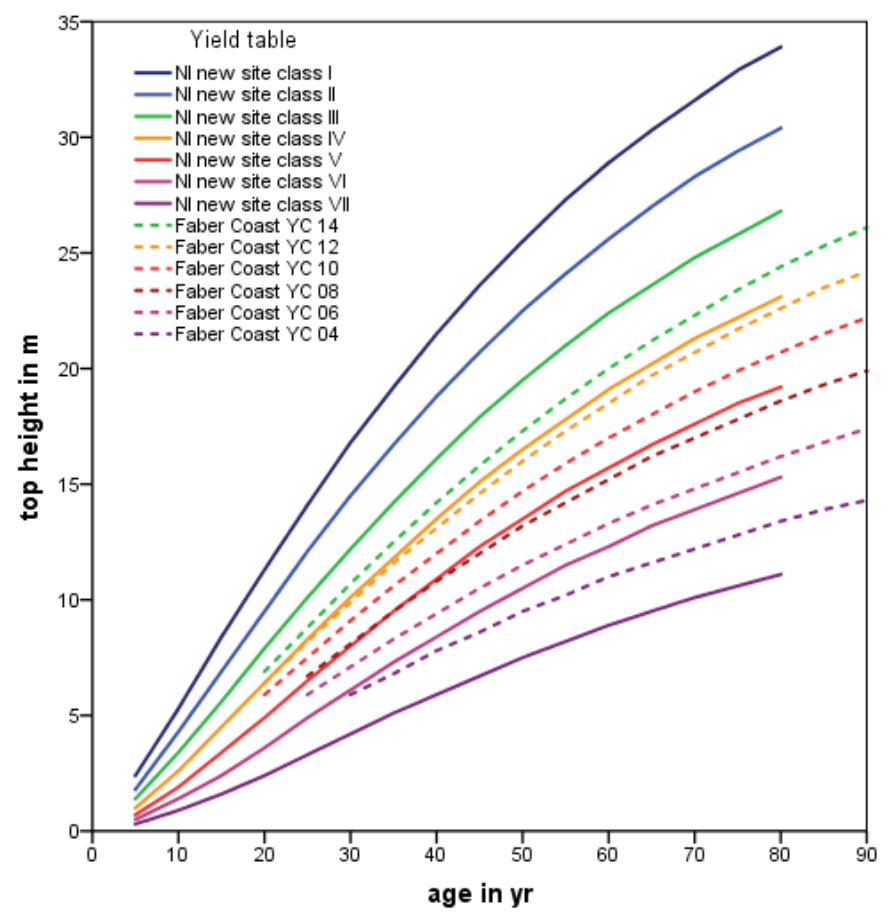

Figuur 24. Hoogteontwikkeling bij Faber (1987) in het Kustgebied en het nieuwe model voor Nederland.

Figure 24. Height development at Faber's coastal yield table and the new model for Netherlands.

De hoogtegroei in alle geraadpleegde opbrengsttabellen komt goed overeen met de nieuwe tabel voor Nederland, in de UK wordt nog een betere boniteit onderscheiden. De nieuwe slechtste $(\mathrm{VII})$ boniteit wordt komt in geen van de vergeleken tabellen voor.

\subsubsection{Productieniveau}

Het productieniveau wordt bij voorkeur gemeten op basis van de gemiddelde volumebijgroei bij zekere leeftijd. Hier is echter naar de totale grondvlakproductie gekeken.

In Figuur 25 is de totale grondvlakproductie per opbrengsttabel uitgezet tegen de opperhoogte voor alle boniteiten. De meeste opbrengsttabellen hebben als startpunt een hoogte van ongeveer 5 à $8 \mathrm{~m}$, en de nieuwe tabel vanaf $1.3 \mathrm{~m}$. Voor tabellen met meerdere dunninggraden (de nieuwe tabellen voor Nederland en die van Schober voor Duitsland) is voor de matige dunning gekozen 


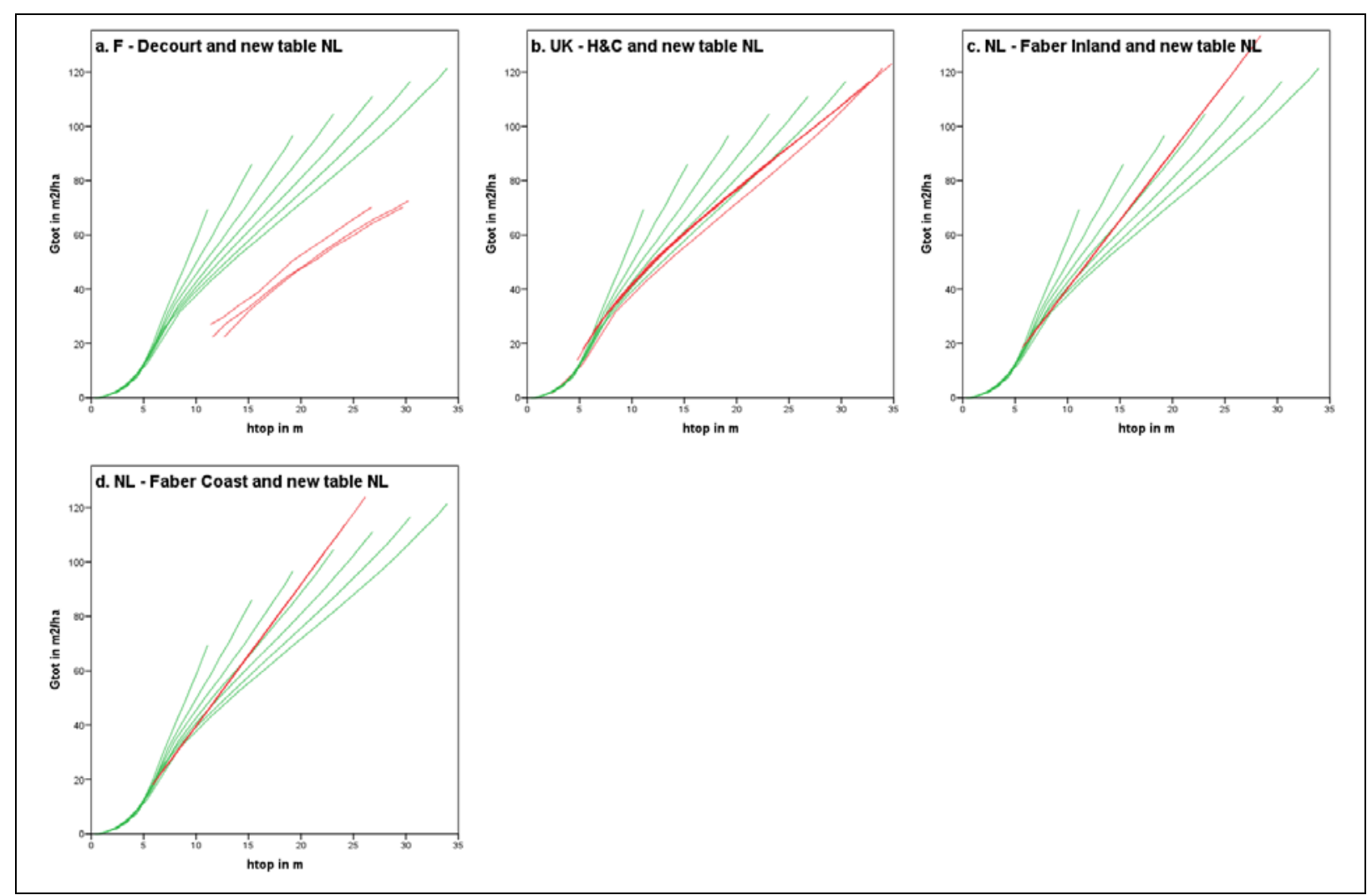

Figuur 25. De totale grondvlakproductie Gtot in relatie tot de opperhoogte bij de nieuwe tabel voor Nederland (in groen) in vergelijking met andere opbrengsttabellen (in rood) voor Decourt (a), Hamilton \& Christie (b), Faber Kustgebied (c) en Faber Binnenland (d).

Figure 25. Total basal area production Gtot in relation to top height for the new table for the Netherlands (in green) in comparison with other yield tables (in red) from Decourt (a), Hamilton \& Christie (b), Faber for inland area (c) and Faber for coastal area (d).

De hellinghoeken van de vergeleken tabellen komen redelijk overeen, dat geldt in veel mindere mate voor de uiteinden. In de nieuwe tabel voor Nederland komt het productieniveau zeer goed overeen met zowel de tabel van Hamilton \& Christie (1971) als de beide tabellen van Faber (1987). De tabel van Decourt (1965) heeft een beduidend lager productieniveau, maar kan ook komen door de startwaarden, deze zijn niet te vergelijken omdat daar geen informatie over beschikbaar is in de vergeleken tabellen.

Een andere manier van vergelijken betreft de leeftijd waarop de totale grondvlakproductie wordt bereikt.

Uit Figuur 26 blijkt dat vorm van de curve voor de beste boniteit voor alle vergeleken tabellen goed overeenkomt, weliswaar is het productieniveau bij Decourt lager. Bij de vergelijking met de tabel van Decourt is als slechtste boniteit de III ${ }^{\mathrm{e}}$ gekozen, omdat Decourt geen lagere boniteiten onderscheid. Bij de vergelijking van de tabellen van Faber is voor het binnenland vergeleken met de $\mathrm{I}^{\mathrm{e}}$ en $\mathrm{V}^{\mathrm{e}}$ boniteit en voor het kustgebied met de $\mathrm{III}^{\mathrm{e}}$ en $\mathrm{VII}^{\mathrm{e}}$ boniteit van de nieuwe opbrengsttabellen. Door heteromorfe stelsel van boniteitlijnen wijken de slechtste boniteiten bij zowel Faber als Hamilton \& Christie steiler. 


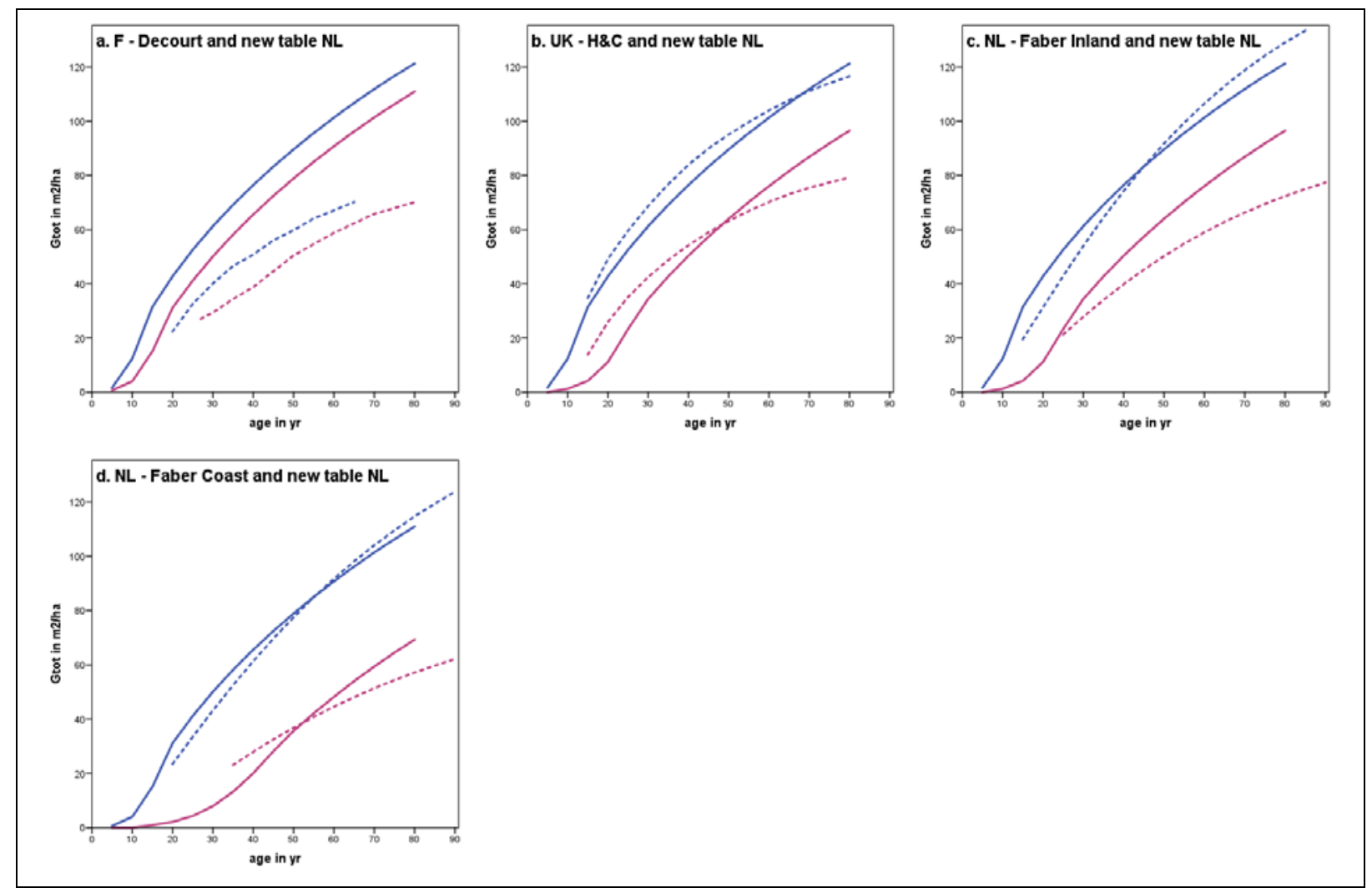

Figuur 26. De totale grondvlakproductie Gtot in relatie tot de leeftijd voor de beste boniteit (blauw) en vergelijkbare slechtste boniteit (paars) bij de nieuwe tabel voor $\mathrm{Ne}$ derland (volle lijnen) in vergelijking met andere opbrengsttabellen (gestreepte lijnen) voor Decourt (a), Hamilton \& Christie (b), Faber Binnenland (c) en Faber Kustgebied (d).

Figure 26. Total basal area production Gtot in relation to age for the best site class (blue) and the worst site class (purple) in the new table for the Netherlands (full lines) in comparison with other yield tables (hashed lines) from Decourt (a), Hamilton \& Christie (b), Faber for inland area (c) and Faber for coastal area $(d)$.

In de tabellen van Hamilton \& Christie en die van Faber is overduidelijk (zie Figuur 25) met het op de "uitgebreide wet van Eichhorn" (Gehrhardt, 1909) gebaseerde RGB-model gewerkt. Deze wet is te vertalen als:

$$
G_{\text {tot }} \approx f\left(h_{\text {top }}\right) \rightarrow R G B=\frac{\Delta G}{\Delta h_{\text {top }}}=f^{\prime}\left(h_{\text {top }}\right)=f_{2}\left(h_{\text {top }}\right)
$$

Maar alleen als $f_{2}$ een constante is geldt het RGB model, omdat zelfs zonder topsterven de berekende waarde $\Delta G / \Delta h_{\text {top }}$ tussen twee opnamen een variabele met een zeer grote variantie betreft kozen La Bastide en Faber (1971) voor een constante, die met een ratio-schatter te bepalen was.

\subsubsection{Dunningsysteem}

In Paragraaf 5.2 is een ander Model (24) ontwikkeld voor de dunningen dan het Reineke Model (22). In Figuur 27 zijn de in de nieuwe opbrengsttabel gevonden relaties tussen $N_{a t}$ en $d_{a t}$ 
weergegeven (Figuur 27a tabel waarden, Figuur 27b na vereffening over de boniteiten). Het blijkt dat de lijnen nagenoeg overeenkomen met die uit Formule (23). De ruis in de lijnen van Figuur 27a wordt veroorzaakt door verschillen per boniteit door de Formule (16).

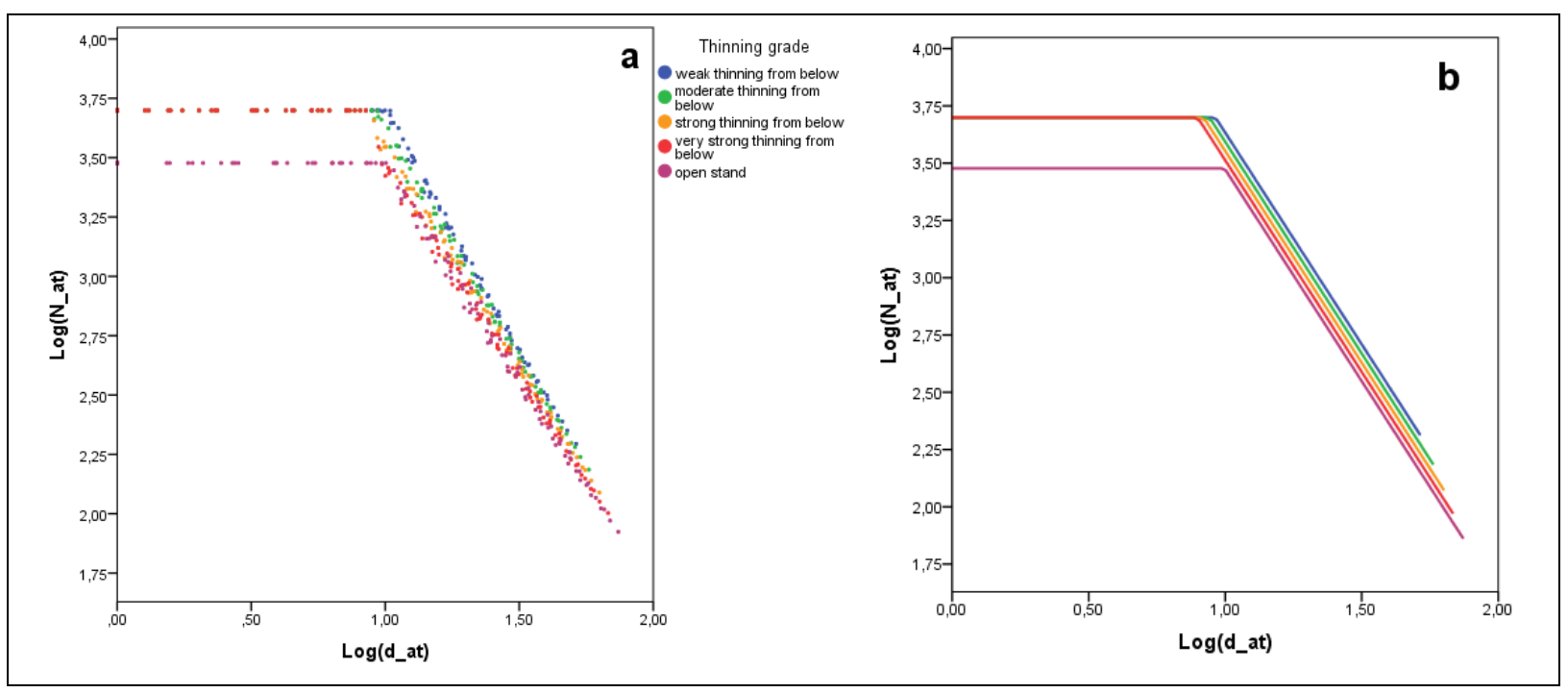

Figuur 27. Reineke-relatie in de nieuwe opbrengsttabellen voor Nederland. Links met alle boniteiten, rechts na vereffening met Formule (23) over de boniteiten.

Figure 27. Reineke's model in the new yield tables for The Netherlands. All site classes and thinning grades (a). After smoothing over the site classes with Formula (23) in b.

De vraag is of in de vergeleken tabellen ook sprake is van vergelijkbare waarden, daarbij is gekeken naar de hellinghoek en of de dunninggraad relevant is voor de intercept. Alle bekeken tabellen blijken een vergelijkbare hellinghoek te hebben, namelijk tussen -1.420 en -1.862. De bij de nieuwe tabellen gevonden waarde ligt daar tussen in, maar wijkt wel af van de in Paragraaf 5.1 met de data en Formule (23) berekende waarde van $c_{15}$ (1.623).

Tabel 19. Vergelijking parameters in gemodificeerd Reineke Model (23) bij diverse opbrengsttabellen.

Table 19. Comparison of the parameters in the modified Reineke Model (23) for various yield tables.

\begin{tabular}{|c|c|c|c|c|c|c|}
\hline \multirow[b]{2}{*}{ variable } & \multirow[b]{2}{*}{ parameter } & \multicolumn{3}{|c|}{ Netherlands } & \multirow{2}{*}{$\begin{array}{l}\text { France } \\
\text { Decourt }\end{array}$} & \multirow{2}{*}{$\begin{array}{c}\text { UK } \\
\text { H \& C }\end{array}$} \\
\hline & & New & Faber Coast & Faber Inland & & \\
\hline Constant & $\mathrm{t} \quad c_{14}$ & 5.446 & 5.078 & 5.149 & 5.085 & 6.041 \\
\hline Log_d & $c_{15}$ & 1.789 & 1.468 & 1.545 & 1.420 & 1.862 \\
\hline Tgr & $c_{16}$ & 0.032 & 0.044 & 0.037 & 0.128 & 0.192 \\
\hline
\end{tabular}

\subsection{Effecten dunning op productie}

Volgens de gangbare opvatting in het bosbeheer (Assmann, 1961, Wenk et al., 1990) zullen opstanden met een zwaardere dunninggraad ten opzichte van een opstand met een lichtere dunninggraad onder overige gelijke omstandigheden:

1. Een geringere volume- en grondvlakbijgroei hebben;

2. Een dikkere diameter (geldt zowel voor de $d_{g}$; als voor de $d_{d o m}$ ) hebben. 
Om een vergelijking mogelijk te maken is het gebruikelijk het in een opbrengsttabel weergegeven grondvlak per ha na dunning aan te geven als het normale grondvlak. Het werkelijke grondvlak van een opstand met dezelfde leeftijd en boniteit zal daarvan afwijken, maar ook opbrengsttabellen met een andere dunninggraad wijken daarvan af. Dit wordt de volkomenheidgraad genoemd.

De volkomenheidgraad van een opstand wordt als volgt gedefinieerd:

$$
\begin{aligned}
s d=\frac{G_{r}}{G_{n}} & \\
\text { where } G_{r} & =\text { the real stand basal area per ha } \\
G_{n} & =\text { the normal basal area per ha } \\
s d & =\text { stocking degree }
\end{aligned}
$$

Het opstandvolume kan nu geschat worden met:

$$
\begin{aligned}
& \hat{V}_{r}=s d \cdot V_{n} \\
& \begin{aligned}
\text { where } \hat{V}_{r}=\text { the estimation of the real stand volume per ha } \\
V_{n}=\text { the normal volume per ha. }
\end{aligned}
\end{aligned}
$$

Dit betreft een berekening over de huidige toestand. De vraag is wat dit betekent voor de bijgroei. Doordat de overgebleven bomen na zo'n sterkere dunning de groeiruimte beter benutten zal de onder punt 1 genoemde geringere volume- en grondvlakbijgroei niet domweg het product zijn van de volkomenheidsgraad en de normale bijgroei uit de tabel. In de literatuur zijn talloze dunningproeven beschreven, waaruit deze teneur blijkt. Als definitie van het normale grondvlak is het grondvlak na dunning voor de nieuwe opbrengsttabel met een matige dunning gekozen. Voor alle boniteiten samen werd met een $R^{2}$ adj van 0.762 voor $h_{\text {top }}>$ $7 \mathrm{~m}$ de volgende functies voor $G_{n}$ gevonden:

$G_{n}=-2.773+0.3100 \times t+2.331 \times h_{\text {top }}-0.03338 \times h_{\text {top }}^{2}-0.01247 \times t \cdot h_{\text {top }}$

De vraag is of de eerste veronderstelling aan het begin van deze paragraaf (zie Pagina 48) klopt in de ontwikkelde opbrengsttabellen. Hiertoe is het niveau van de grondvlakbijgroei voor dunninggraad 3 (matige laagdunning) op 1 gesteld en die van de andere dunninggraden als fractie daarvan uitgedrukt. Gekozen is om de toestand bij 70 jaar te presenteren. In Figuur 28 dat er grote variatie is tussen boniteiten per dunninggraad. De volgende relatie werd in concreto gevonden:

$$
c f= \begin{cases}1 & s d \geq 1 \\ 0.996 \cdot s d^{0.594} & s d<1\end{cases}
$$

Deze Formule (46) sluit redelijk aan bij de Staatsbosbeheer-benadering ${ }^{1}$ voor alle soorten:

\footnotetext{
1 Formule (47) was opgenomen in de software waarmee de opstandinventarisatie van het Staatsbosbeheer werd verwerkt in de periode 1970-1985.
} 


$$
c f= \begin{cases}1 & s d \geq 0.8 \\ \sqrt{s d} & s d<0.8\end{cases}
$$

Maar de bruikbaarheid is gering gezien de grote variatie.

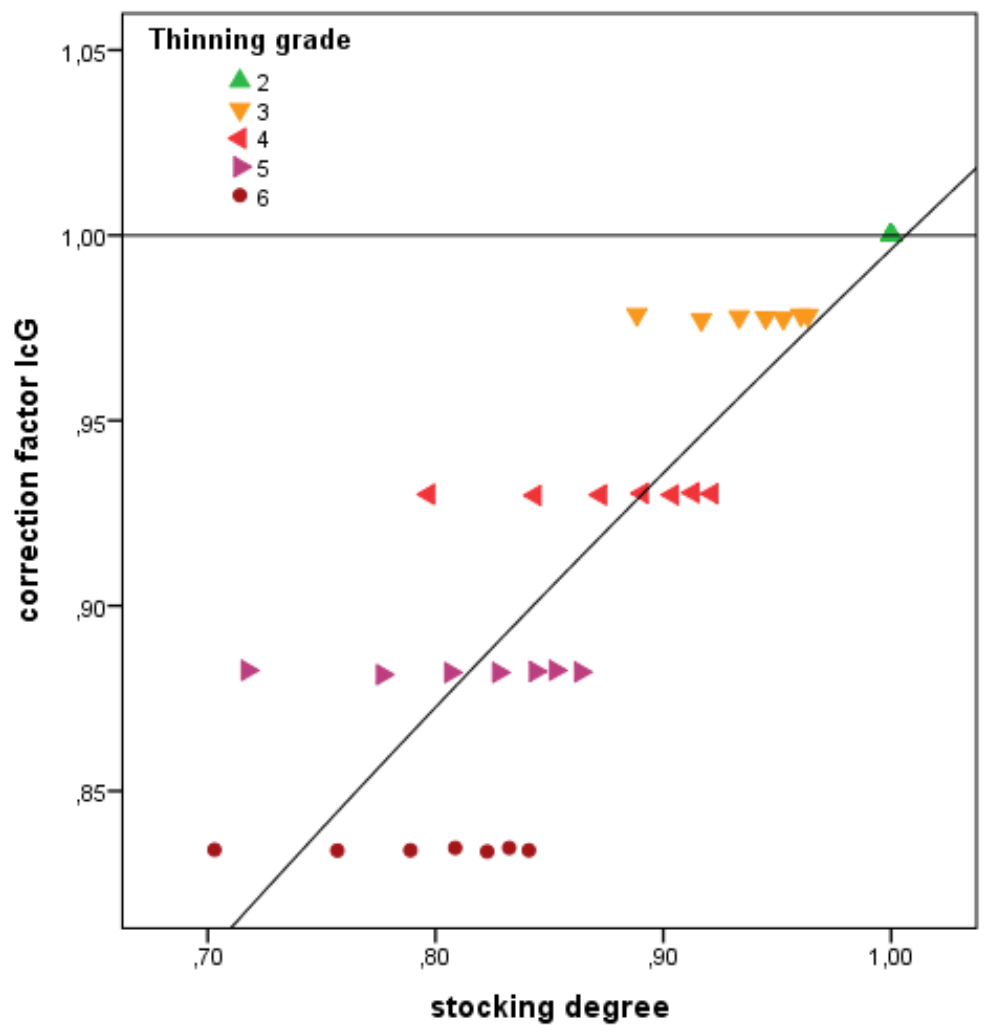

Figuur 28. Correctiefactor grondvlakbijgroei en volkomenheidgraad met de punten uit de nieuwe opbrengsttabel en de daarbij behorende lijnen bij 70 jaar.

Figure 28. Correction factor for basal area increment and stocking degree with the points from the new yield tables and associated lines at 70 year.

De andere voorveronderstelling met betrekking tot de effecten van een lagere volkomenheidsgraad gingen over de diameterontwikkeling. In Figuur 29 is duidelijk dat deze wat betreft de gemiddelde diameter na dunning en de dominante diameter opgaat, want de volkomenheidgraad is gerelateerd aan de dunninggraad, deze weer aan het $S$-procent, en deze aan de wortel uit het stamtal. Om hetzelfde relatieve grondvlak te houden zal de diameter dus sneller moeten groeien.

In Figuur 29 is te zien dat bijvoorbeeld een III $^{\mathrm{e}}$ boniteit de diameter na dunning bij een matige laagdunning $38.1 \mathrm{~cm}$ is en dat deze in een open opstand $49.0 \mathrm{~cm}$ bedraagt, deze afleiding is ook bij 70 jaar uitgevoerd. Voor de dominante diameter bedragen deze waarden respectievelijk 44.4 en $53.2 \mathrm{~cm}$. 
In Paragraaf 6.6 wordt een dunningmethode besproken waarbij met steeds krachtiger ingrepen toekomstbomen worden vrijgesteld (de zogenaamde vrije groei). In Figuur 29 is deze methode met de code FG opgenomen. Voor de III ${ }^{\mathrm{e}}$ boniteit bedraagt de diameter na dunning $59.9 \mathrm{~cm}$ en deze is dan gelijk aan de dominante diameter.
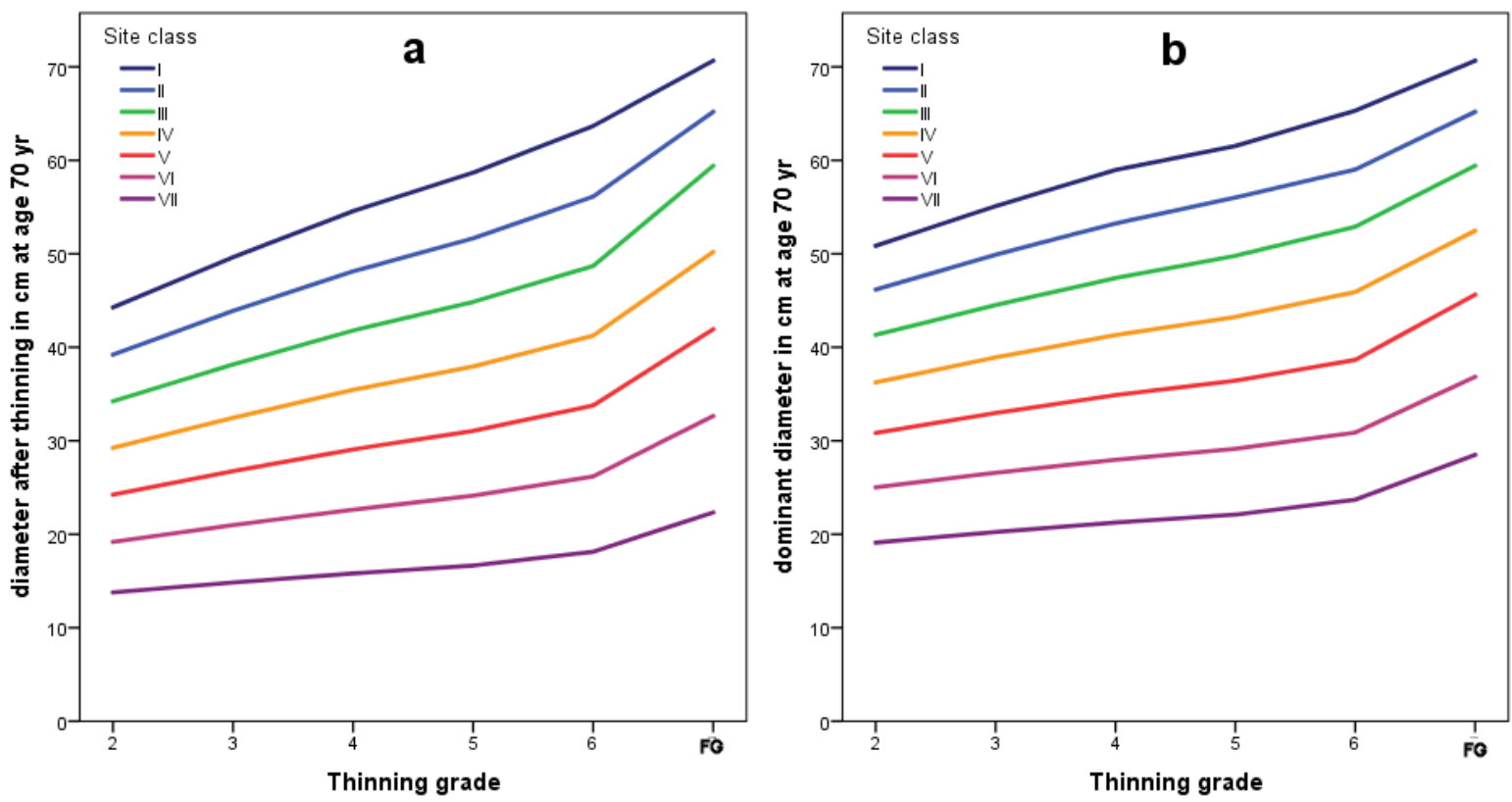

Figuur 29. Relatie tussen diameter (a) en dominante diameter (b) na dunning op 70 jaar met boniteit en dunninggraad en vrije groei (FG).

Figure 29. Relation between diameter (a) or dominant diameter (b) after thinning and thinning grade and for free growth (FG) by site class at 70 years.

\subsection{Vrije groei}

Jobling \& Pearce introduceerde in 1977 een dunningmethode voor de zomereik die ze "Free growth" noemde. Hierbij worden op 25-jarige leeftijd ongeveer 80 à 100 toekomstbomen aangewezen, die volledig vrijgesteld worden. In de rest van de opstand (de matrix) wordt sterk gedund. De toekomstbomen worden opgesnoeid, met het doel noestvrij hout te produceren.

In Nederland is een bijna identieke methode onder de naam QD-Beheer bekend (Thomassen \& Nyssen, 2013).

Als alle bomen uit de matrix zijn verdwenen wordt er niet meer gedund. Voor Corsicaanse den bij de $\mathrm{I}^{\mathrm{e}}$, II en III boniteit is dat het geval na 55 tot 65 jaar het geval. Voor de IV boniteit bij 80 jaar en voor de $\mathrm{V}^{\mathrm{e}}$ en hogere boniteiten is dat nooit het geval. Daarmee is de methode is minder geschikt voor de IV en slechtere boniteiten. In het simulatiemodel is hier geen rekening mee gehouden. 


\section{Discussie en conclusies}

\subsection{Hoogtegroei}

De hoogteontwikkeling van de opstand is een resultante van hoogtegroei en topsterfte. Een biologisch relevant groeimodel moet een buigpunt en een asymptoot hebben. Over dat buigpunt en de asymptoot zijn kwantitatieve gegevens afgeleid daarnaast is bekend wat de leeftijd op borsthoogte moet zijn. Met nog wat aanvullende criteria zijn zes modellen getest, geen voldeed volledig aan alle criteria. Het model van Jansen-Hildebrand (1986) voldeed het best:

$$
h_{\text {top }}=S \cdot\left(1-e^{-c_{1} \cdot t}\right)^{b} \quad \text { where } b=c_{2}-c_{3} \cdot S
$$

De asymptoot, hier de site index $S$ genoemd, is een maat voor de geschiktheid van de standplaats (boniteit) voor de Corsicaanse den, in de praktijk wordt echter $h_{50}$ als maat voor de boniteit gebruikt. Boniteren is met dit model lastig, want vereenvoudigd volgt uit Formule (48) voor de inverse functie $g$ van (48) $S=g\left(s, t, h_{\text {tot }}\right)$, je moet dus met een startwaarde voor $S$ werken en iteratief naar een oplossing werken als volgt:

$$
\begin{aligned}
& \rightarrow S_{\text {new }}=h_{\text {top }} \cdot\left(1-e^{-c_{1} \cdot t}\right)^{-b} \quad \text { where } b=c_{2}-c_{3} \cdot S_{\text {old } 1} \\
& \rightarrow S_{\text {old } 2}=\left(3 \cdot S_{\text {old } 1}+S_{\text {new }}\right) / 4
\end{aligned}
$$

Dit herhalen tot $S=S_{\text {new }}=S_{\text {old }}$ en vervolgens volgt $h_{50}=f_{49}(S, 50)$

De $R^{2}$ adj bleek met een waarde van 0.995 vrij hoog, en beduidend hoger dan in eerdere studies werd gevonden, namelijk 0.986 voor douglas (Jansen et al., 2016), 0.985 voor Japanse lariks (Jansen et al., 2018a), voor fijnspar 0.982 (Jansen et al., 2018b), voor grove den 0.970 (Jansen et al., 2018c), voor zomereik 0.983 (Jansen et al., 2018d) en voor beuk 0.969 (Jansen et al., 2018e). In al deze studies werd ook een heteromorf groeimodel gevonden. In de vigerende opbrengsttabel van Faber (1987) is sprake van twee regionale tabellen. Eén voor het Kustgebied en één voor het Binnenland, in geen van de onderzochte modellen bleek er een significant verschil tussen parameters per regio, wel was er verschil tussen de gemiddelde boniteit en de range van boniteiten per regio. Dit is opgelost door 7 boniteiten te onderscheiden, waarbij Boniteit I tot V bruikbaar zijn in het Binnenland en boniteit III tot VII in het Kustgebied.

\subsection{Diameter en grondvlak}

In Paragraaf 4.2 is het model voor de lopende bijgroei van het grondvlak ontwikkeld. Dit model start na het bereiken van een opperhoogte van $7 \mathrm{~m}$. In Paragraaf 7.2.2 wordt hierop ingegaan. Om een startwaarde voor de diameter voor dunning en het grondvlak per ha voor dunning te hebben op het tijdstip $t_{7}$ is in Paragraaf 4.1 een model ontwikkeld voor de diameterontwikkeling. In Paragraaf 7.2.1 wordt dit besproken. 


\subsubsection{Diameterontwikkeling}

In Paragraaf 4.1 werd Formule (14) gevonden voor de diameterontwikkeling gevonden, in vereenvoudigde vorm luidt dit:

$$
\begin{gathered}
d_{b t}=f_{2}\left(h_{\text {top }}, d_{7}\right) \text { for } h_{\text {top }} \leq 7 \\
\text { where } d_{7}=f_{1}\left(h_{50}, N_{R}\right) \quad \text { (the diameter at a height of } 7 \mathrm{~m} \text { ) } \\
N_{R}=\text { Number of trees before refinement }
\end{gathered}
$$

In het oorspronkelijke model van Jansen et al. (2016) is $f_{2}$ een Gompertz-functie, in latere studies, bij voorbeeld voor beuk (Jansen et al., 2018e) waren er vaak te weinig waarnemingen en werd voor $f_{2}$ een power-functie gebruikt en moesten er andere hulpmiddelen worden gebruikt om een niet al te sterke schatting te krijgen. Voor Corsicaanse den waren er voldoende (125) waarnemingen (waarvan 55 in ongedunde opstanden) met een hoogte beneden de $7 \mathrm{~m}$ en werd de kwaliteit van het model met bevestigd met een $R^{2}$ adj van $0.890 \mathrm{Er}$ bleek geen verschil tussen de beide regio's. Er waren veel waarnemingen met $h_{\text {top }} \leq 7 \mathrm{~m}$ (zie Tabel 6) waar al eerder gezuiverd of gedund werd. In het oorspronkelijke model van Jansen et al. (2016) geldt $d_{7}=f_{1}\left(N_{0}\right)$, net als bij de grove den (Jansen et al., 2018c) is daarom $N_{0}$ vervangen door $N_{R}$. De toevoeging van $h_{50}$ aan $f_{1}$ bleek nodig omdat in het Kustgebied bij de slechte boniteiten de diameter werd onderschat, uiteindelijk bleek het model daardoor overal zuiver te schatten.

In alle vergeleken opbrengsttabellen is dit traject niet beschreven en starten de tabellen bij de eerste dunning in de buurt van een hoogte van $7 \mathrm{~m}$. In Figuur 24 is te zien dat die beginwaarden voor $G_{b t}$ bij de tabellen voor UK en Nederland goed overeenkomen met de berekende waarde via $G_{7_{-} b t}=N_{0} \cdot \pi \cdot\left(d_{7} / 200\right)^{2}$ en $d_{7}$ uit Formule (50). De opbrengsttabel van Decourt (1965) voor de Sologne in Frankrijk voldoet hier niet aan.

Voor de ontwikkeling van de set opbrengsttabellen betekent dit dat bij de open stand en bij vrije groei $\left(N_{0}=3000\right) d_{b t}$ gemiddeld $24 \%$ dikker is bij een hoogte van $7 \mathrm{~m}$ dan bij de overige dunninggraden $\left(N_{0}=5000\right)$. Bij de boniteit VII is $d_{7} 12 \%$ dikker dan bij boniteit I.

\subsubsection{Grondvlakbijgroei}

In Paragraaf 4.2 werd Formule (18) voor de grondvlakbijgroei gevonden, in vereenvoudigde vorm luidt dit:

$$
\begin{aligned}
i_{G, i j k}= & f_{1}(S \%) \cdot f_{2}(\text { site }) \cdot\left\{\frac{F_{3}\left(h_{2}, t_{2}\right)-F_{3}\left(h_{1}, t_{1}\right)}{t_{2}-t_{1}}\right\} \cdot Y I_{k} \\
& \text { for the } j^{\text {th }} \text { plot at age } i=t_{m}=\left(t_{1}+t_{2}\right) / 2 \text { in the } k^{\text {th }} \text { year of recording }
\end{aligned}
$$

Ook hier bleek een power-functie voor $F_{3}$ het meest geschikt. Net als bij de douglas (Jansen et al. 2016) stijgt de grondvlakbijgroei met toenemende boniteit, de stijging is alleen een gevolg van $F_{3}$. Die stijging bleek ongeveer gelijk aan die in de vigerende opbrengsttabellen van 
Faber (1987) voor beste boniteit en voor de slechtste boniteit, zie Figuur 26. In de opbrengsttabellen van Faber is een relatieve grondvlakbijgroei $R G B$ (zie La Bastide en Faber, 1972) gebruikt, deze geeft een min of meer rechtevenredig verband tussen grondvlak en hoogte. De afgeleide van de $F_{3}$ functie uit Formule (51) is een ingewikkelde functie van de opperhoogte en geen constante RGB. In Figuur 25 is goed te zien dat de totale grondvlakproductie in relatie tot de opperhoogte van de nieuwe opbrengsttabel gemiddeld het meest overeenkomt met die van Faber. Bij Hamilton \& Christie (1971) voor Groot-Brittannië komt totale grondvlakproductie in relatie tot de opperhoogte van de beste boniteit overeen, maar ook hier is sprake van een $R G B$-model. Bij Corsicaanse den bleek $f_{2}$ slechts een constante en geen functie van de boniteit, dat was ook het geval bij douglas (Jansen et al., 2016), Japanse lariks (Jansen et al., 2018a), grove den (Jansen et al., 2018c), zomereik (Jansen et al., 2018d), en beuk (Jansen et al., 2018e). Bij fijnspar (Jansen et al., 2018b) bleek $f_{2}$ wel van belang. De correctiefactor voor de grondvlakbijgroei $f_{1}$ is actief vanaf een $S \%$ van ongeveer 22.4 .

\subsection{Variatie in groei tussen verschillende jaren}

Er was onvoldoende materiaal om de jaarindex $(Y I)$ in Formule (51) te bepalen, zie Figuur 30a. Er zijn 54 verschillende jaren van opname geregistreerd, hiervan zijn er slechts 13 stuks die meer dan 20 maal of vaker voorkomen, waarvan 11 tussen 1962 en 1977 en 2 stuks bij de HOSP-plots in 1987 en 1988. Er is daarom met een periode-index (PI) gewerkt. In Figuur $30 \mathrm{~b}$ is te zien dat de gemiddelde lopende grondvlakbijgroei $\left(i_{c G}\right)$ per periode verschilt en deels ook significant verschilt.

Tabel 20. Relatieve gemiddelde grondvlakbijgroei en periode-index

Table 20. Relative mean basal area increment and period-index.

\begin{tabular}{|c|c|c|c|c|c|c|c|c|c|}
\hline \multirow[b]{2}{*}{ period } & \multirow[b]{2}{*}{$\mathrm{n}$} & \multicolumn{4}{|c|}{ Relative mean $i_{c G}$} & \multicolumn{4}{|c|}{ Period Index } \\
\hline & & mean & $\begin{array}{l}\text { std. } \\
\text { error }\end{array}$ & $\begin{array}{r}95 \% \text { co } \\
\text { low }\end{array}$ & $\begin{array}{l}\text { interv. } \\
\text { upper }\end{array}$ & mean & $\begin{array}{l}\text { std. } \\
\text { error }\end{array}$ & $\begin{array}{c}95 \% \text { co } \\
\text { low }\end{array}$ & $\begin{array}{l}\text { interv. } \\
\text { upper }\end{array}$ \\
\hline$<1955$ & 40 & 0.83 & 0.10 & 0.64 & 1.02 & 0.85 & 0.04 & 0.77 & 0.93 \\
\hline 1955 - 1965 & 137 & 1.04 & 0.06 & 0.92 & 1.17 & 0.94 & 0.03 & 0.88 & 0.99 \\
\hline 1965 - 1975 & 246 & 1.19 & 0.03 & 1.14 & 1.25 & 1.13 & 0.03 & 1.08 & 1.18 \\
\hline $1975-1985$ & 79 & 0.97 & 0.02 & 0.93 & 1.02 & 1.13 & 0.03 & 1.07 & 1.18 \\
\hline 1985 - 1995 & 108 & 0.68 & 0.02 & 0.63 & 0.73 & 0.94 & 0.03 & 0.88 & 1.00 \\
\hline$>1995$ & 27 & 0.62 & 0.05 & 0.53 & 0.72 & 1.02 & 0.06 & 0.91 & 1.14 \\
\hline
\end{tabular}

De waarden uit Figuur 30b betreffen uiteraard niet de periode-indices, omdat er een zeer hoge correlatie bestaat tussen leeftijd en jaar van opname en leeftijd is een onderdeel van model (51). Daarom zijn in Tabel 20 zowel de met Model (18) berekende periode-indices weergegeven met de gemiddelde relatieve periodieke grondvlakbijgroei (dat is de periodieke bijgroei gedeeld door de totale gemiddelde bijgroei). 

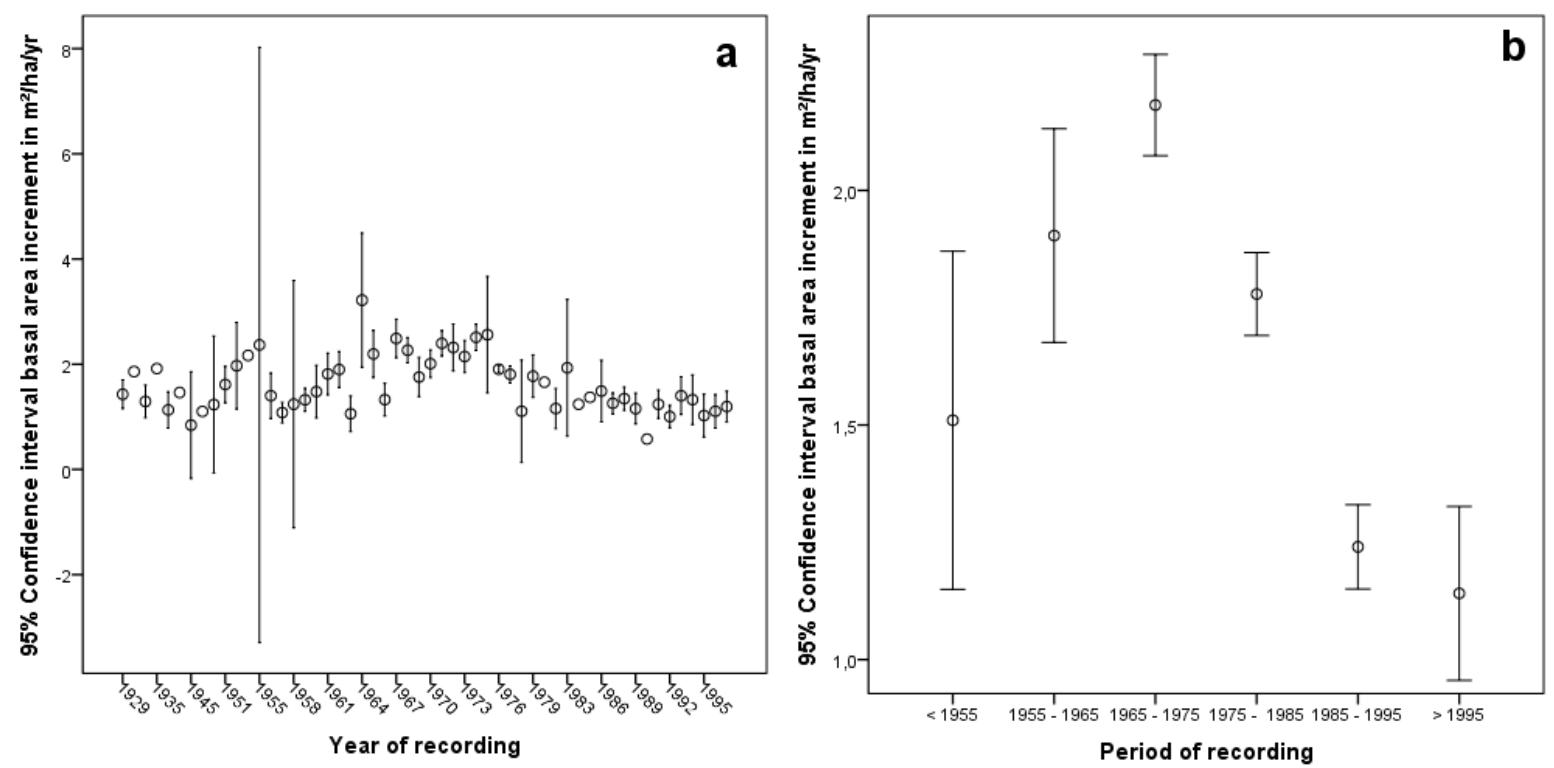

Figuur 30. Error bar lopende grondvlakbijgroei per opnamejaar (a) en periode van opname (b).

Figure 30. Error bar current basal area increment per year of recording (a) and per period of recording (b).

Ook de periode indices zijn alle significant verschillend, maar zijn alleen gebruik om de parameters van Model (18) te schatten voor een gemiddelde periode. De waarden van de periode-indices worden beïnvloed door het klimaat en wisselwerking ervan op de bijgroei en aantasting door Brunchorstia.

\subsection{Dunning}

Om de dunning te kwantificeren is een dunninggraad gebruikt. De in Duitsland gebruikelijke indeling met een A- tot en met D-graad gebaseerd op het dunnen van bomen behorend tot een of meerdere Kraftse boomklassen is in Nederland nooit aangeslagen. Becking (1953) vindt deze methode te weinig kwantitatief en kiest voor een $S$ \% (volgens Hart, 1928) van 16 $\%$ voor een zwakke laagdunning, met $3 \%$ erbij is dan sprake van de volgende dunninggraad, namelijk bij $19 \%$ een matige laagdunning. In tabel 12 is een volledig overzicht van het $S \%$ en de bijbehorende namen. In andere opbrengsttabellen is een geleidelijk toename een bepaald $S \%$ te zien vanaf ongeveer 50 jaar. Dit is logisch omdat op latere leeftijd de kroonvorm verandert, waardoor bij gelijkblijvende standruimte een hogere $S \%$ nodig is. De mate van deze verandering is geschat en vergeleken met andere opbrengsttabellen en in Formule (20) weergegeven. De logaritmische relatie tussen het stamtal en de diameter na (zelf)dunning blijkt met een hellinghoek van -1.79 matig te voldoen aan het Reineke-model (Reineke, 1933). In andere opbrengsttabellen voor de Corsicaanse den, blijken de hellinghoeken een tangens tussen -1.42 en -1.86 te hebben, dus nog ruimer af te wijken van de Reineke-constante 1.6.

Het Reineke model is overigens minder geschikt om het effect van een bepaalde dunning te kwantificeren. Het ratiomodel (24) van La Bastide en Faber (1972) is gebruikt in gemodificeerd vorm, waarbij de ratio afhankelijk is van de dunninggraad en leeftijd. De boniteit-parameter $h_{50}$ bleek niet significant.

De diameter blijkt gemiddeld per dunninggraad met bijna $11 \%$ te stijgen ten opzichte van opstanden met een zwakke laagdunning. Boven een dunninggraad van 2 neemt de lopende 
grondvlakbijgroei met gemiddeld $4 \%$ per dunninggraad af. Voor overige effecten van de dunning, zie Tabel 21.

Tabel 21. Relatieve waarden $I_{G}, d_{a t}$ en $d_{d o m}$ per dunninggraad en verdwijnend stamtal en grondvlak door dunning bij III ${ }^{\mathrm{e}}$ boniteit en $\mathbf{7 0} \mathrm{jr}$.

Table 21. Relative values of $I_{\mathrm{G}}, \mathrm{d}_{\mathrm{at}}$ and $\mathrm{d}_{\mathrm{dom}}$ per thinning grade and the changing stem density and basal area and by thinning at III ${ }^{\mathrm{e}}$ site class and age $=70 \mathrm{yr}$.

\begin{tabular}{|r|rrrr|rr|}
\hline $\boldsymbol{T} \boldsymbol{g}$ & $\boldsymbol{I}_{\boldsymbol{g}}$ & $\boldsymbol{I}_{\boldsymbol{g}}$ & $\boldsymbol{d}_{\boldsymbol{a t}}$ & $\boldsymbol{d}_{\boldsymbol{d o m}}$ & $\boldsymbol{N}_{\boldsymbol{t h}}$ & $\boldsymbol{G}_{\boldsymbol{t h}}$ \\
\hline 2 & $100 \%$ & $100 \%$ & $100 \%$ & $100 \%$ & $92 \%$ & $47 \%$ \\
3 & $98 \%$ & $100 \%$ & $112 \%$ & $108 \%$ & $94 \%$ & $49 \%$ \\
4 & $93 \%$ & $99 \%$ & $122 \%$ & $115 \%$ & $95 \%$ & $51 \%$ \\
5 & $88 \%$ & $96 \%$ & $131 \%$ & $121 \%$ & $96 \%$ & $53 \%$ \\
6 & $83 \%$ & $89 \%$ & $144 \%$ & $129 \%$ & $94 \%$ & $50 \%$ \\
\hline $\mathrm{FG}$ & $56 \%$ & $83 \%$ & $175 \%$ & $145 \%$ & $98 \%$ & $63 \%$ \\
\hline
\end{tabular}

Omdat de zwakke dunning niet in alle opbrengsttabellen voorkomt is diametertoename bij de open stand ook vergeleken met de matige dunning, deze bedraagt $29 \%$. Jansen et al. (2016) vonden bij de douglas een groter effect van de dunning, de diameter na dunning was $36 \%$ dikker in de open stand ten opzichte van de matige dunning. Bij Japanse lariks (Jansen et al., 2018a) was dat 33 \%, fijnspar (Jansen et al., 2018b) 16 \%, grove den (Jansen et al., 2018c) 21 \%, bij zomereik (Jansen et al., 2018d) 13 \% en bij de beuk (Jansen et al., 2018e) is dat $23 \%$.

\subsection{Kwaliteit van het model}

Om de kwaliteit van het model te toetsen zijn de eerste $n$-3 opnamen van ieder proefperk modelmatig drie opnamen "doorgegroeid" waarbij dezelfde dunning van het stamtal als in werkelijkheid werd doorgevoerd, bij perken met maar 2 of 3 opnamen is doorgegroeid naar de laatste opname (zie Tabel 18).

De schattingen voor zowel de opperhoogte, het grondvlak na dunning, de grondvlakbijgroei als de diameter na dunning van de "laatste" vervolgopname bleken onzuiver, en werden respectievelijk met $1.0 \%$, overschat en $0.8 \%, 2.4 \%$ en $8.1 \%$ onderschat en dit werd voornamelijk veroorzaakt door uitbijters bij de plantafstandproef in de opnamen waarbij de hoogte van $7 \mathrm{~m}$ werd gepasseerd. Zonder deze uitbijters werd de grondvlakbijgroei met $2.3 \%$ onderschat. Aangezien de afzonderlijke opnamen een ander gewicht in deze analyse hebben dan in de oplossing van het regressiemodel (16) kan hieraan geen consequentie worden verbonden. 
Tabel 22. Groeiklasse per dunninggraad en boniteit.

Table 22. Yield class (mean annual volume increment at $70 \mathrm{yr}$.) per thinning grade and site class.

\begin{tabular}{|l|rrrrrrr|}
\hline & \multicolumn{7}{|c|}{ Boniteit } \\
Dunninggraad & I & II & III & IV & V & VI & VII \\
\hline zwakke laagdunning & 18.0 & 15.6 & 13.1 & 10.6 & 8.1 & 5.5 & 2.7 \\
matige laagdunning & 17.4 & 15.0 & 12.6 & 10.3 & 7.9 & 5.4 & 2.7 \\
sterke laagdunning & 16.9 & 14.6 & 12.2 & 9.9 & 7.6 & 5.3 & 2.7 \\
zeer sterke laagdunning & 16.0 & 13.8 & 11.6 & 9.4 & 7.3 & 5.0 & 2.7 \\
open stand & 15.1 & 13.0 & 10.9 & 8.9 & 6.8 & 4.6 & 2.4 \\
\hline Vrije groei & 15.3 & 12.9 & 10.9 & 8.6 & 6.4 & 4.3 & 2.3 \\
\hline
\end{tabular}

In Tabel 22 is de groeiklasse per boniteit en dunninggraad aangegeven. Deze groeiklasse is het totaal geproduceerde (en deels geoogste) gemiddelde spilhoutvolume in $\mathrm{m}^{3} \mathrm{ha}^{-1} \mathrm{jr}^{-1} \mathrm{bij}$ een leeftijd van 50 jaar. Naast de verschillende dunninggraden is ook de dunningmethode "vrije groei" van Paragraaf 6.6 weergegeven.

De nieuwe tabel voor de zwakke dunning geeft de maximale grondvlakproductie aan. Als het grondvlak na dunning als het normale grondvlak wordt gedefinieerd met een volkomenheidgraad van 1. Bij een hogere dunninggraad daalt de volkomenheidgraad naar 0.90 bij een sterke dunning tot $0.82 \mathrm{bij}$ een open stand, terwijl de grondvlakbijgroei op respectievelijk $93 \%$ en $83 \%$ bleef.

De dunningmethode "vrije groei" komt in onze waarnemingen niet voor, maar de daarbij behorende wijde stand komt wel voor. In Figuur 29 is het verschil op de diameter bij 70 jaar gedemonstreerd voor de III boniteit.

De hoogteontwikkeling bij de vergeleken opbrengsttabellen van Frankrijk, Groot-Brittannië en Nederland zijn er veel boniteiten die wat betreft de vorm goed overeen komen met het in deze studie gevonden model. Volgens https://www.monumentaltrees.com/nl/hoogterecords/nld/ (geraadpleegd 13-9-2017) staat de hoogste Corsicaanse den (34.5 m met een leeftijd van ca 87 jaar) van Nederland op "Begraafplaats Heidehof" te Beekbergen. Maar volgens dezelfde bron staan er voldoende Corsicaanse dennen in ons omringende landen met hoogten tot $41 \mathrm{~m}$ in Duitsland, tot $46 \mathrm{~m}$ in UK, tot $36 \mathrm{~m}$ in België hoog, dus de hoogste waarde voor de opperhoogte van 33.9 m voor boniteit I bij 80 jaar moet mogelijk zijn. Dit betreft nogal een extrapolatie omdat de data niet verder reiken dan 29 jaar en zelfs in de $4^{\mathrm{e}}$ Bosstatistiek (1985) is de oudste opstand met een $\mathrm{I}^{\mathrm{e}}$ boniteit slecht 51 jaar. 


\section{Samenvatting}

Dit is een rapport over de groei en productie van de Corsicaanse den (Pinus nigra subsp. salzmannii var. corsicana) in Nederland. Er is onderzocht hoe de ontwikkeling van de hoogte, diameter en het grondvlak in de tijd is geweest en hoe deze beïnvloed wordt door de dunning. Met de gevonden relaties en andere allometrische relaties is een set opbrengsttabellen opgesteld voor diverse dunninggraden.

De gebruikte dataset betreft de gegevens die sinds 1925 in Nederland in groei- en productieonderzoek bij de Corsicaanse den zijn verzameld door diverse bosbouwonderzoekgroepen die nu alle tot de WUR behoren. De grootste verzameling data betreft het groei- en productieonderzoek van de voormalige Dorschkamp, gemeten tussen 1925 en 1990; dit omvat 106 proefperken. Daarnaast het dunningonderzoek van Becking; dit omvat 4 proefperken, gemeten tussen 1951 en 1984. De rest van de collectie bestaat uit 29 proefperken in een plantafstandenproef. In totaal betreft het 139 proefperken met in totaal 685 opnamen. Daarnaast zijn 54 plots uit de $4^{\mathrm{e}}$ bosstatistiek, en later de HOSP, gebruikt als controle plots. In totaal bestaat de dataset uit 193 plots met 869 opnamen.

Per opname zijn leeftijd, opnamedatum en opperhoogte bekend en per toestand voor, na en van de dunning stamtal, grondvlak, diameter, hoogte en volume. Van een aantal proefperken zijn ook de basisgegevens per boom bekend, inclusief de stamvoetcoördinaten. In deze studie is hiervan geen gebruik gemaakt.

De hoogteontwikkeling is onderzocht met zes bekende groeimodellen en bleek het best te verklaren met het model van Jansen \& Hildebrand. (1986), een variant van de Chapman-Richards functie: $h_{\text {top }}=S \cdot\left(1-e^{-c_{1} \cdot t}\right)^{b}$. Hierin is $S$ een proefperkspecifieke parameter en maat voor een absolute hoogteboniteit, $c_{1}$ een soortspecifieke parameter, $b=c_{2}-c_{3} \cdot S$. Hiermee wordt een heteromorf stelsel van hoogtegroeicurven gecreëerd. Voor het totale model werd een $R^{2}$ adj van 0.995 gevonden. Voor praktische gebruik is de hoogte bij 50 jaar $\left(h_{50}\right)$ als maat voor de boniteit gekozen. Naast het $R^{2}$ adj werden 5 andere criteria in de keuze voor het model meegewogen te weten de variatiecoëfficiënt van de $S$-parameter, en de gemiddelden en intervallen voor de schattingen van $S, h_{50}, t_{130}$ (leeftijd op borsthoogte), $h_{\text {if }}$ (buigpunt) en daarnaast de nauwkeurigheid van de schattingen van de overige parameters per model.

De hoogteontwikkeling bij de vergeleken tabellen van zowel Decourt (1965), Hamilton \& Christie (1971) als van Faber (1987) komt zeer goed overeen met die van de nieuwe tabel. Faber maakt onderscheid tussen het Kustgebied en het Binnenland, maar de parameters bleken niet te verschillen tussen beide gebieden. Wel verschilt de gemiddelde $h_{50}$ in beide gebieden bijna 6 meter. Er is daarom voor een indeling in 7 boniteiten gekozen waarbij de vijf beste boniteiten voornamelijk in het Binnenland voorkomen en de vijf slechtste in het Kustgebied.

De diameterontwikkeling tot een hoogte van $7 \mathrm{~m}$. werd verklaard met het model van Jansen et al. (2016) $d_{b t}=d_{7} \cdot f\left(h_{\text {top }}\right)$ waarbij een Gompertz-functie is gebruikt. Wel werd $d_{7}$ iets anders verklaard dan bij Jansen et al. (2016) namelijk: $d_{7}=f\left(h_{50}, N_{R}\right)$ in plaats van $d_{7}=f\left(N_{0}\right)$. Hier is het stamtal na zuivering $N_{R}$ gebruikt in plaats van het beginstamtal $N_{0}$ omdat in het merendeel van de waarnemingen al vroege zuiveringen of dunningen plaatsvonden, tevens bleek er verschil per boniteit. Bij een beginstamtal van 5000 en geldt voor de beste boniteit 
$d_{7}=6.8 \mathrm{~cm}$ en voor de slechtste $d_{7}=7.7 \mathrm{~cm}$. De $R^{2}$ adj bleek 0.890 . Voor het traject boven een hoogte van $7 \mathrm{~m}$ is de grondvlakbijgroei gemodelleerd met een ander model van Jansen et al. (2016): $i_{G}=f\left(h_{\text {top }}, t, S \%, y o r\right)$ waarbij gebruik gemaakt is van een powermodel. Voor de standruimte index van Hart $S \%>22.4$ daalt de grondvlakbijgroei lineair met $1.6 \%$ per dunninggraad verschil. De $R^{2}$ adj is 0.590 . Het jaar van opname (yor) is vervangen door de een periode-index, hiervoor zijn ook de controle plots gebruikt omdat die alle in andere perioden vielen. De schommelingen in de periode-indices werden verondersteld te zijn veroorzaakt door het optreden van Brunchorstia-aantasting, welke periodiek optrad. Het model is in strijd met de wet van Eichhorn.

Het effect van de dunning op de diameter na dunning $\left(d_{a t}\right)$ is gemodelleerd met een modificatie van het La Bastide-Faber model (1972); het model van Reineke (1933) is als controle op de uitkomsten gebruikt.

Met deze modellen is een opstand projectie model gemaakt om de werking van de integratie van de modellen voor hoogtegroei, grondvlakgroei en het effect van de dunning te toetsen. Het resultaat van deze test bleek goed voor plots met een beginhoogte boven de $7 \mathrm{~m}$, en matig voor plots met een beginhoogte beneden de $7 \mathrm{~m}$. Met de geïntegreerde modellen zijn opbrengsttabellen gemaakt voor een leeftijd tot 80 jaar met 7 boniteiten en 5 dunninggraden. Deze zijn vergeleken met tabellen in Frankrijk en het Verenigd Koninkrijk en met die van Faber (1987) voor Nederland. Bij de vergelijking bleken de productieniveaus in de opbrengsttabel van Hamilton \& Christie (1971) voor het Verenigd Koninkrijk en die van Faber (1987) voor Nederland goed overeen te komen met de nieuwe tabel voor Nederland. Bij de Franse tabel van Decourt (1965) is het productieniveau beduidend lager.

Op hoofdlijnen bleek het model van Jansen et al. (2016) voor de douglas ook bruikbaar voor de Corsicaanse den. 


\section{Summary}

This report concerns growth and yield of Corsican pine (Pinus nigra subsp. salzmannii var. corsicana) in Netherlands. The report deals with development of height, diameter and basal area over time, based on permanent field plots, and the effect of thinning on these characteristics. The regularities and allometric relationships found were used to construct a set of yield tables for various thinning grades in even-aged stands of Corsican pine.

The dataset used in this study is composed of all growth and yield related research on Corsican pine in the Netherlands, carried out since 1925 by various forestry research groups, now all part of Wageningen University and Research (WUR). The largest data collection concerns the growth and yield research carried out by the former Dorschkamp research institute, which includes 106 experimental plots measured between 1925 and 1990. In addition, a thinning trial initiated by Becking in 1948, with 4 experimental plots measured between 1951 and 1984 was included. Furthermore, the dataset includes an additional 29 plots from a stand density trial. Finally, 54 plots from the Fourth Dutch National Forest Inventory, and later the timber prognosis system HOSP, were used as control plots. In total, the dataset consists of 193 plots with 869 recordings.

Each plot record includes stand age, recording date and top height, as well as stem density, basal area, diameter, height and volume before and after thinning, and of the thinning itself. In many plots, the individual tree attributes within the plots are also known, including stem coordinates, but these were not used in the analysis reported here.

Height development was analysed using five well-known equations, and the best fit was found with Jansen \& Hildebrand's model (1986); this polymorphic model is given by: $h_{\text {top }}=S \cdot\left(1-e^{-c_{1} \cdot t}\right)^{b}$ where $b=c_{2}-c_{3} \cdot S$. Here, $S$ is a plot specific parameter and a measure for site index, and $c_{1}, c_{2}$ and $c_{3}$ are species-specific parameters that determine the shape of the curve. For practical use the height at an age of 50 year $\left(h_{50}\right)$ is chosen as site index. With non-linear regression (NLR) a solution was found with, for a height growth model, a rather high $R^{2}$ adj of 0.995 . Besides $R^{2}$ adj, five other criteria were used in the selection process: the coefficient of variation for the $S$-parameter, the means and intervals of the estimates for $S$, $h_{70}, t_{130}$ (age when breast height is reached), and $h_{\text {if }}$ (inflection point of height curve), together with the precision of the estimates for the other parameters of the model. The height development was compared with those of yield tables from Belgium (Decourt, 1965) and the United Kingdom (Hamilton \& Christie, 1971), and with those published by Faber (1987) for The Netherlands. There was a very good match with all these tables. Faber split up his data for two separate forest districts "Inland area" and "Coastal area". But with the new model we made 7 site classes where the five best appear in the "Inland area" and the five poorest in the "Coastal area".

The diameter development (before thinning: $d_{b t}$ ) up to a height of $7 \mathrm{~m}$ was described by the model by Jansen et al. (2016) $d_{b t}=d_{7} \cdot f\left(h_{\text {top }}\right)$ with a Gompertz function. For the diameter at a height of $7 \mathrm{~m}\left(d_{7}\right)$ instead of $d_{7}=f\left(N_{0}\right)$ another function was found: $d_{7}=f\left(h_{50}, N_{R}\right)$, where $N_{R}$ is the density after refinements. With $N_{0}=5000, d_{7}$ is $6.8 \mathrm{~cm}$ for the best site class and 7.7 for the lowest site class. The $R^{2}$ adj was 0.890 . The model was only used for diameter and basal area development up to a height of $7 \mathrm{~m}$. For the development above $7 \mathrm{~m}$, basal area increment was expressed using another model from Jansen et al (2016): 
$i_{G}=f\left(h_{\text {top }}, t, S \%\right.$, yor $)$, using a power function. For the Becking-Hart spacing index $S \%>22.4$ the basal area increment decreased nonlinearly relative to $S \%$ with $1.6 \%$ per unit. The $R^{2}$ adj is 0.590 . The year of recording was replaced by a period-index, also using the control plots. The fluctuation in the period-index were assumed to have a relation with Brunchorstia dieback. The model does not follow Eichhorn's law.

The effect of thinning on diameter after thinning $\left(d_{a t}\right)$ was modelled with a modification of the La Bastide-Faber model (1972); Reineke's model (1933) was used as an overall check of the results.

With these models a stand projection model was made, to analyse the integration of the models for height and basal area growth, as well as the effect of thinning. The results of this test appeared reasonably acceptable. Using the integrated models, yield tables were created for even-aged stands of ages up to 80 years, using seven site classes and six thinning grades. These yield tables were compared with tables from France and the United Kingdom, and with those published by Faber (1987) for The Netherlands. The production level at Hamilton \& Christie's (1971) for the UK and of Faber's for the Netherlands matched very well with those of the new tables for the Netherland. The production level of Decourt's table for France was much lower.

Overall, the model of Jansen et al. (2016) for Douglas fir turned out to be suitable also for Corsican pine. 


\section{Literatuur}

Assmann, E., 1961. Waldertragskunde: organische Produktion, Struktur, Zuwachs und Ertrag von Waldbestaenden. München.

Bartelink, H.H., A.F.M. Olsthoorn, A. Oosterbaan \& S.M.J. Wijdeven, 2001. Overzicht van een eeuw onderzoek naar groei en opstandsontwikkeling in relatie tot groeiplaats en beheer. Alterra, Research Instituut voor de Groene Ruimte, Wageningen, Alterrarapport 256.

Becking, J. H., 1953. Thinning research in forestry. Netherlands Journal of Agricultural Science; 1953. 1(2):122-9.

Becking, J.H. en P.G. de Vries, 1959. Richtlijnen voor de bedrijfsregeling van bosbezit in Nederland: samengesteld door de commissie bosbedrijfsregeling van de Nederlandsche Boschbouwvereeniging, ingesteld op 7 januari 1954.

Burkhart, H,E. \& R.B. Tennent, 1977. Site index equations for radiata pine in New Zealand. New Zealand Journal of Forestry Science 7: 408416.

C.B.S. (Centraal Bureau voor de Statistiek),1985. De Nederlandse Bosstatistiek, deel 1: de oppervlakte bos,1980 1983. Staatsuitgeverij, s'Gravenhage

Cieszewski C.J., 2001. Three methods of deriving advanced dynamic site equations demonstrated on inland Douglas-fir site curves. Can. J. For. Res. 31: 165-173 .

Decourt, N. 1965. Pin laricio de Corse en Sologne.In: Vannière, B., 1984. Tables de production pour les forêts françaises. Centre national de recherches forestières. Office national des forêts. Ecole nationale du génie rural, des eaux et des forêts. Institut national de la recherche agronomique. pp 25-28.

De Kam, M., 1987. Effecten van weersomstandigheden en herkomstverschillen op de ontwikkeling van Brunchorstia bij Corsicaanse den. Nederlands bosbouwtijdschrift 59 193-200

Dik, E.J., 1984. De schatting van het houtvolume van staande bomen van een aantal in de bosbouw gebruikte soorten. Uitvoerig verslag Rijksinstituut voor onderzoek in de bos en landschapsbouw "De Dorschkamp" Band 19(1), Wageningen.

Faber, P.J., 1987. De Corsicaanse den in Nederland: een nieuwe groeiprognose. Uitvoerig verslag Rijksinstituut voor onderzoek in de bos en landschapsbouw "De Dorschkamp" Band 21(1), Wageningen.

Gehrhardt, E., 1909. Über Bestandeswachstumsgesetze und ihre Anwendung zur Aufstellung von Ertragstafeln. Allg. Forst- u. J.-Ztg. 85: 117-128.

Gompertz, B. 1832. "On the Nature of the Function Expressive of the Law of Human Mortality, and on a New Mode of Determining the Value of Life Contingencies." Phil. Trans. Roy. Soc. London 123, 513-585.

Gremmen, J., 1966. Wat is de werkelijke oorzaak van de Brunchorstia ziekte van de Oostenrijkse en Corsicaanse den? Nederlands bosbouwtijdschrift 38 304-309

Hamilton, G.J. and J.M. Christie, 1971. Forest management tables (metric). Forestry Commission Booklet no. 34. HMSO, London.

Hart, H.M.J., 1928. Stamtal en dunning : een orienteerend onderzoek naar de beste plantwijdte en dunningswijze voor den djati. Proefschrift Wageningen. Mededeelingen Proefstation voor het Boschwezen (21) 219 p. + 7 bijl. Veenman, Wageningen.

Heisterkamp, S.H., 1981. Opstandsinhoudsfuncties. Rapport Rijksinstituut voor onderzoek in de bos- en landschapsbouw "De Dorschkamp" 271, Wageningen.

Hummel, F.C. and Christie, J. 1952. Revised yield tables for conifers in Great Britain. Forest Record (24). 
IUFRO, 1959. The standardization of symbols in forest mensuration. International Union of Forest Research Organizations, Londen.

Jansen, J.J. \& J.W. Hildebrand, 1986. Een nieuwe opbrengsttabel voor de fijnspar (Picea abies Karst.) in Nederland. Landbouwhogeschool, Vakgroep Boshuishoudkunde, Wageningen.

Jansen, J.J., J. Sevenster \& P.G. Faber (redactie), 1996. Opbrengsttabellen voor belangrijke boomsoorten in Nederland. IBN rapport 96/Hinkeloord reports No.17, 202 pag.

Jansen, J.J., H. Schoonderwoerd, G.M.J. Mohren \& J. den Ouden, 2016. Groei en productie van douglas in Nederland. Becking's dunningproeven ontsloten. Wageningen Academic Publishers.

Jansen, J.J., A. Oosterbaan, G.M.J. Mohren \& J. den Ouden, 2018a. Groei en productie van Japanse lariks in Nederland. FEM Groei en productie rapport 2018-1, Wageningen Universiy.

Jansen, J.J., G.M.J. Mohren, A. Oosterbaan \& J. den Ouden, 2018b. Groei en productie van fijnspar in Nederland. FEM Groei en productie rapport 2018 - 2, Wageningen Universiy.

Jansen, J.J., G.M.J. Mohren, A. Oosterbaan , L. Goudzwaard en J. den Ouden, 2018c. Groei en productie van grove den in Nederland. FEM Groei en productie rapport 2018 -3, Wageningen Universiy.

Jansen, J.J., A. Oosterbaan, G.M.J. Mohren \& J. den Ouden, 2018d. Groei en productie van zomereik in Nederland. FEM Groei en productie rapport 2018 -4, Wageningen Universiy.

Jansen, J.J., G.M.J. Mohren, A. Oosterbaan , L. Goudzwaard en J. den Ouden, 2018e. Groei en productie van beuk in Nederland. FEM Groei en productie rapport 2018 - 5, Wageningen Universiy.

Jobling, J. \& M.L. Pearce, 1977. Free growth of oak, Forest record number 113, Forestry Commission HMSO, London.

Korf, V., 1939. Př́spevěk k matematické formulaci vzrůstového zákona lesních porostů. [Contribution to mathematical definition of the law of stand volume growth.] Lesnická práce, 18: 339-379.

La Bastide, J.G.A. \& P.J. Faber, 1972. Revised yield tables for six tree species in the Netherlands. Uitvoerig Verslag Bosbouwproefstation "De Dorschkamp", band 11, nr. 1.

Oosterbaan A., J.J. Jansen, J.F. Oldenburger, G.M. Mohren \& J. den Ouden, 2016. FEM growth and yield data Monocultures - Corsican pine. Available at: http://dx.doi.org/10.17026/dans-zwm-kpmu.

Pienaar, L.V., \& K.J. Turnbull, 1973. The Chapman-Richards generalization of von Bertallanffy's growth model for basal area growth and yield in even-aged stands. Forest Science 19: 2-22.

Reineke, L.H., 1933. Perfecting a stand density index for even-aged forests. Jour. Agric. Res. 46, 627-638.

Schumacher, F.X. \& Hall, F.S., 1933. Logarithmic expression of timber-tree volume. Journal of Agricultural Research, v.47, n.9, p.719-734.

Thomassen, E., \& Nyssen, B. (2013). QD-beheer: mooi bos, dikke bomen en eindelijk fineer. Vakblad Natuur Bos Landschap, 24 - 27.

Van Gerwen, C.P., 1983. Brunchorstia taksterven van Corsicaanse en Oostenrijkse den; analyse van het verband tussen weersomstandigheden in het voorjaar en het optreden 
van epidemieen. Rijksinstituut voor Onderzoek in de Bos- en Landschapsbouw De Dorschkamp, Rapport no. 347

Wenk, G., Antanaitis, V. and Smelko, S., 1990. Waldertragslehre. Landwirtschaftsverlag, Berlin. 


\section{Bijlage 1. Opbrengsttabellen voor Corsicaanse den Nederland 2018}

\section{Toelichting opbrengsttabellen}

In de kop van de opbrengsttabellen zijn een aantal standaard symbolen (IUFRO, 1959). In onderstaande tabel wordt de SI-eenheid vermeld en de betekenis van het symbool weergegeven.

\begin{tabular}{|c|c|c|}
\hline symbool & eenheid & betekenis \\
\hline Boniteit & & relatieve indeling in groeiklassen \\
\hline & $\mathrm{m}$ & Site index (opperhoogte op 50 jr) \\
\hline$P 50$ & $m^{3} h a^{-1} j^{-1}$ & Productieklasse op 50 jr ${ }^{1)}$ \\
\hline$t$ & j & leeftijd vanaf kieming \\
\hline$h_{\text {top }}$ & $\mathrm{m}$ & opperhoogte \\
\hline$h_{\text {dom }}$ & $\mathrm{m}$ & dominante hoogte \\
\hline$d_{d o m}$ & $\mathrm{~cm}$ & gemiddelde diameter van dominante hoogte boom \\
\hline$N$ & $h a^{-1}$ & stamtal per ha \\
\hline S\% & & Hart-Becking dunning-index \\
\hline G & $m^{2} h a^{-1}$ & grondvlak per ha \\
\hline$d_{g}$ & $\mathrm{~cm}$ & diameter (1,30 m) van de middenboom ${ }^{2)}$ \\
\hline$h_{g}$ & $\mathrm{~m}$ & hoogte van de middenboom \\
\hline$V$ & $m^{3} h a^{-1}$ & volume per ha ${ }^{3)}$ \\
\hline$I c_{G}$ & $m^{2} h a^{-1} j^{-1}$ & lopende grondvlakbijgroei per ha per jaar op leeftijd $t$ jaar \\
\hline$I c_{V}$ & $m^{2} h a^{-1} j^{-1}$ & lopende volumebijgroei per ha per jaar op leeftijd $t$ jaar \\
\hline $\operatorname{Im}_{G}$ & $m^{3} h a^{-1} j^{-1}$ & gemiddelde grondvlakbijgroei per ha per jaar tot op leeftijd $t$ jaar \\
\hline $\operatorname{Im}_{V}$ & $m^{3} h a^{-1} j^{-1}$ & gemiddelde volumebijgroei per ha per jaar tot op leeftijd $t$ jaar \\
\hline
\end{tabular}

1) gemiddelde productie, inclusief dunning maar exclusief sterfte (volumebijgroei) per ha tot op leeftijd 50 jaar

2) boom met gemiddeld boomgrondvlak en boomvolume

3) Het volume is gedefinieerd als het spilhoutvolume met schors. 


\section{Explanation yield tables}

In the header of the yield tables a number of standard symbols (IUFRO, 1959) are used. In the table below the SI units and the meaning of the symbols are given.

\begin{tabular}{|c|c|c|}
\hline symbol & unit & meaning \\
\hline Site class & & relative partition in site classes \\
\hline$h_{50}$ & $\mathrm{~m}$ & Site index (top height at $50 \mathrm{yr}$ ) \\
\hline P50 & $\mathrm{m}^{3} \mathrm{ha}^{-1} \mathrm{yr}^{-1}$ & Production class at $50 \mathrm{yr}^{1)}$ \\
\hline$t$ & j & age since germination \\
\hline$h_{\text {top }}$ & $\mathrm{m}$ & top height \\
\hline$h_{d o m}$ & $\mathrm{~m}$ & dominant height \\
\hline$d_{d o m}$ & $\mathrm{~cm}$ & mean diameter of dominant height tree \\
\hline$N$ & $\mathrm{ha}^{-1}$ & Number of stems per ha \\
\hline$S \%$ & & S\% (Hart-Becking spacing index) \\
\hline G & $m^{2} h a^{-1}$ & Basal area per ha \\
\hline$d_{g}$ & $\mathrm{~cm}$ & diameter $(1,30 \mathrm{~m})$ of the basal area mean tree \\
\hline$h_{g}$ & $\mathrm{~m}$ & height of the basal area mean tree \\
\hline$V$ & $m^{3} h a^{-1}$ & volume per ha ${ }^{2)}$ \\
\hline$I c_{G}$ & $\mathrm{~m}^{2} \mathrm{ha}^{-1} \mathrm{yr}^{-1}$ & current basal area increment per ha per year at age $t$ \\
\hline$I c_{V}$ & $\mathrm{~m}^{2} \mathrm{~h} \mathrm{a}^{-1} \mathrm{yr}^{-1}$ & current volume increment per ha per year at age $t$ \\
\hline $\operatorname{Im} m_{G}$ & $\mathrm{~m}^{3} \mathrm{ha}^{-1} \mathrm{yr}^{-1}$ & mean basal area increment per ha per year until age $t$ \\
\hline $\operatorname{Im}_{V}$ & $\mathrm{~m}^{3} \mathrm{ha}^{-1} \mathrm{yr}^{-1}$ & mean volume increment per ha per year until age $t$ \\
\hline
\end{tabular}

1) Mean production, including thinning but excluding mortality (volume increment) per ha until age $50 \mathrm{yr}$.

2) The volume is defined as the stem volume over bark. 


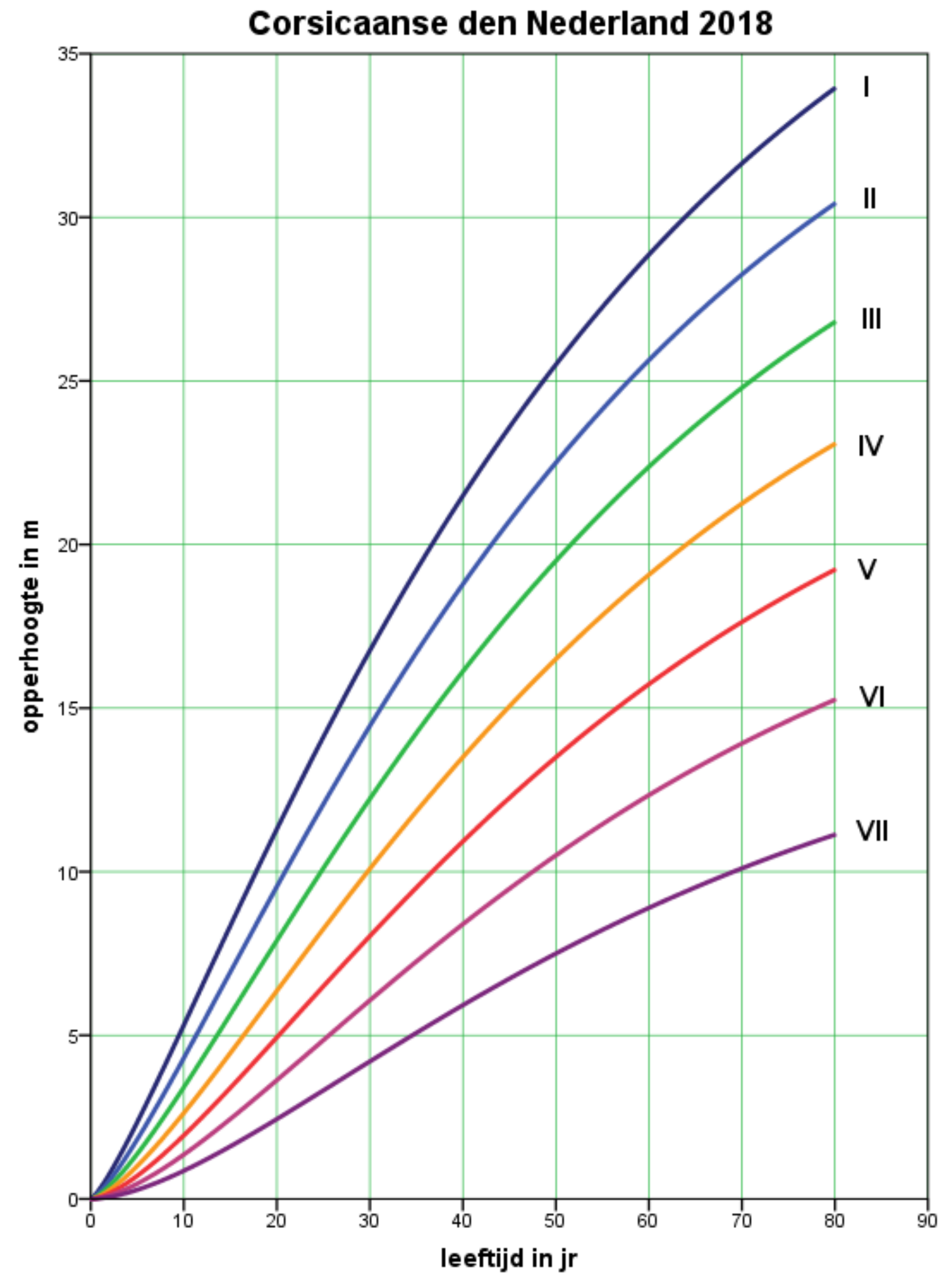




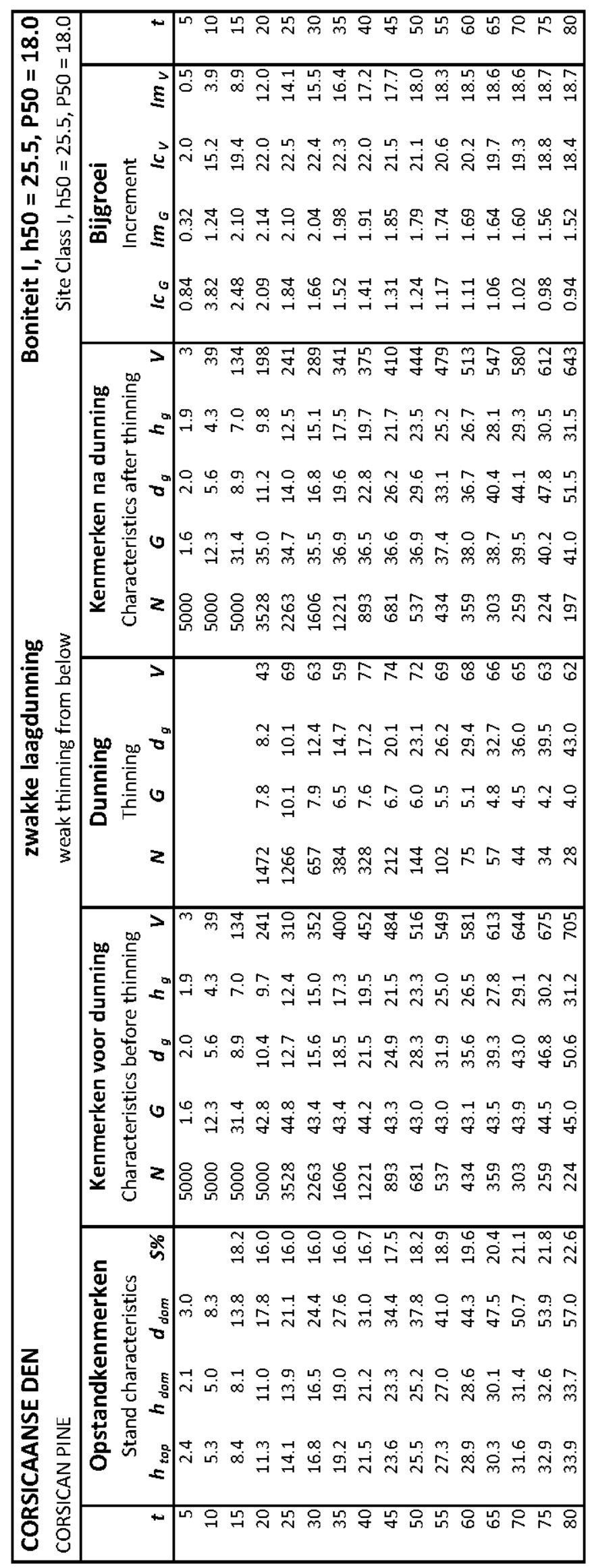




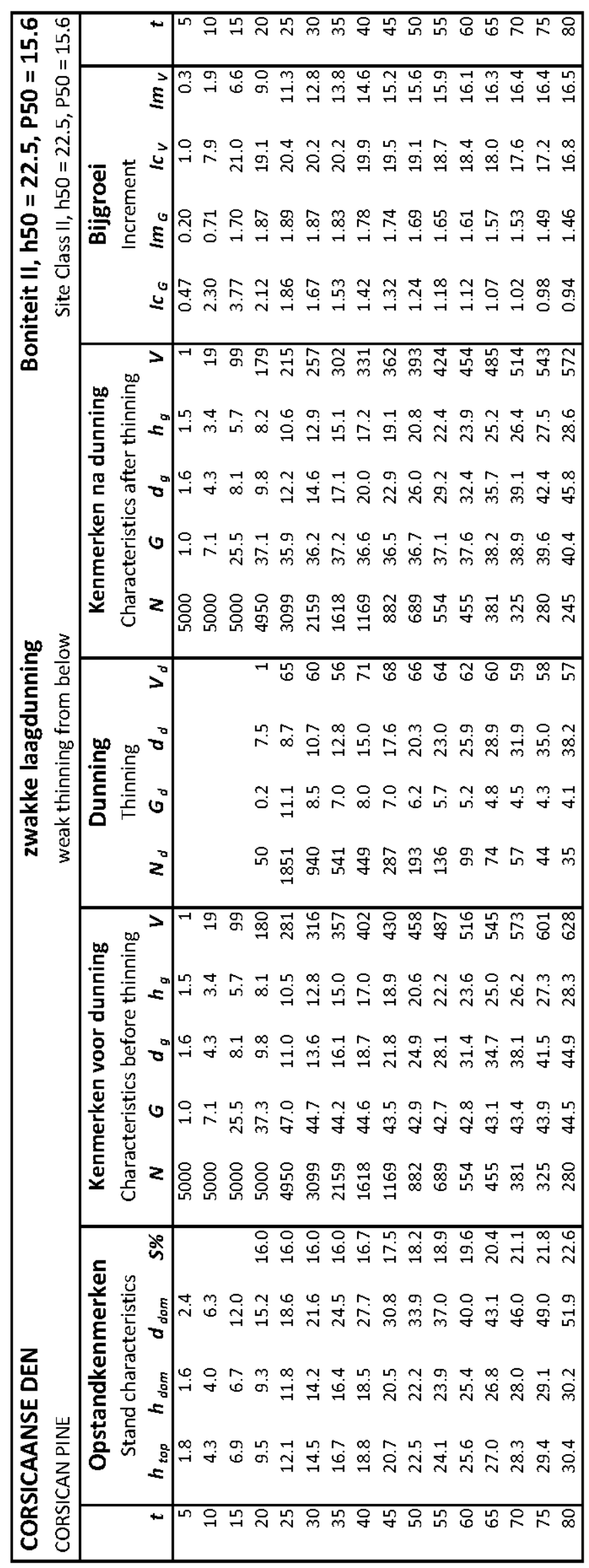




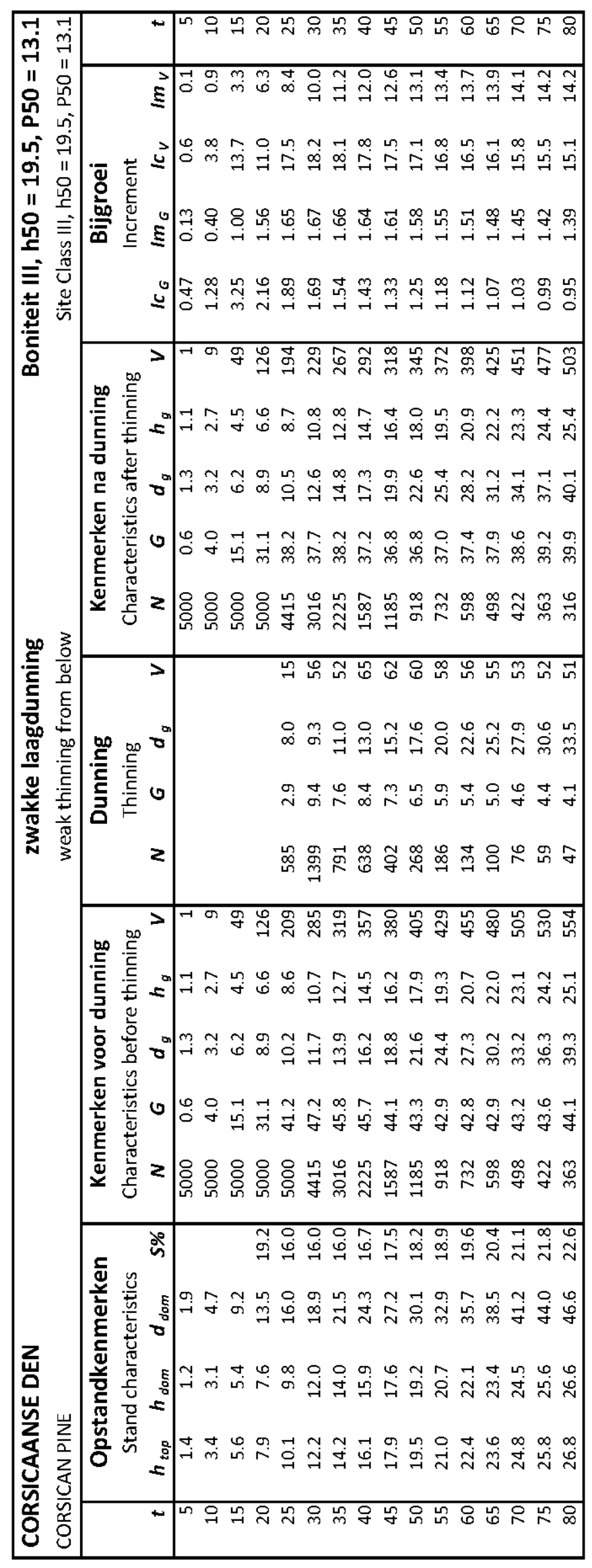




\begin{tabular}{|c|c|c|}
\hline 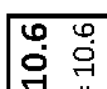 & & $\rightarrow \rightarrow N C$ \\
\hline 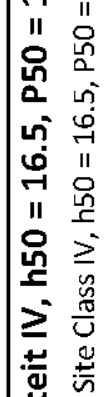 & 。 & 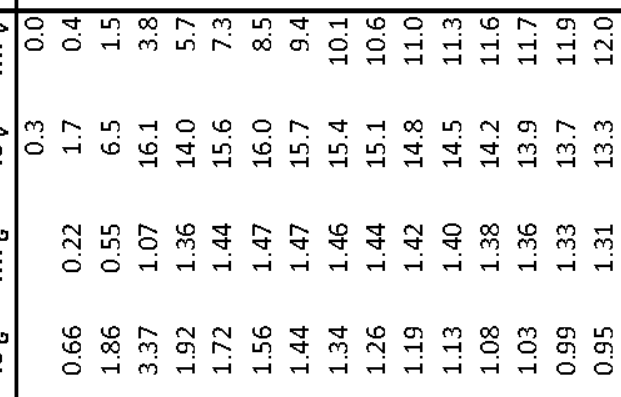 \\
\hline & 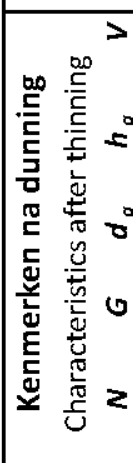 & 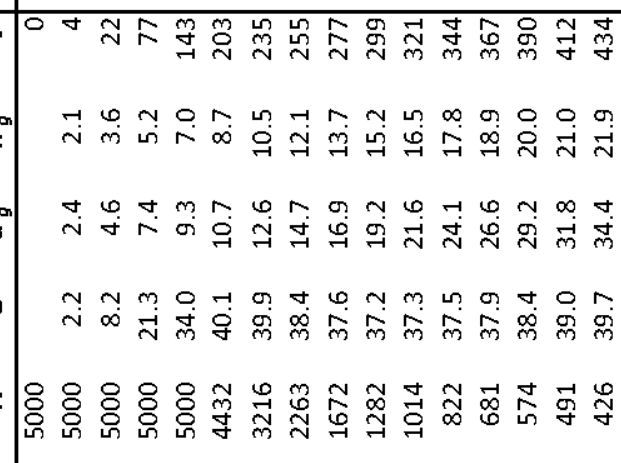 \\
\hline 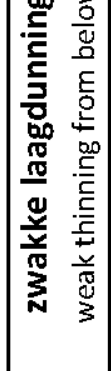 & |c & 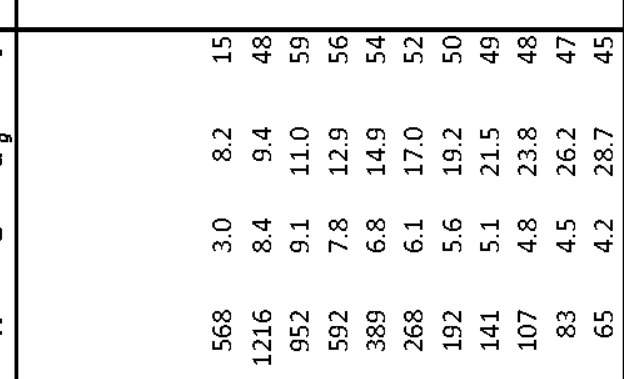 \\
\hline & 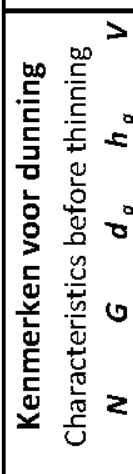 & 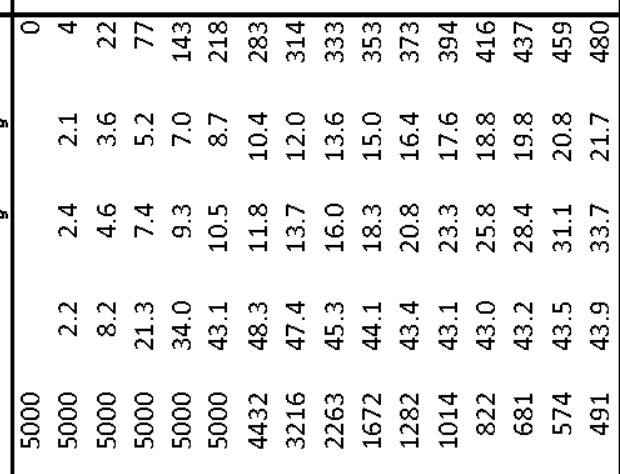 \\
\hline 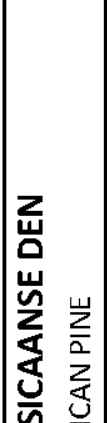 & 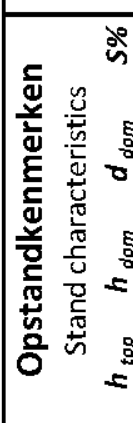 & 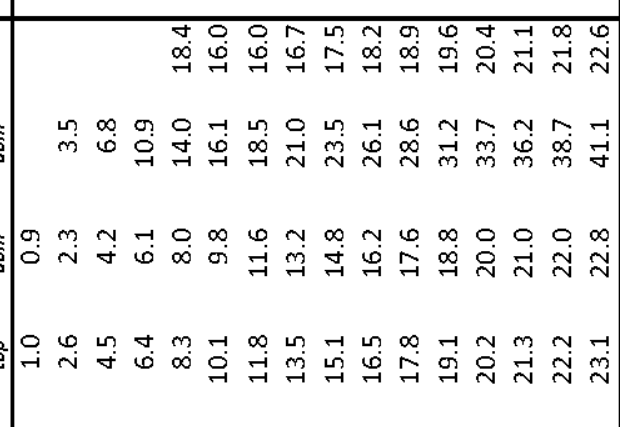 \\
\hline & & స్ \\
\hline
\end{tabular}




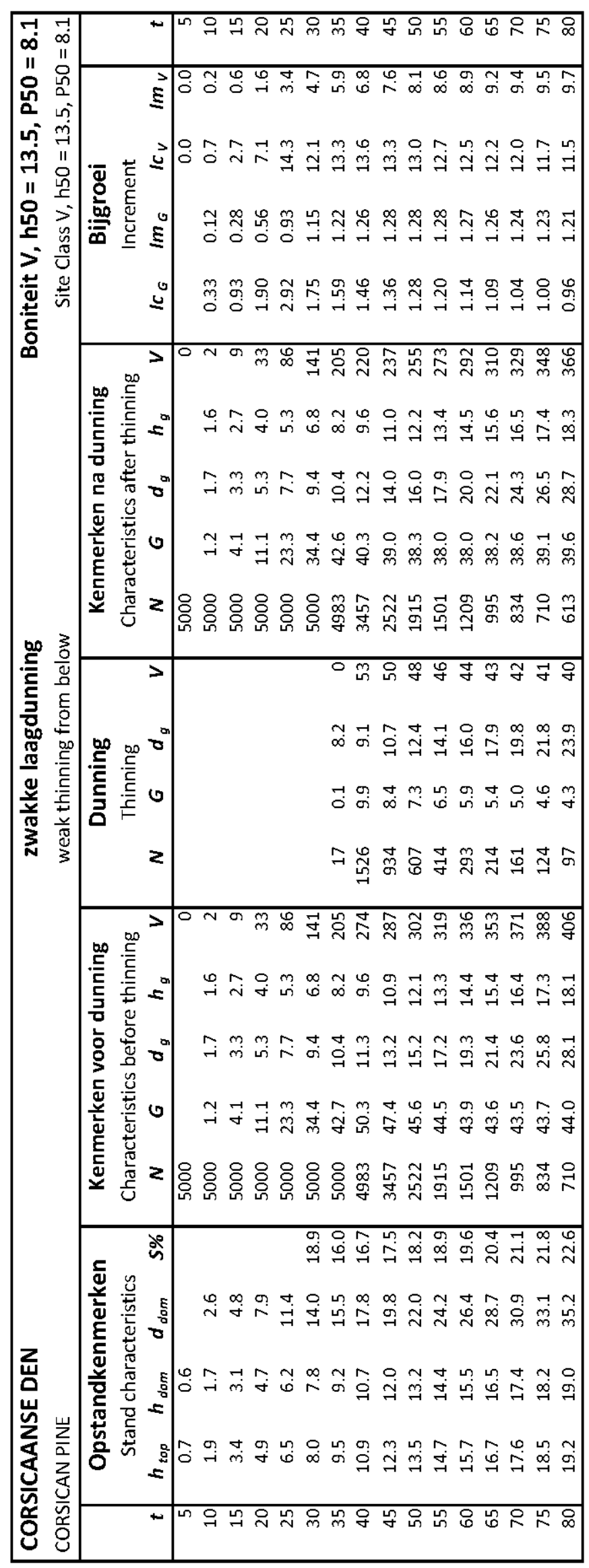




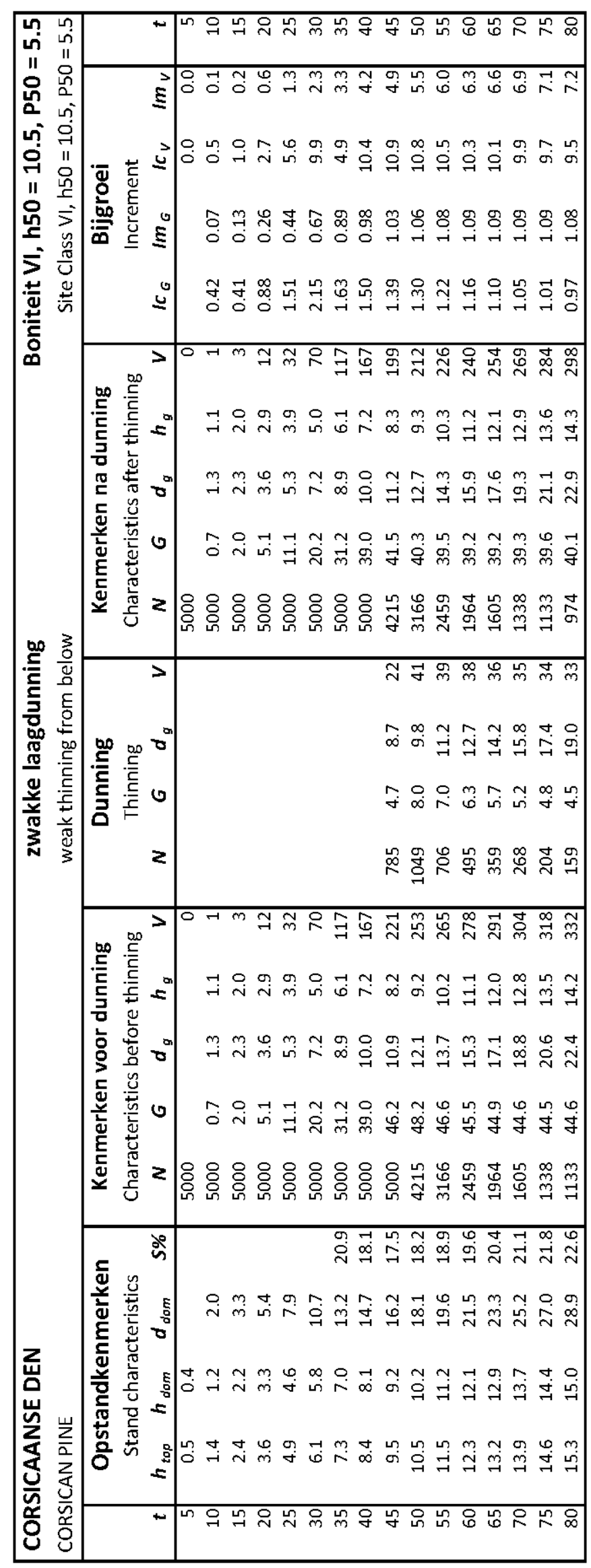




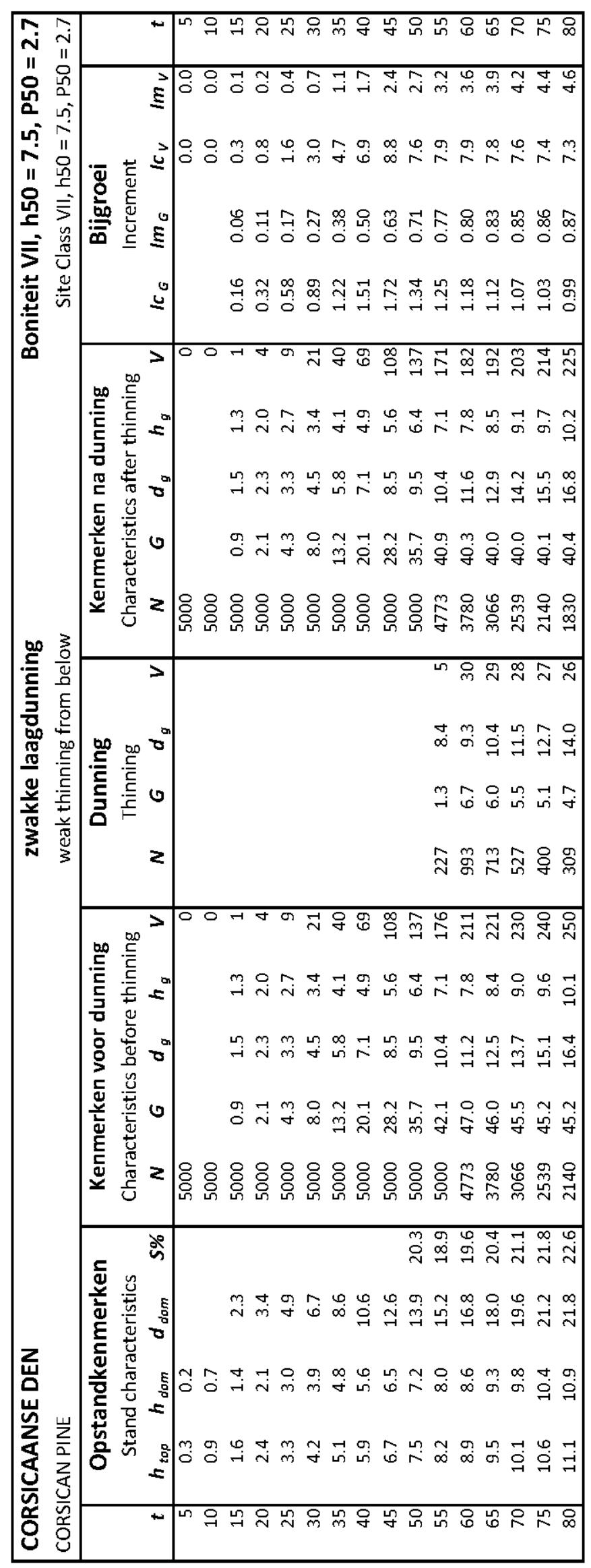




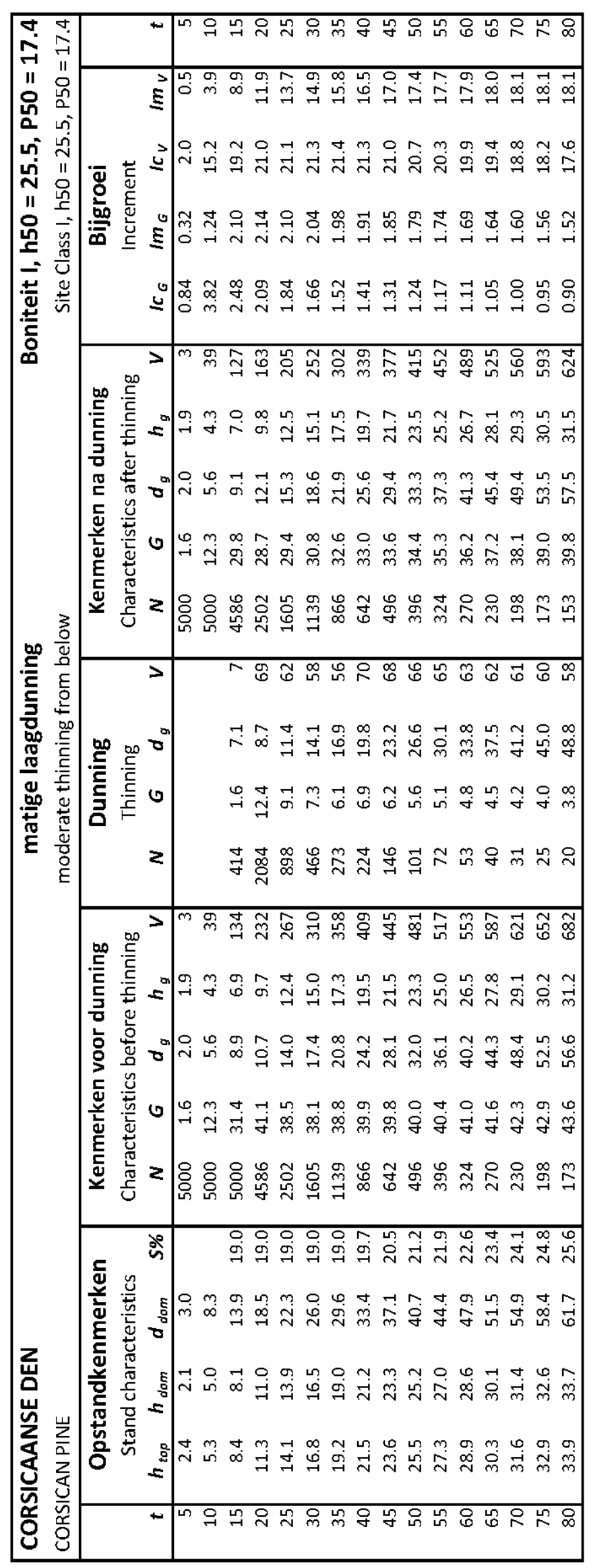




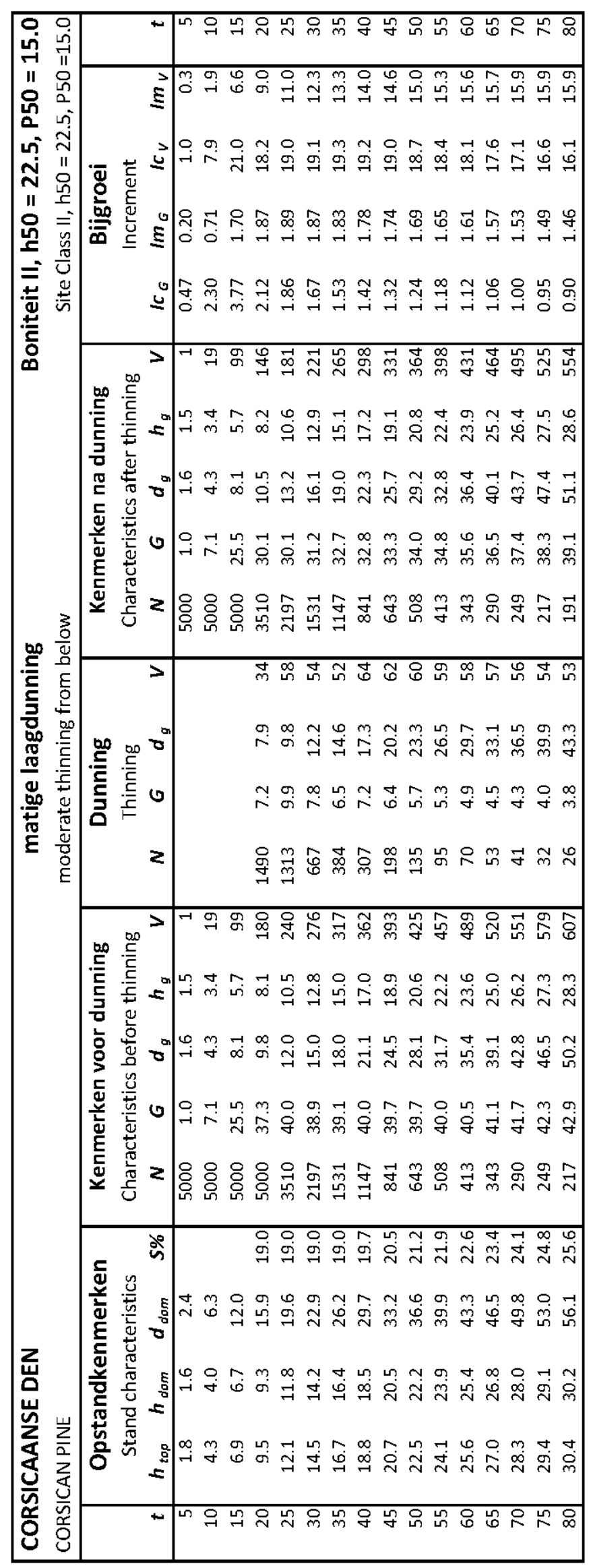




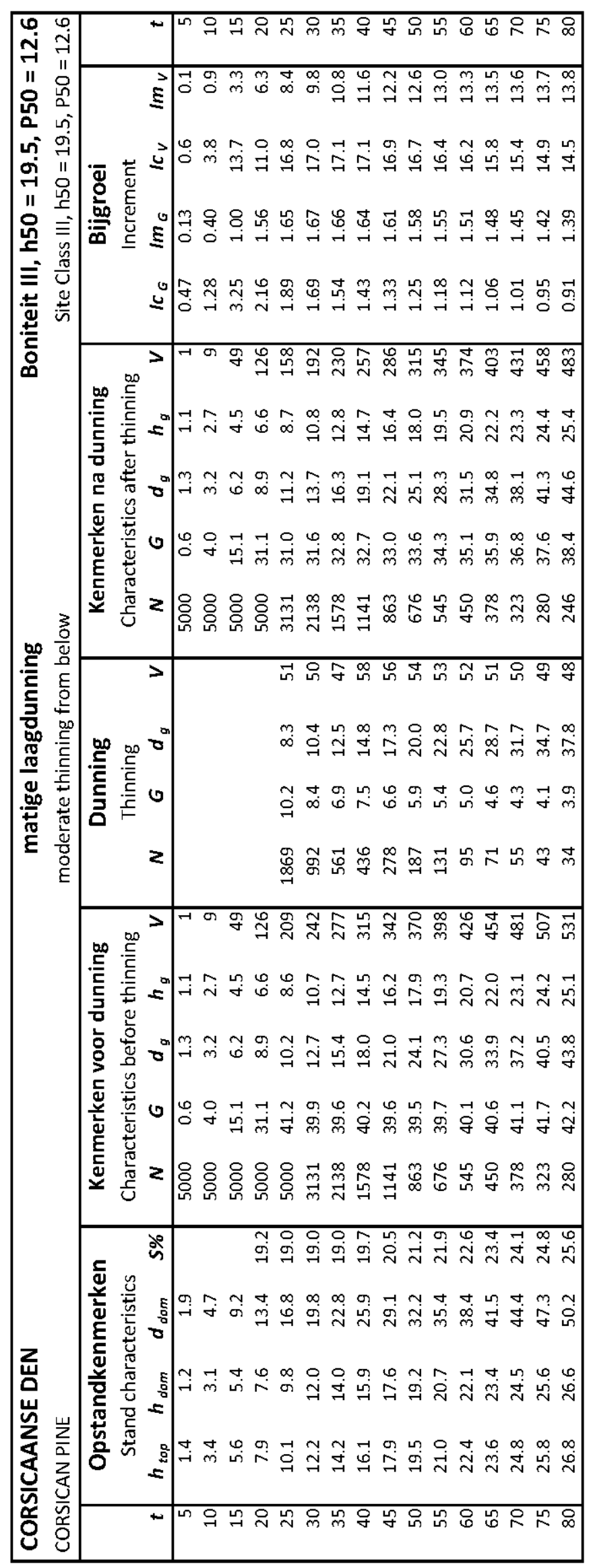




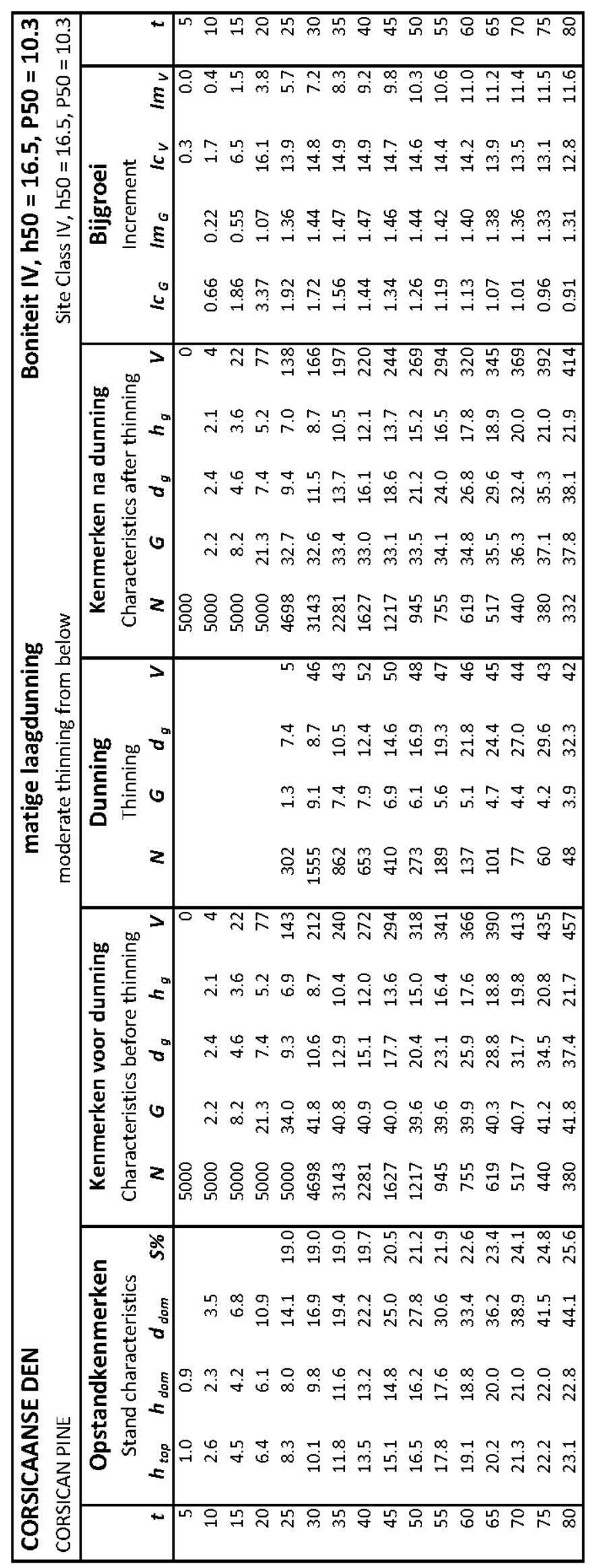




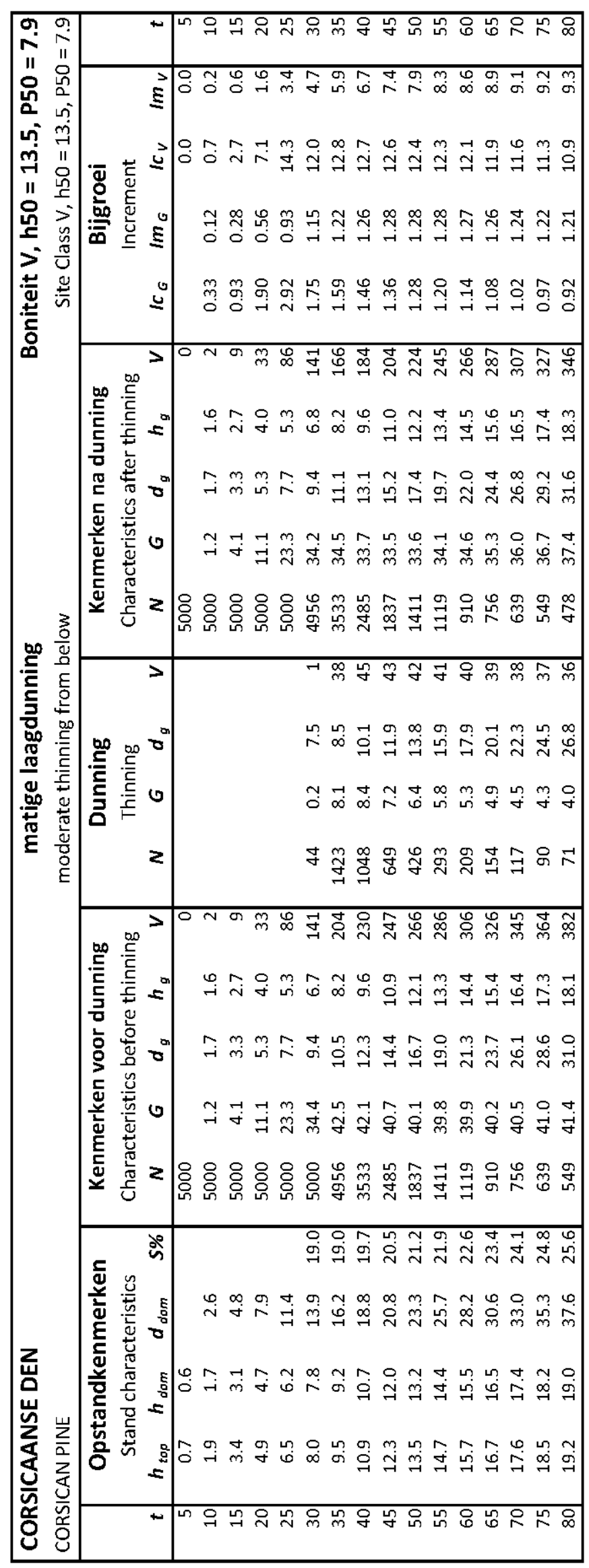




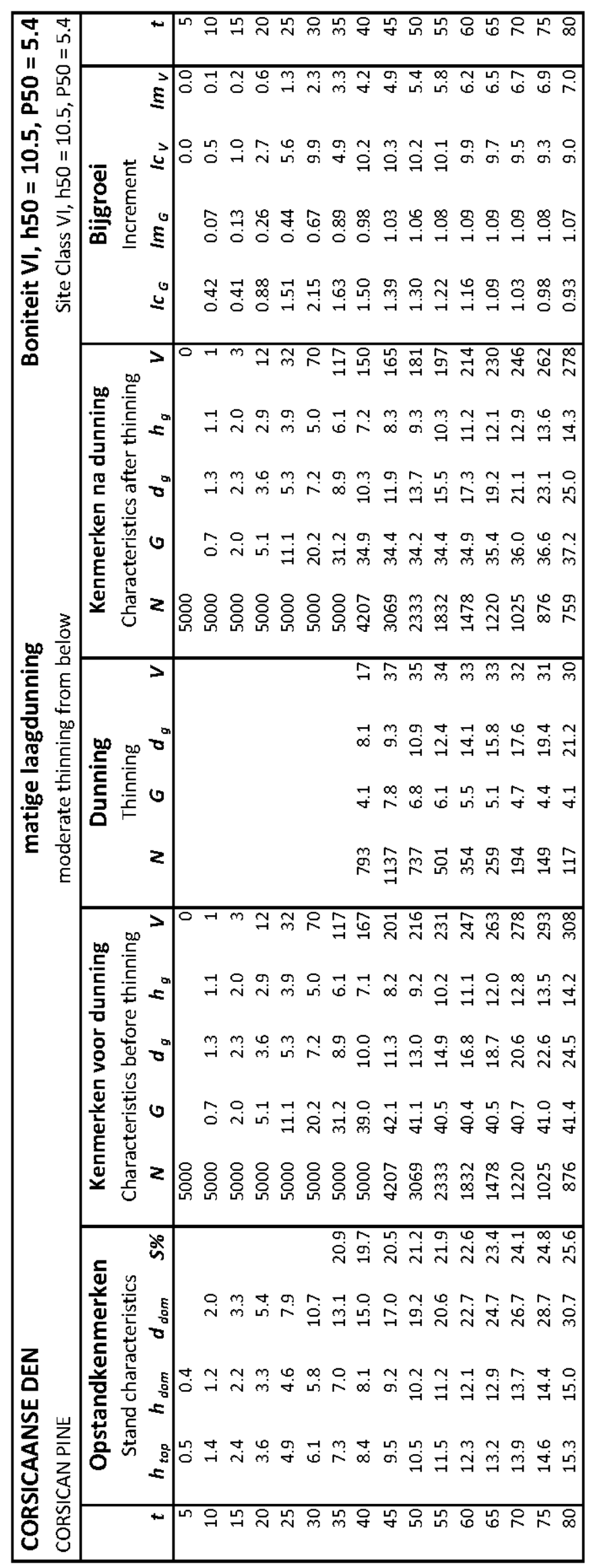




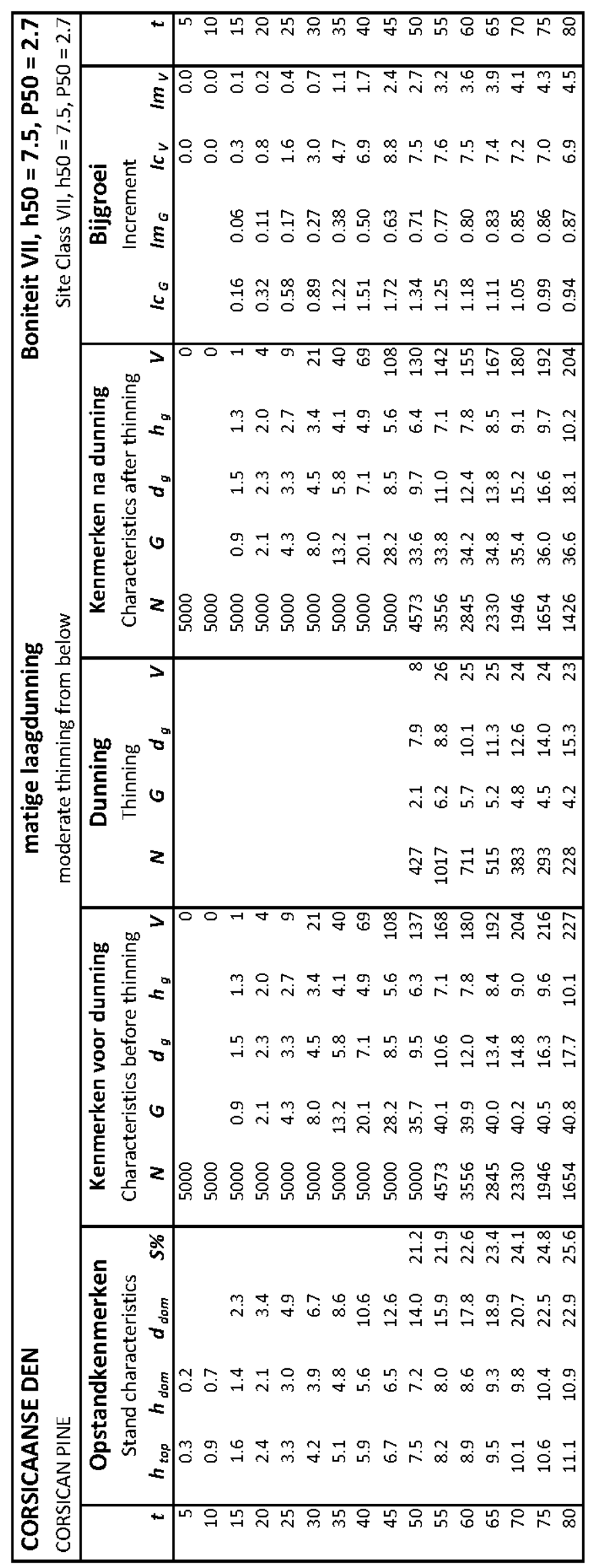




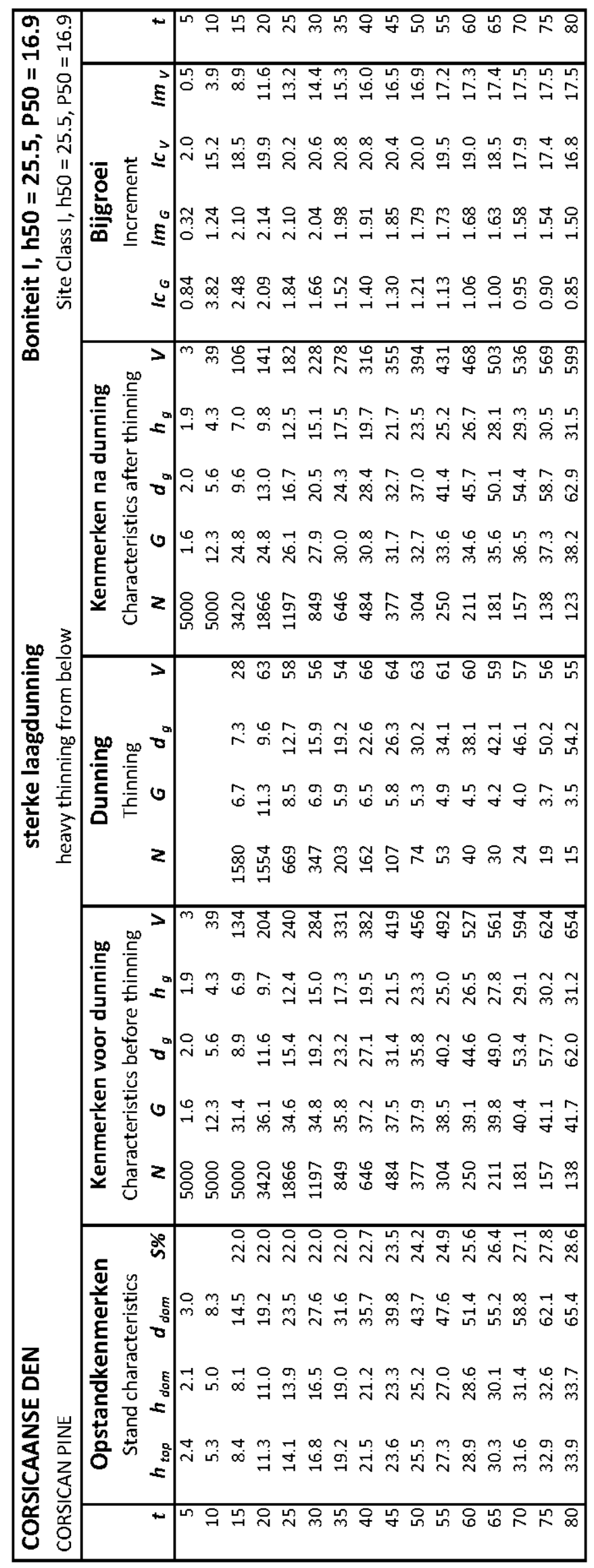




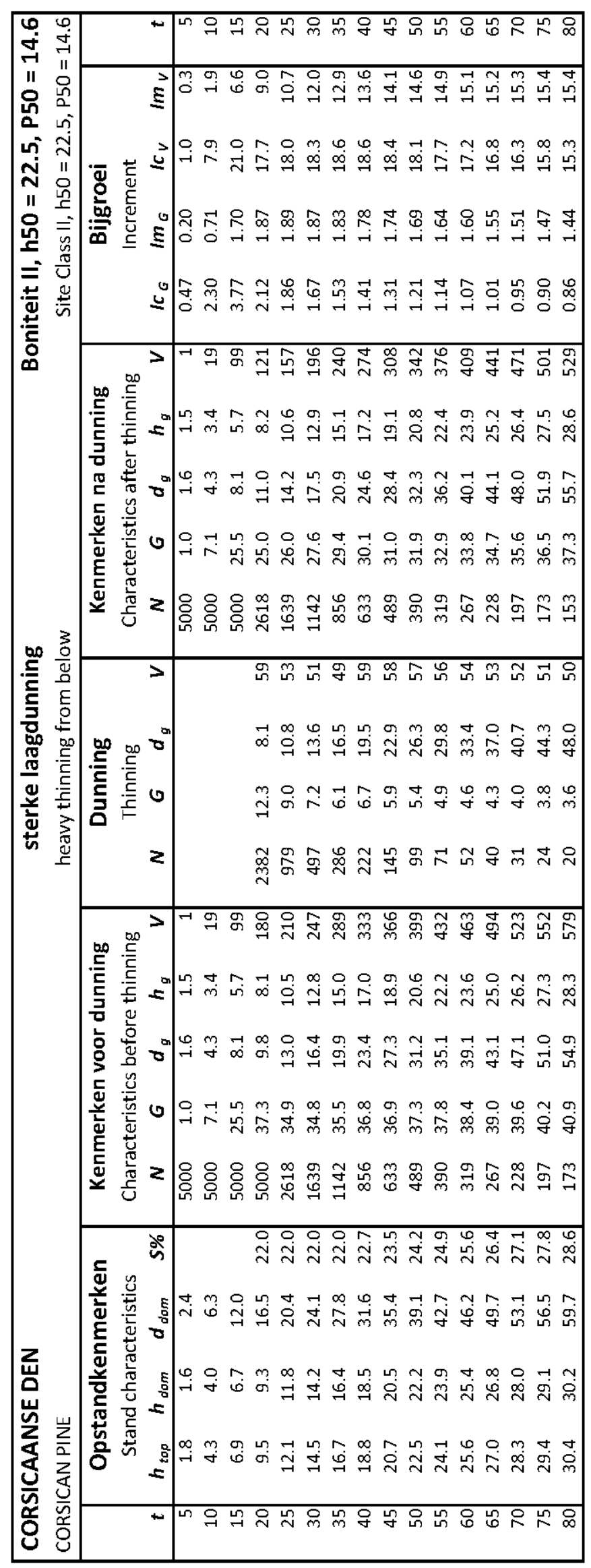




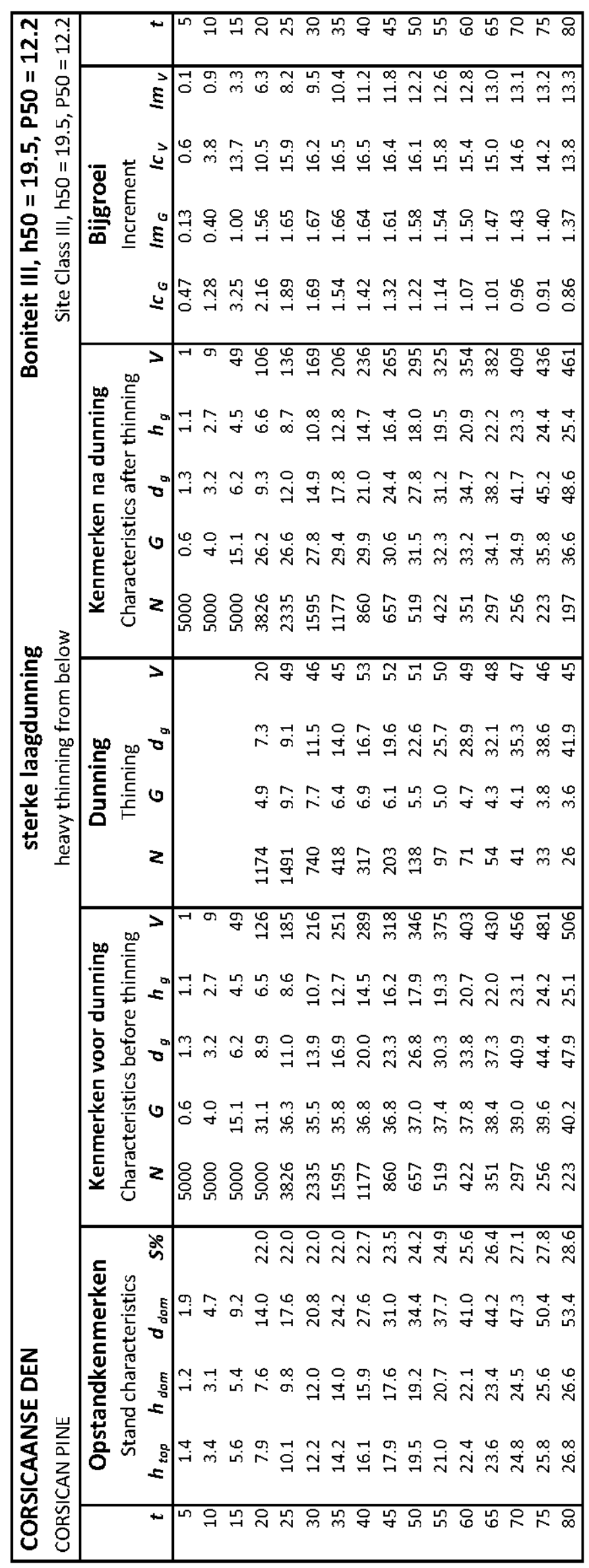




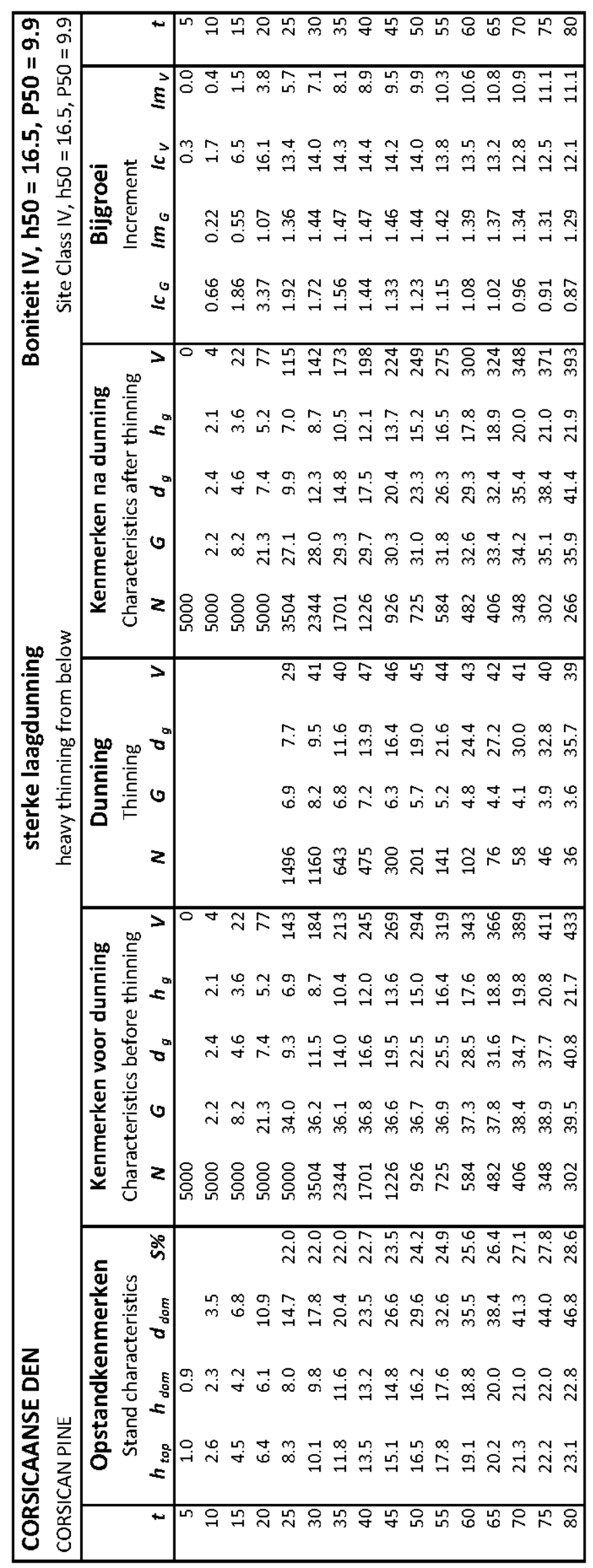




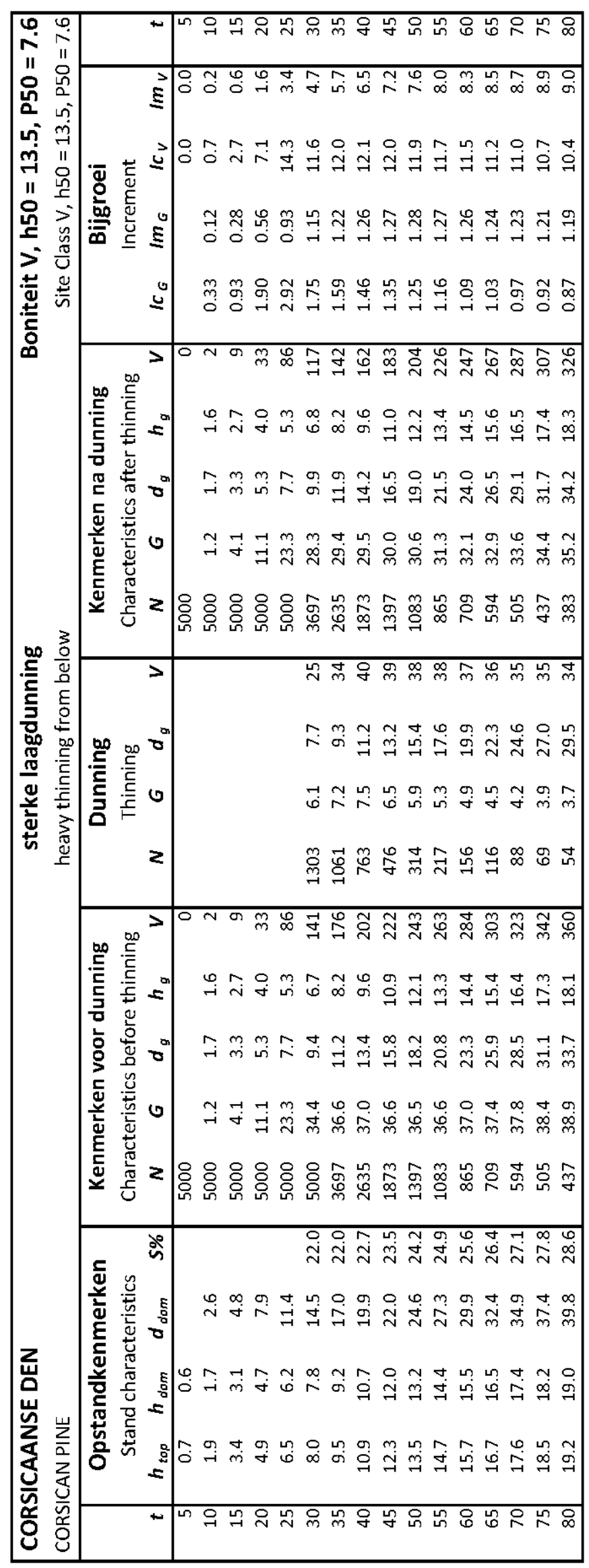




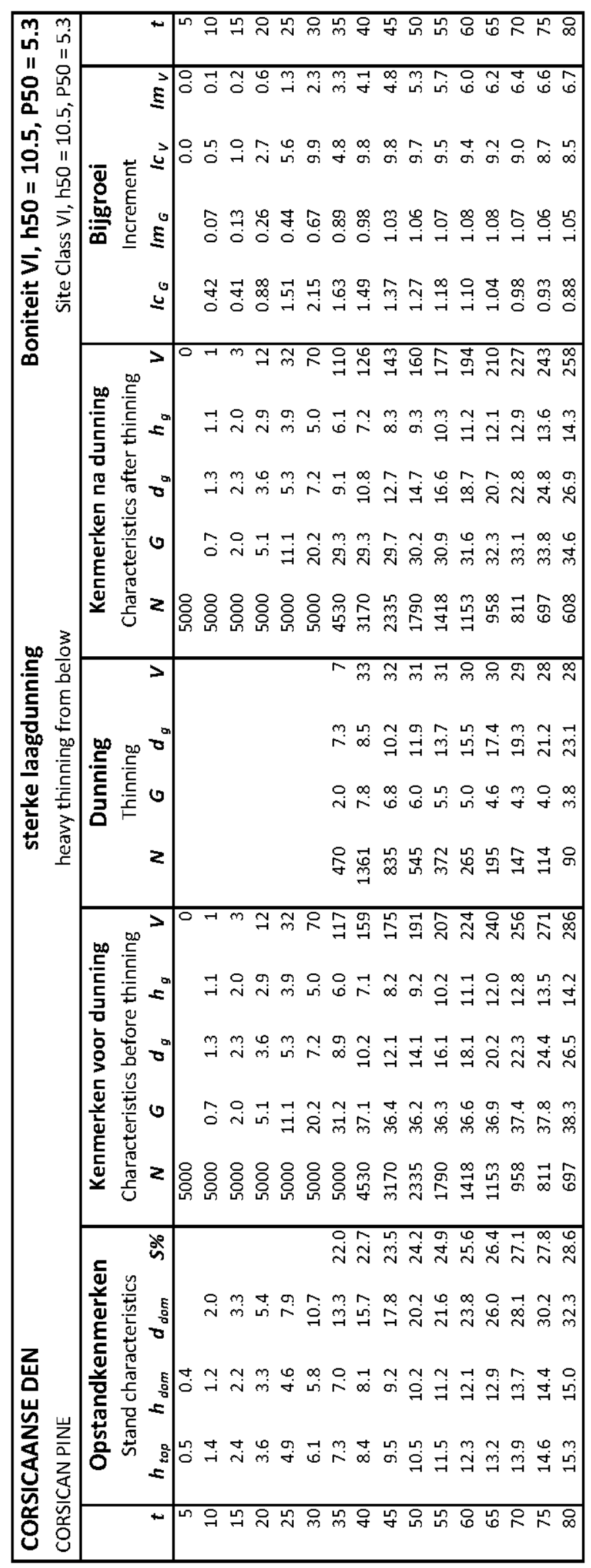




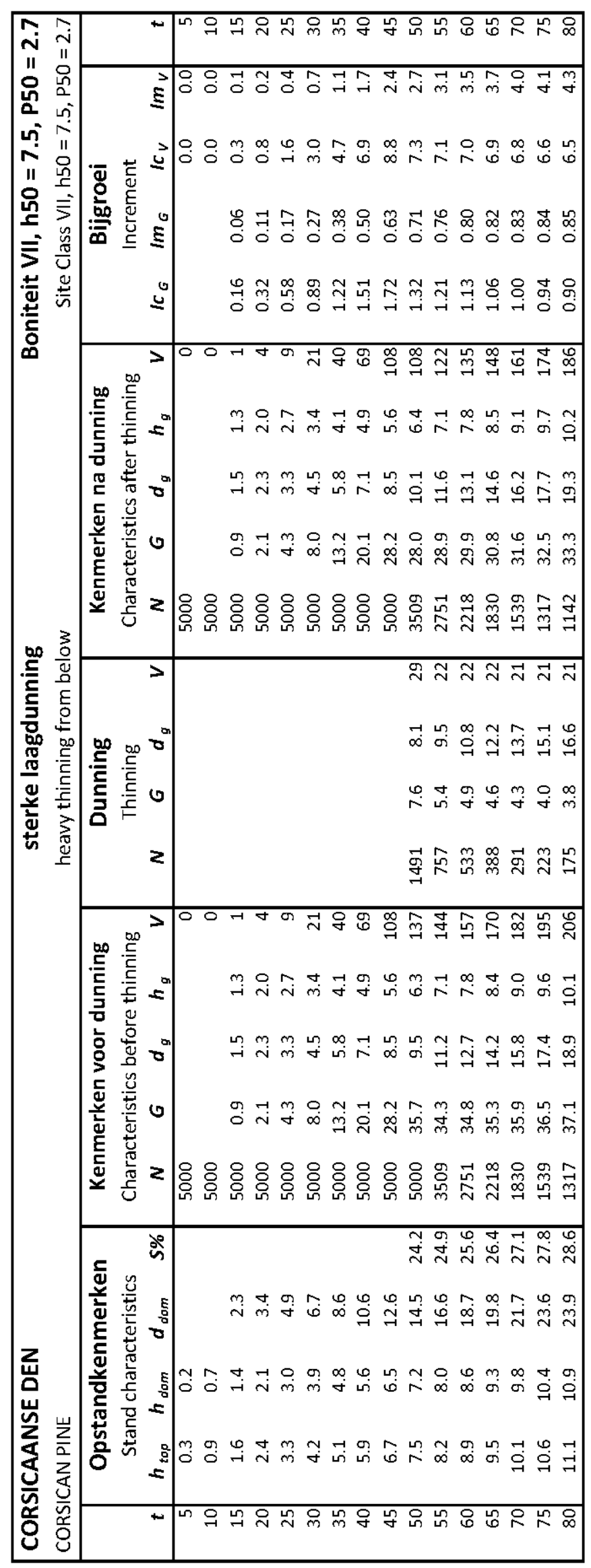




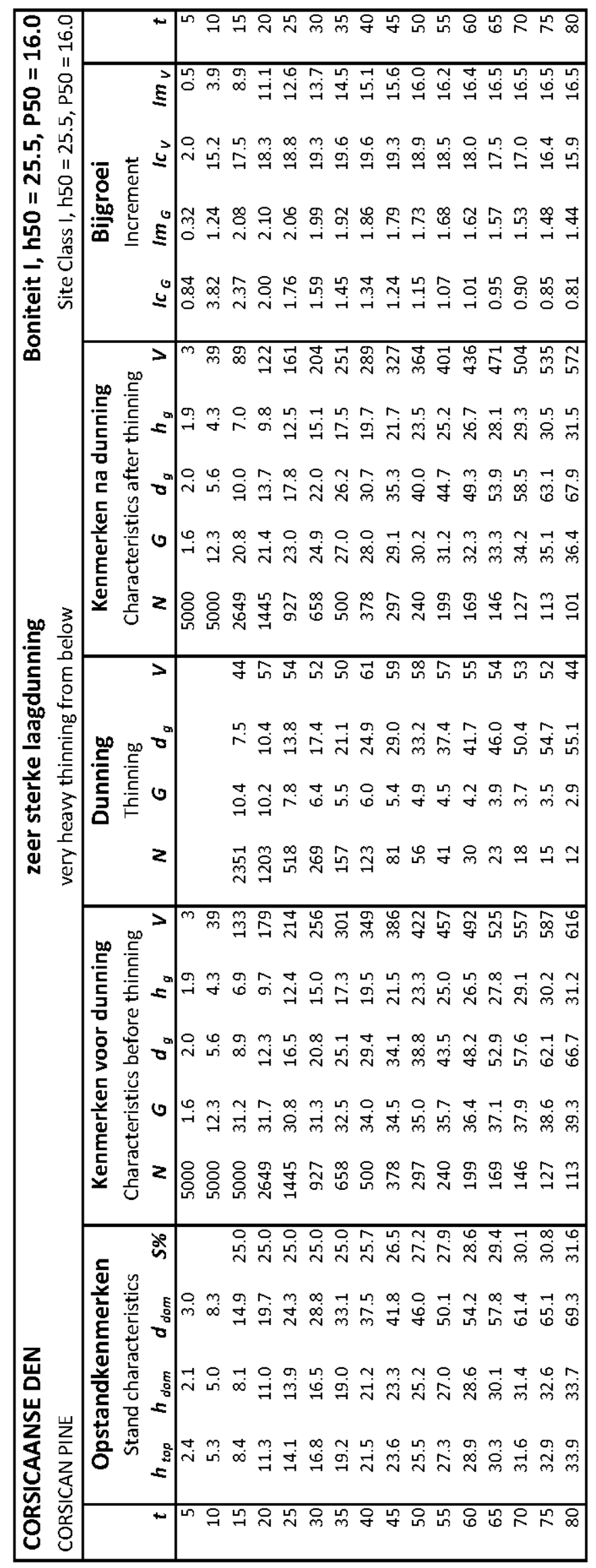




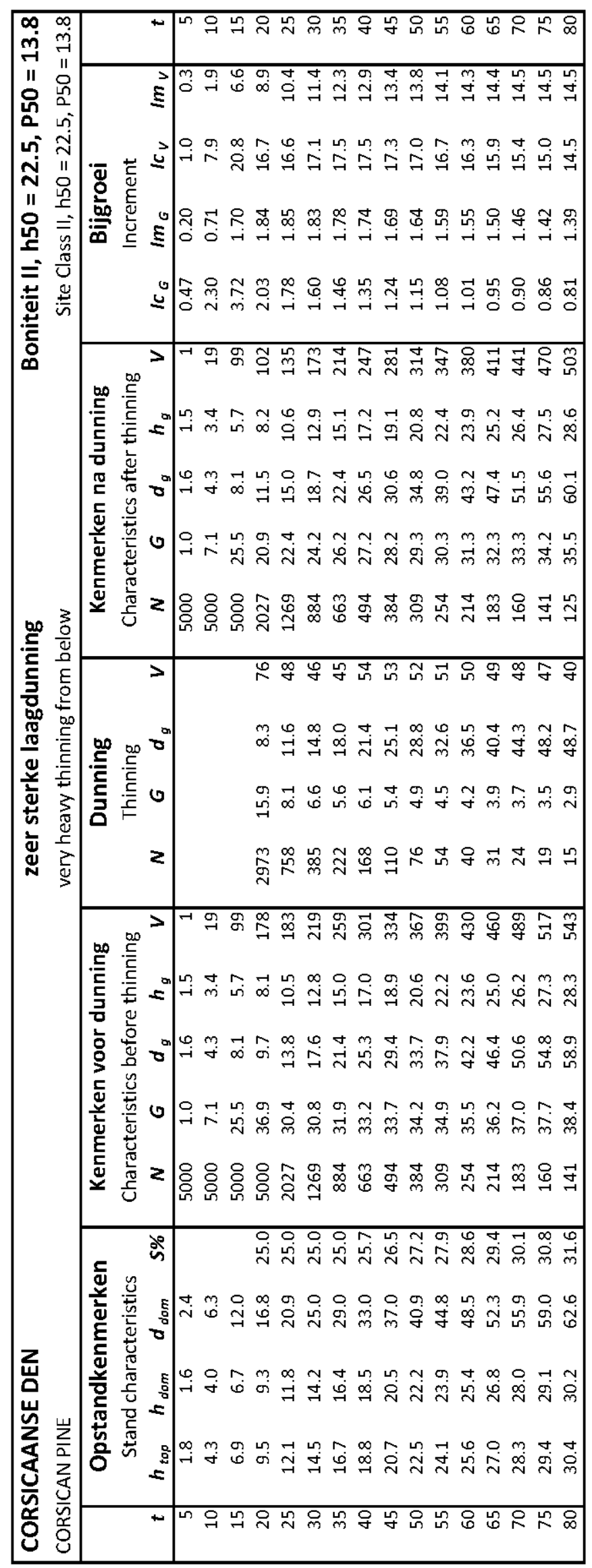




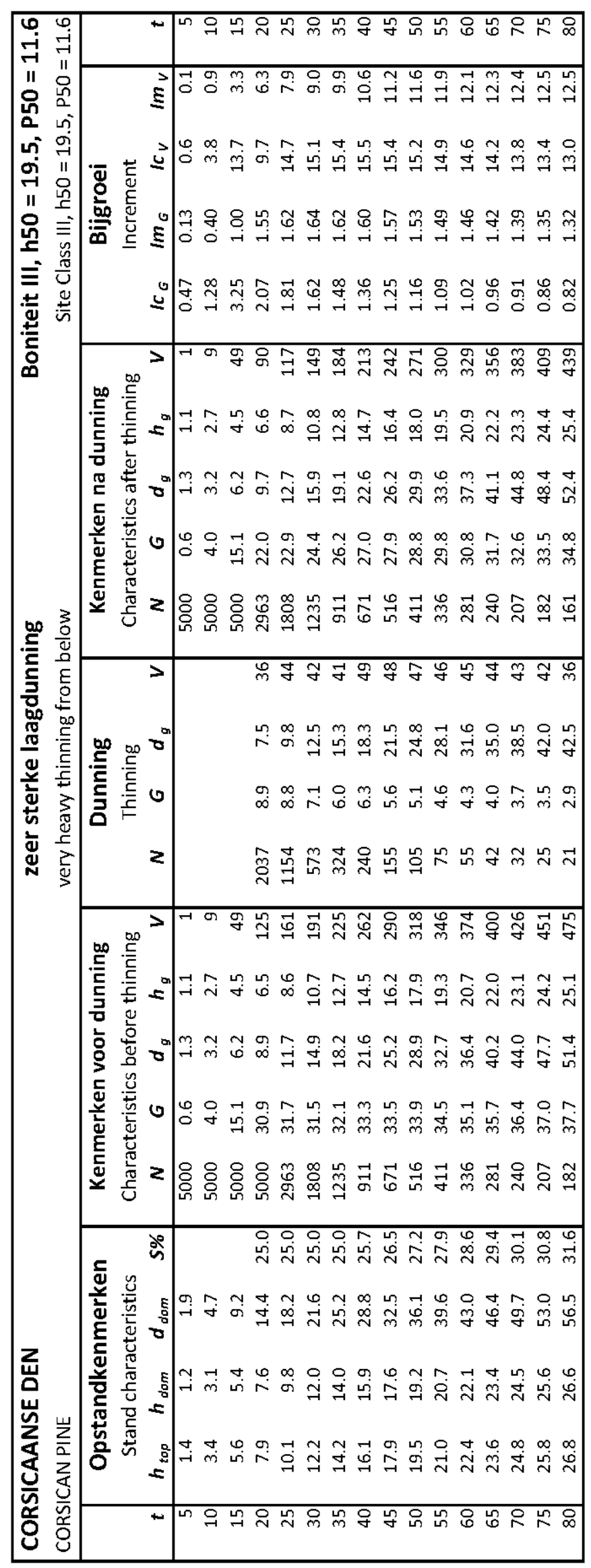




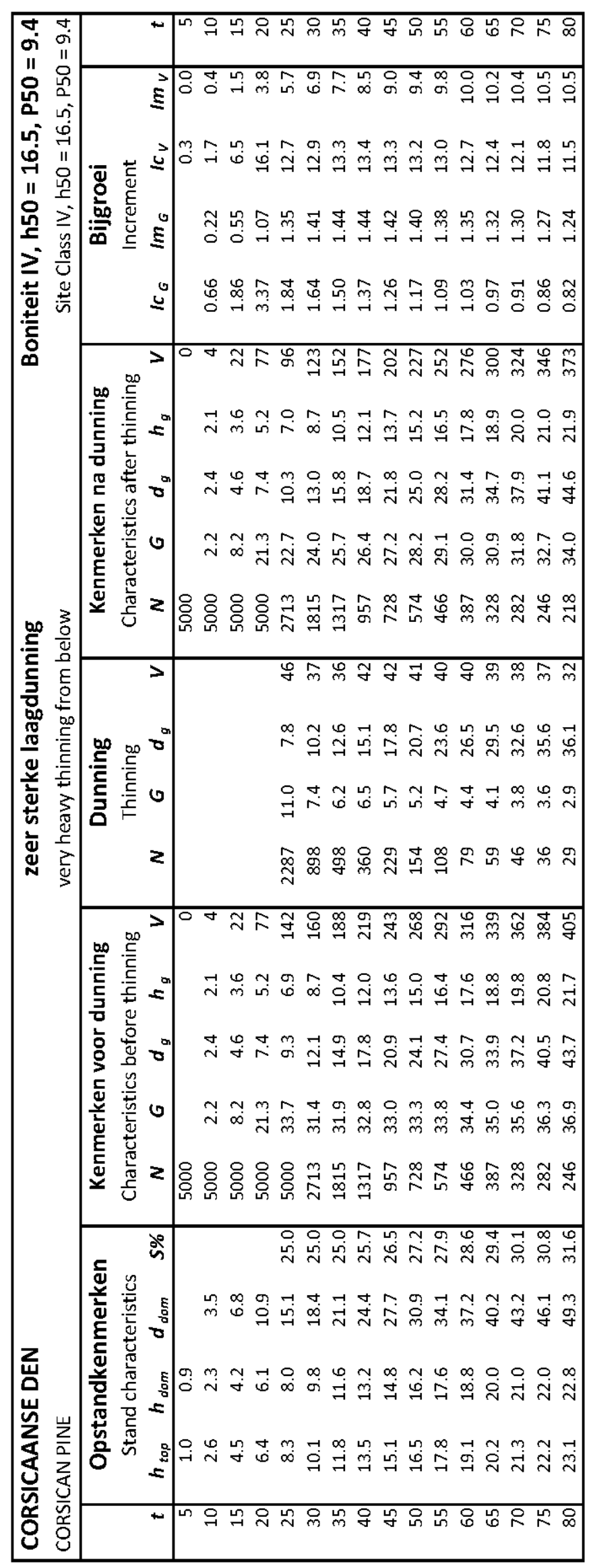




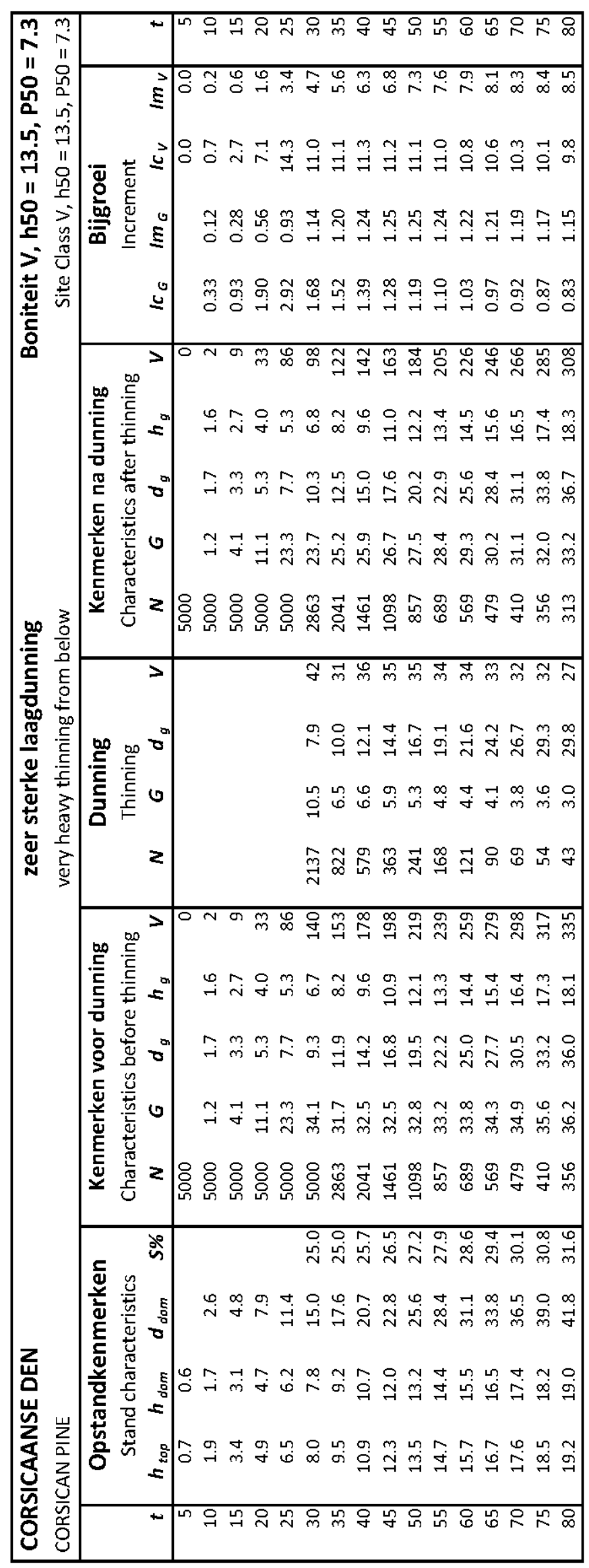




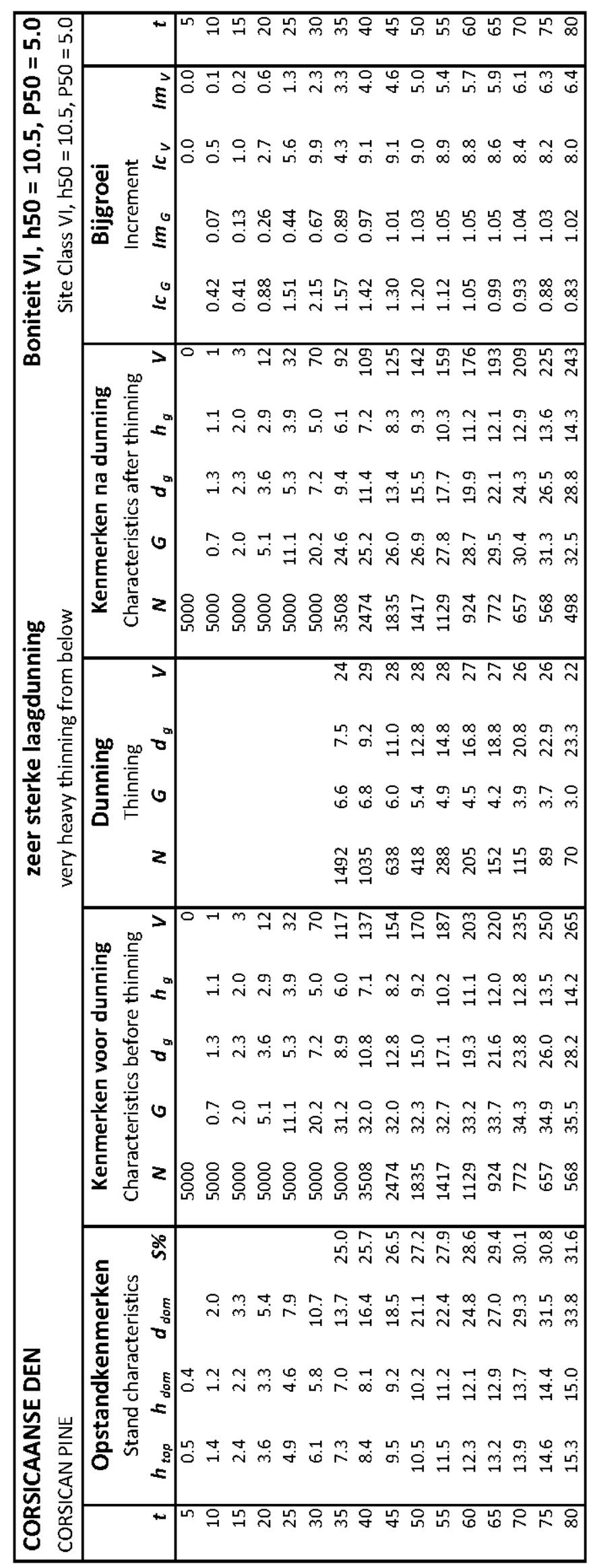




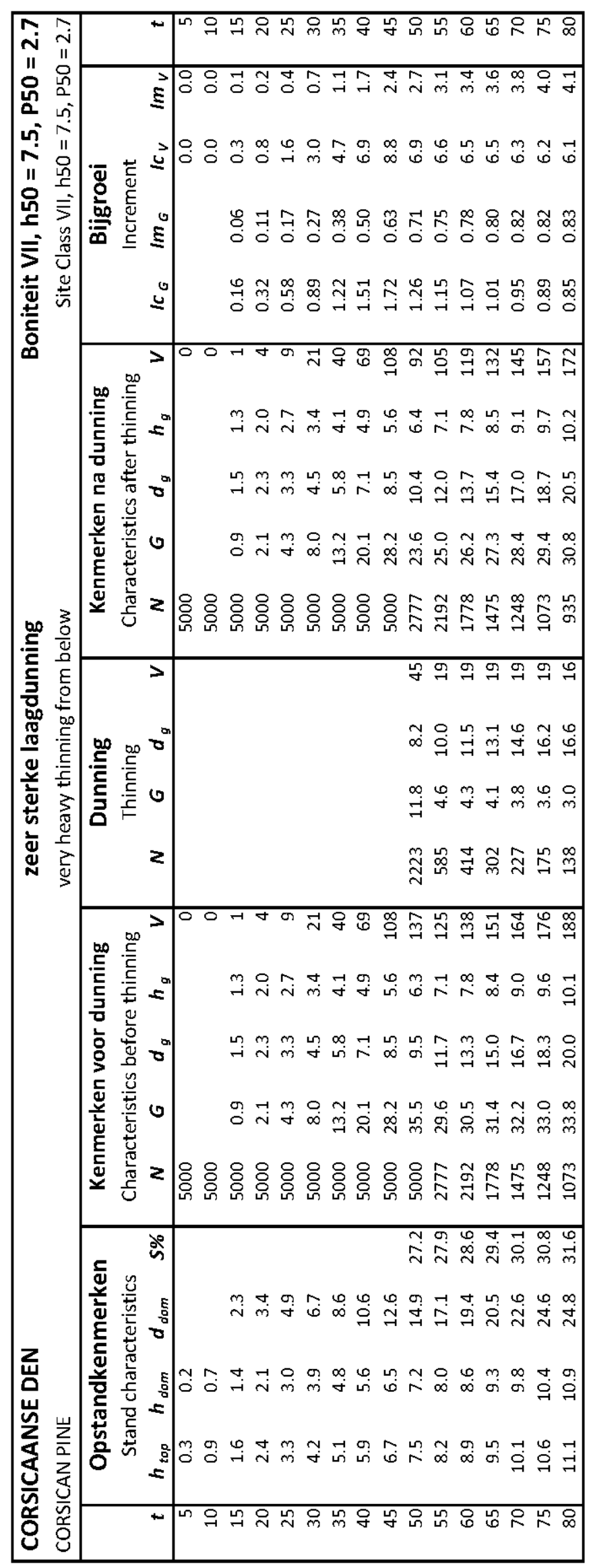




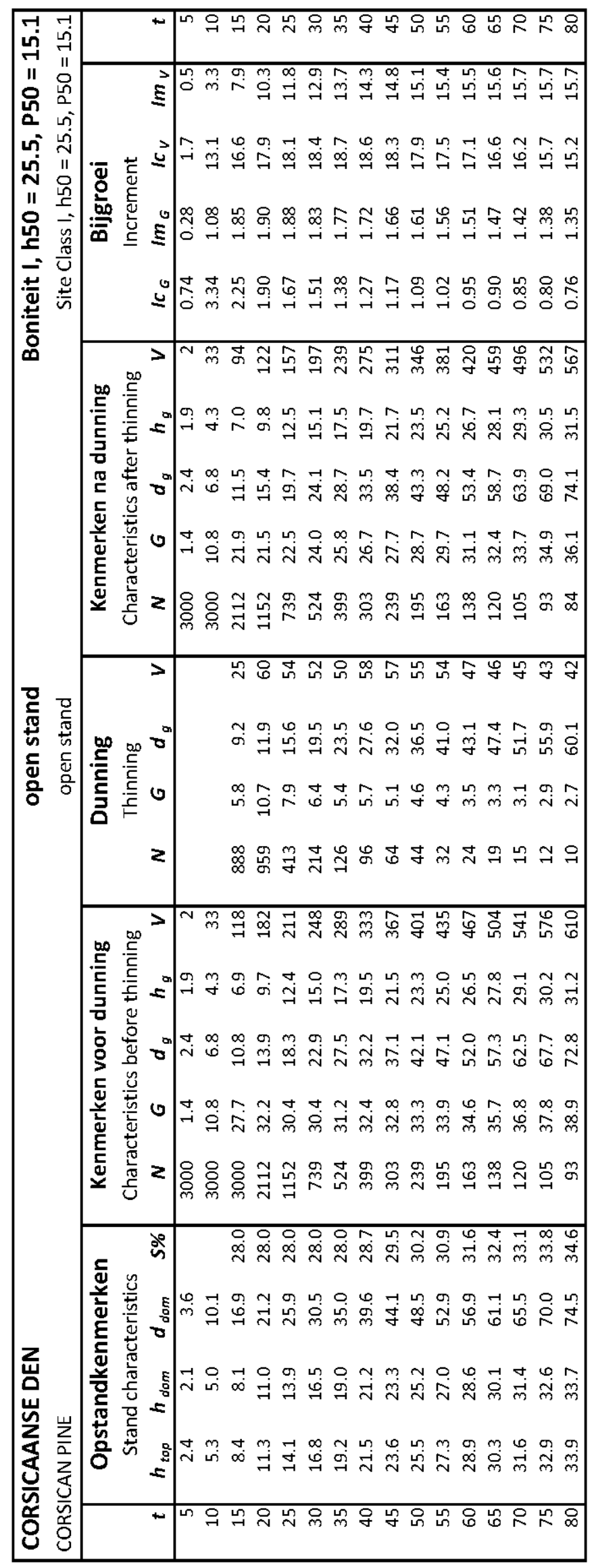




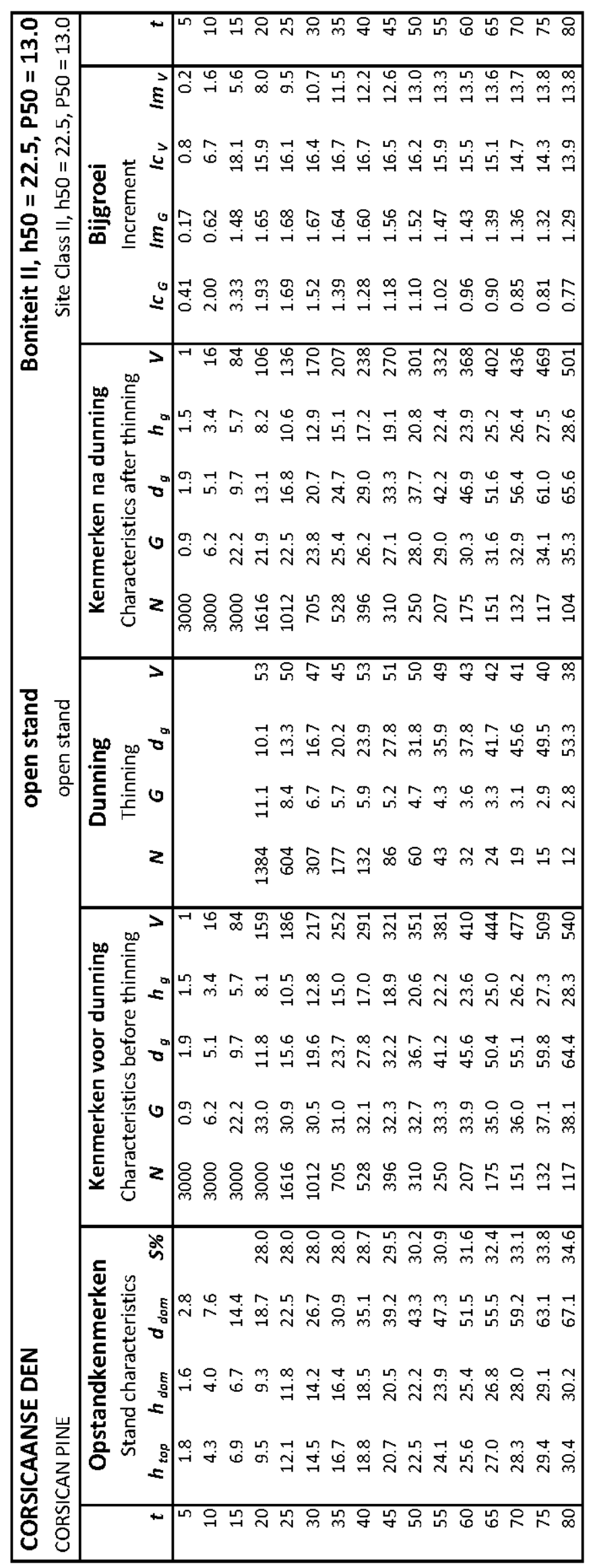




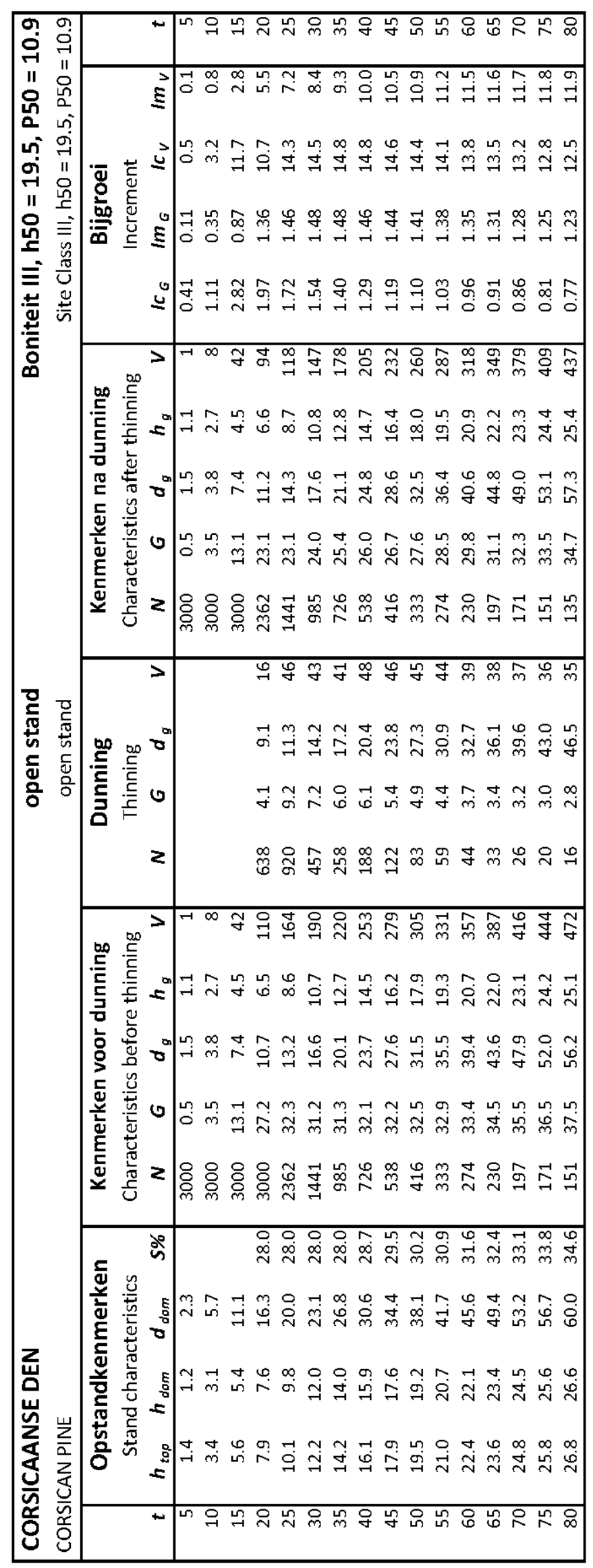




\begin{tabular}{|c|c|c|}
\hline & & 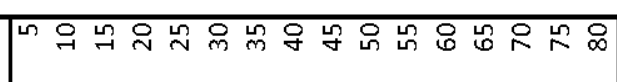 \\
\hline 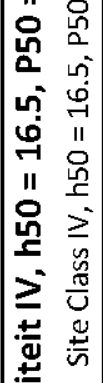 & 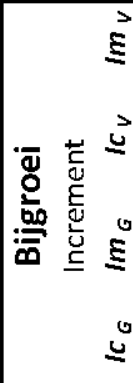 & 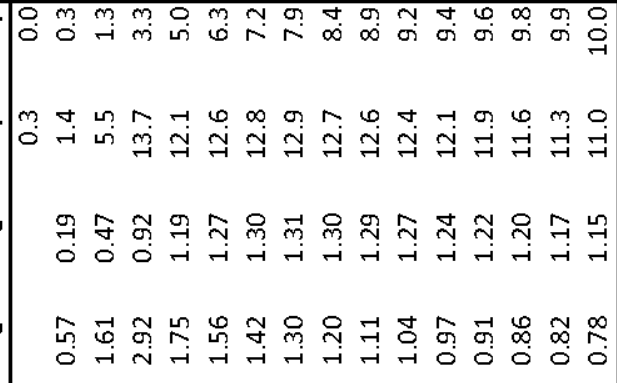 \\
\hline & 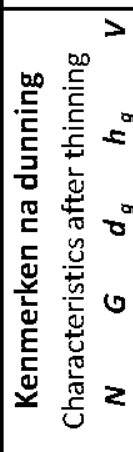 & 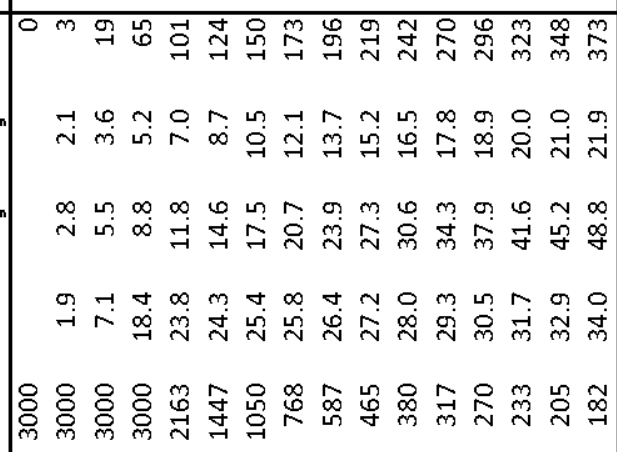 \\
\hline 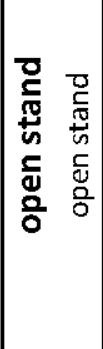 & 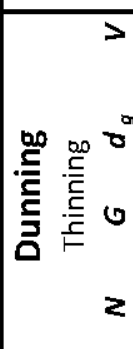 & 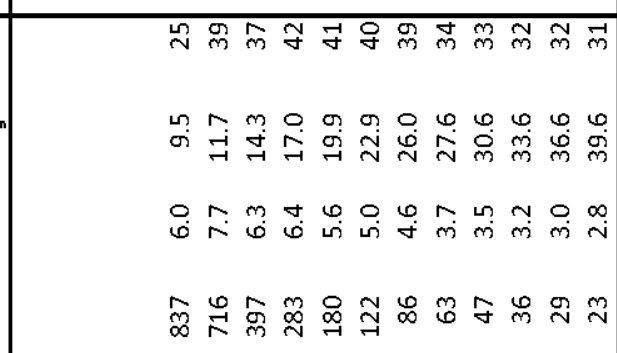 \\
\hline & 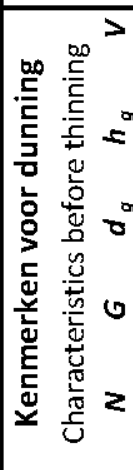 & 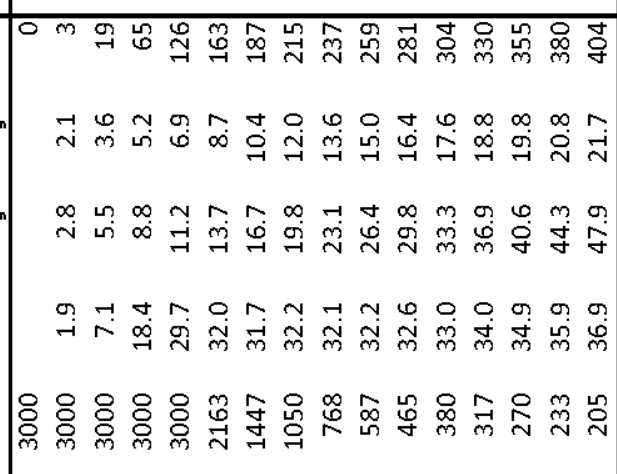 \\
\hline 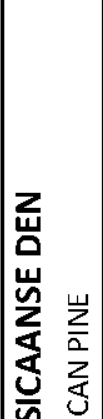 & 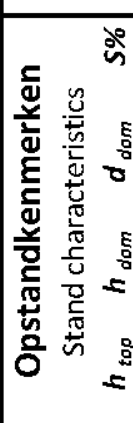 & 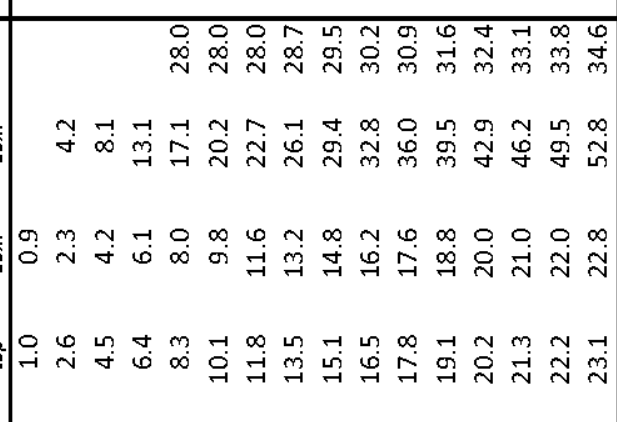 \\
\hline 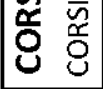 & & 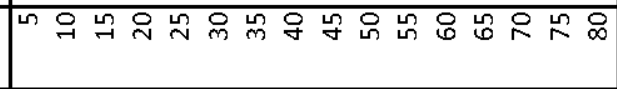 \\
\hline
\end{tabular}




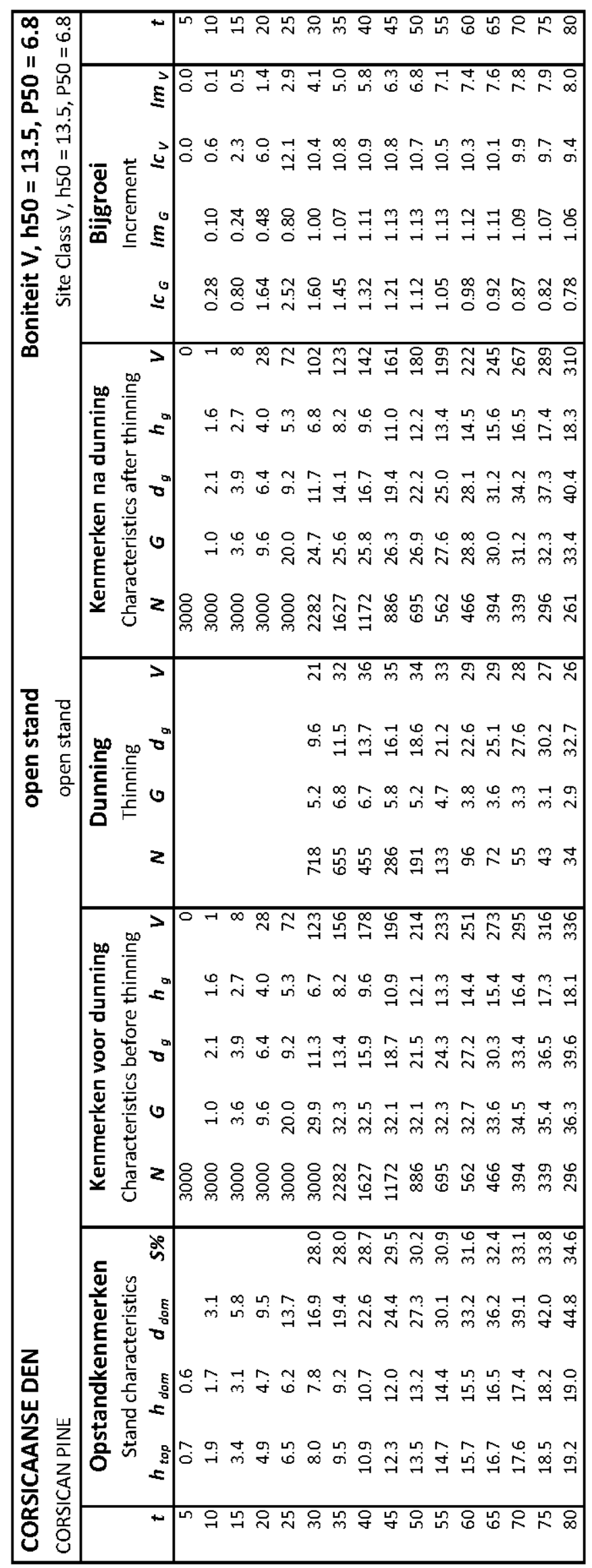




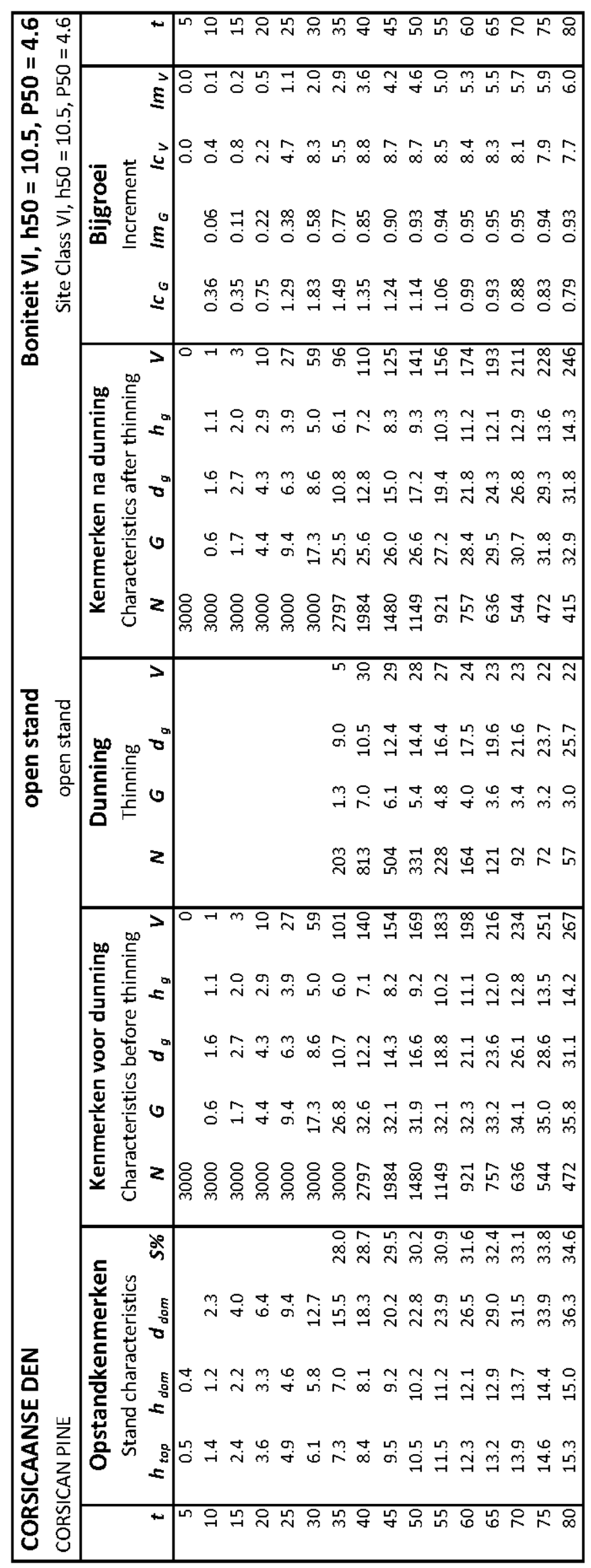




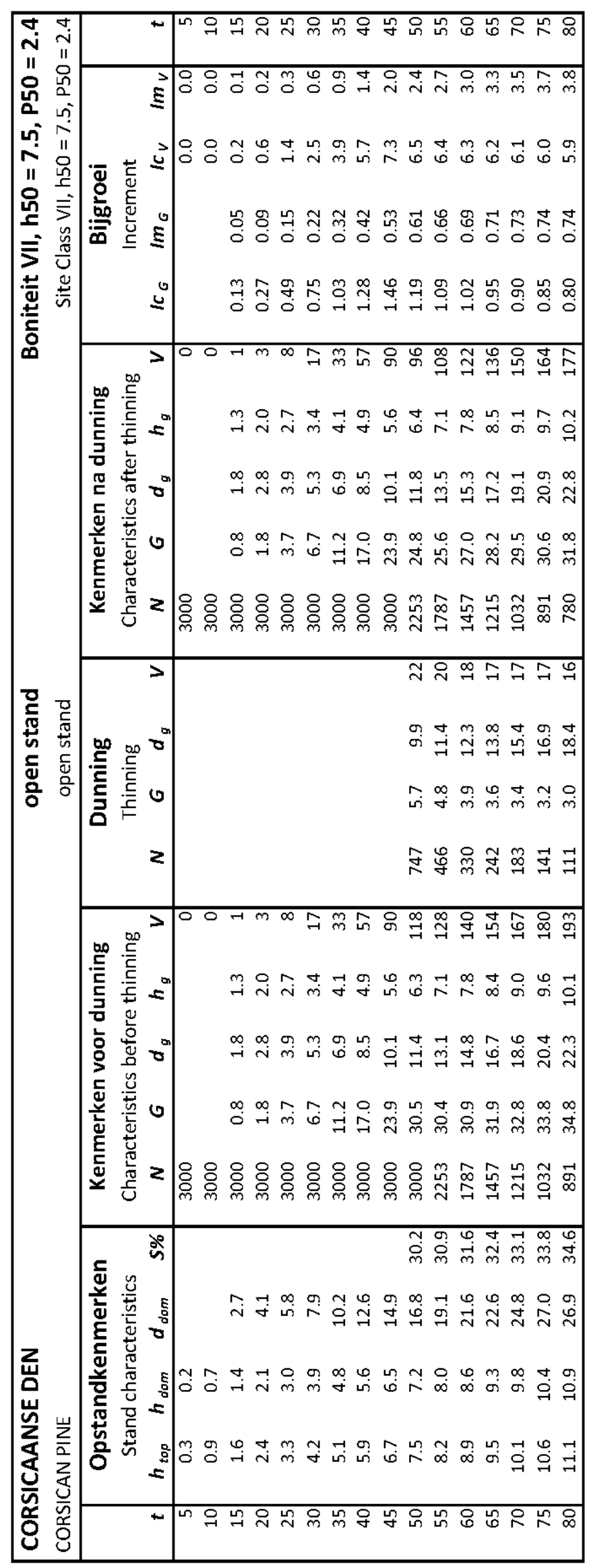




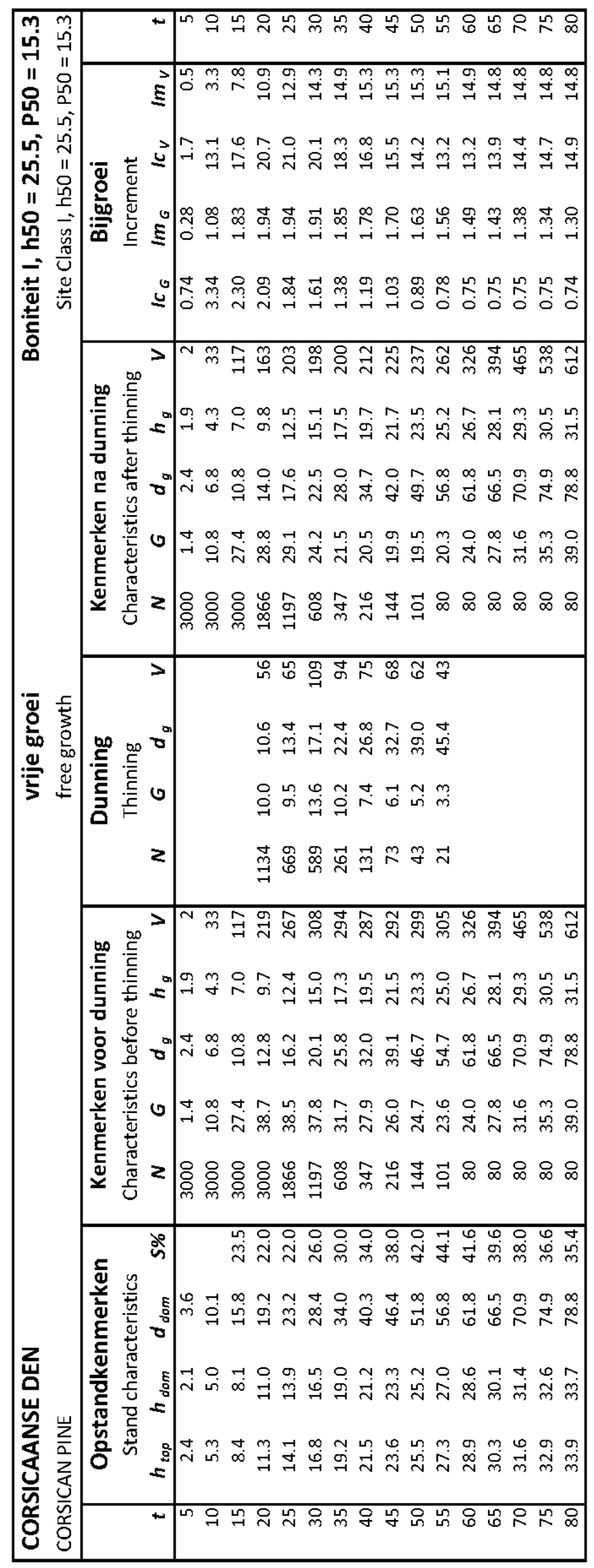




\begin{tabular}{|c|c|c|}
\hline & & 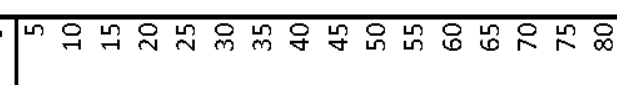 \\
\hline 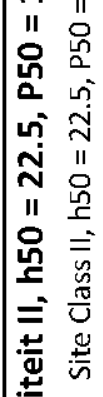 & 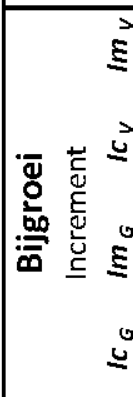 & 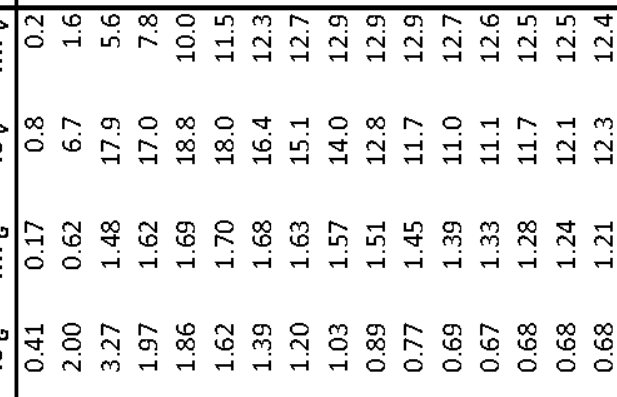 \\
\hline & 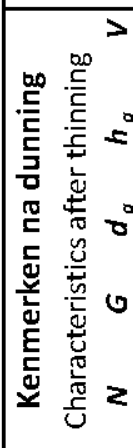 & 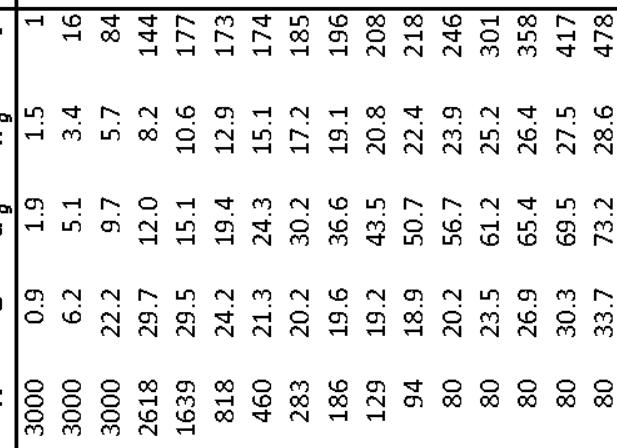 \\
\hline 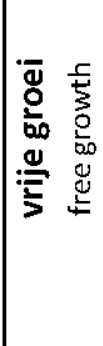 & 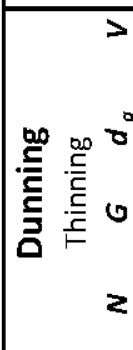 & 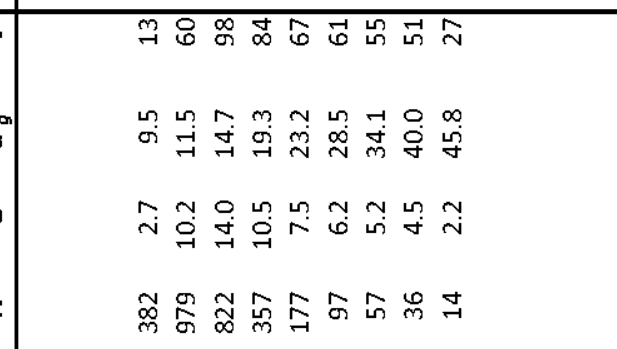 \\
\hline & 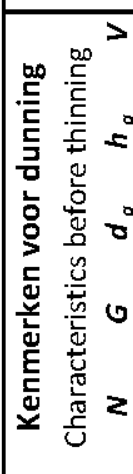 & 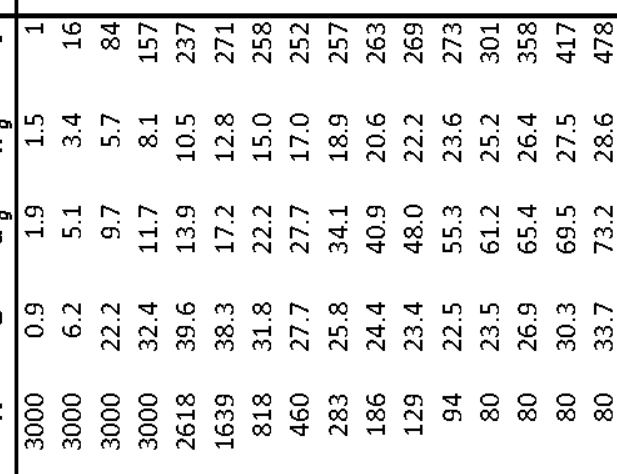 \\
\hline 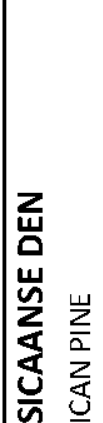 & 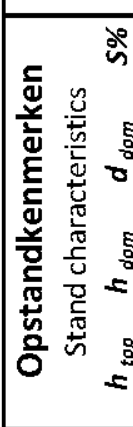 & 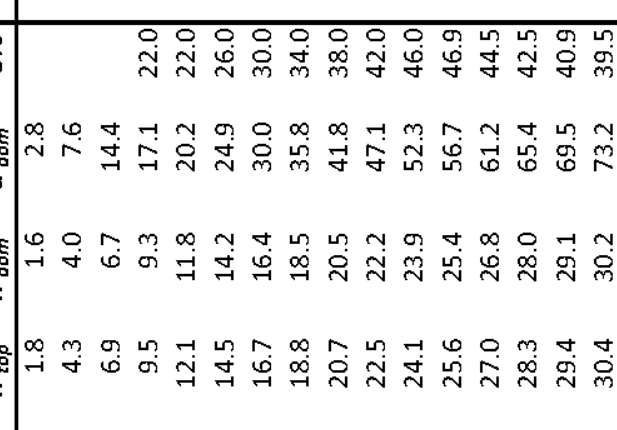 \\
\hline ס্তু & & 윰요 \\
\hline
\end{tabular}




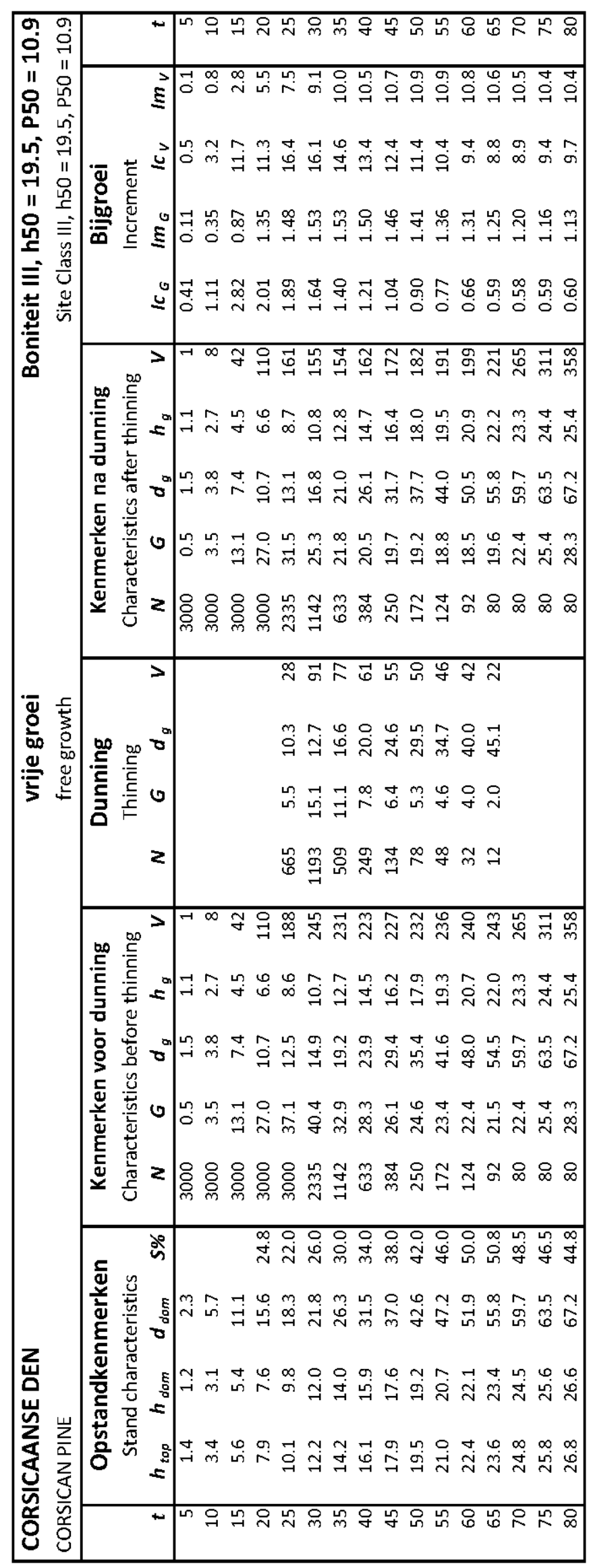




\begin{tabular}{|c|c|c|}
\hline & & 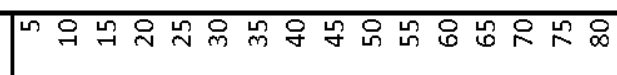 \\
\hline 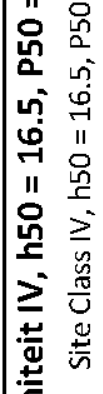 & 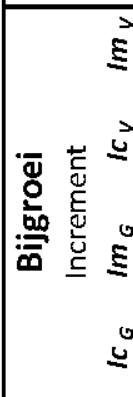 & 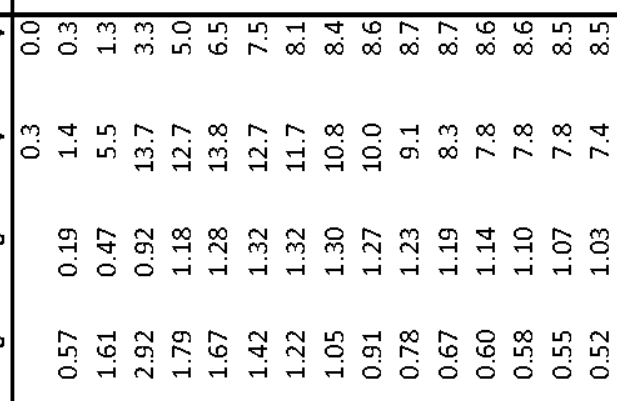 \\
\hline & 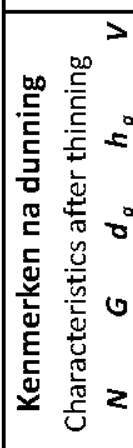 & 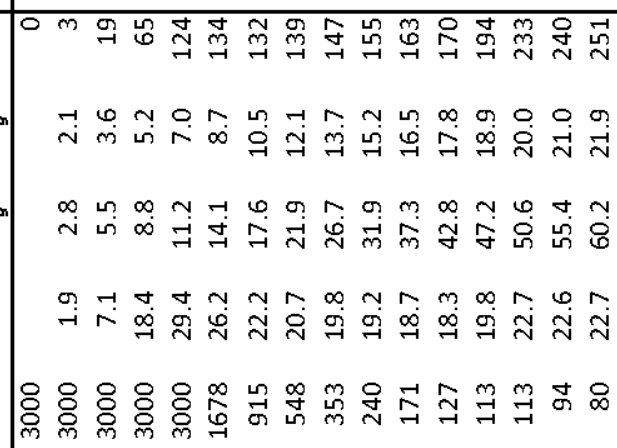 \\
\hline 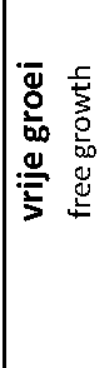 & ن & 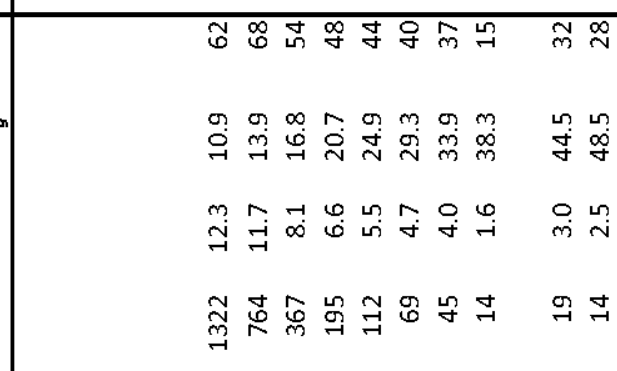 \\
\hline & 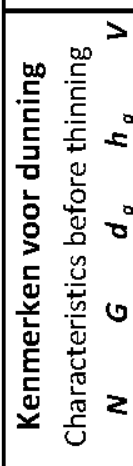 & 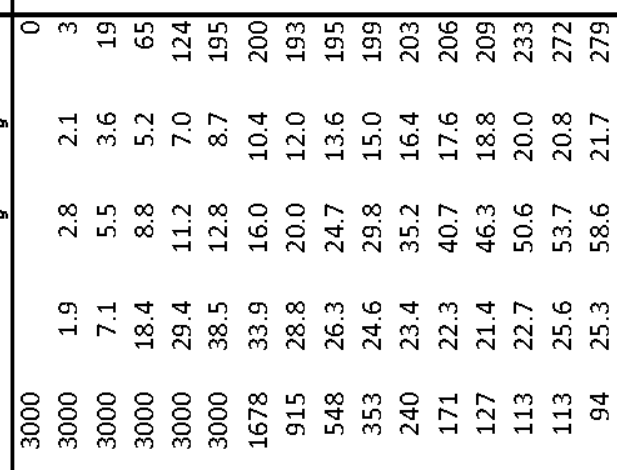 \\
\hline 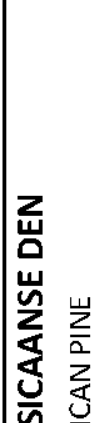 & 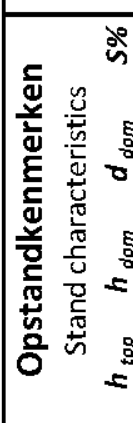 & 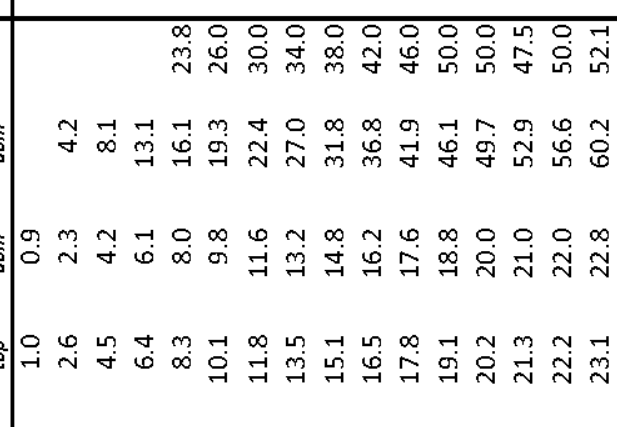 \\
\hline & & స్ స్ \\
\hline
\end{tabular}




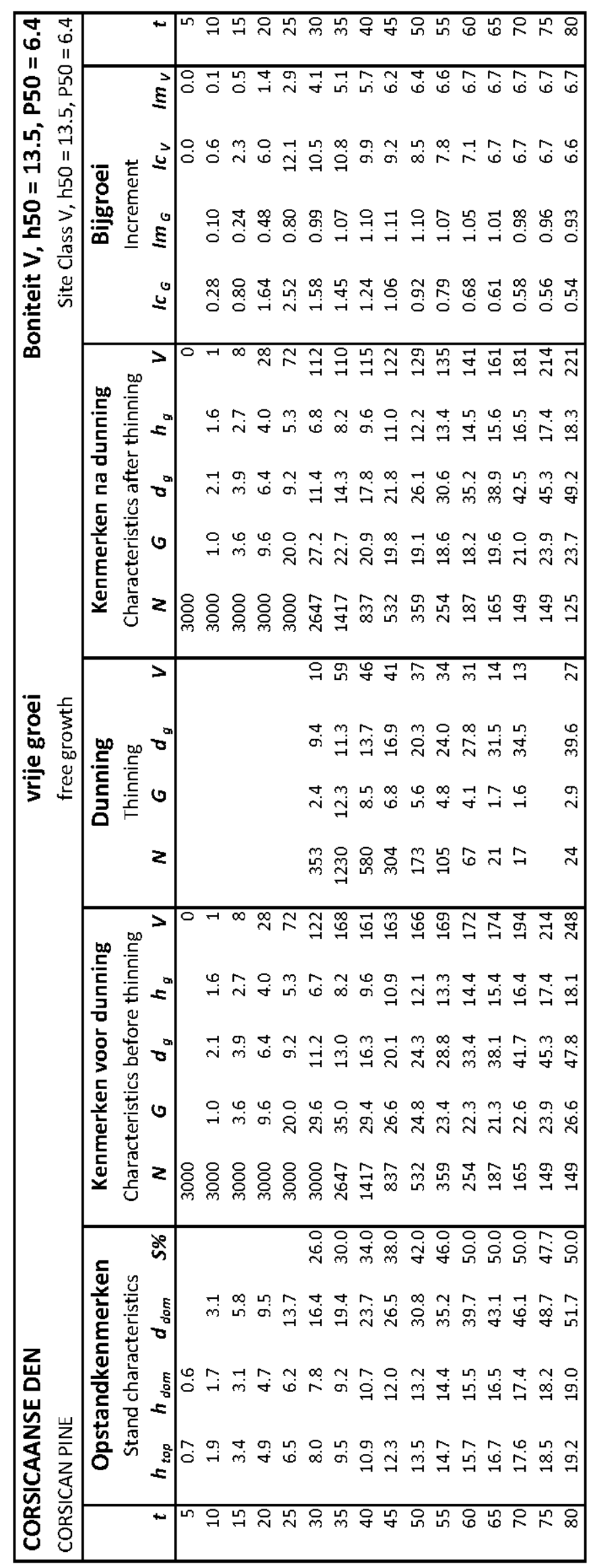




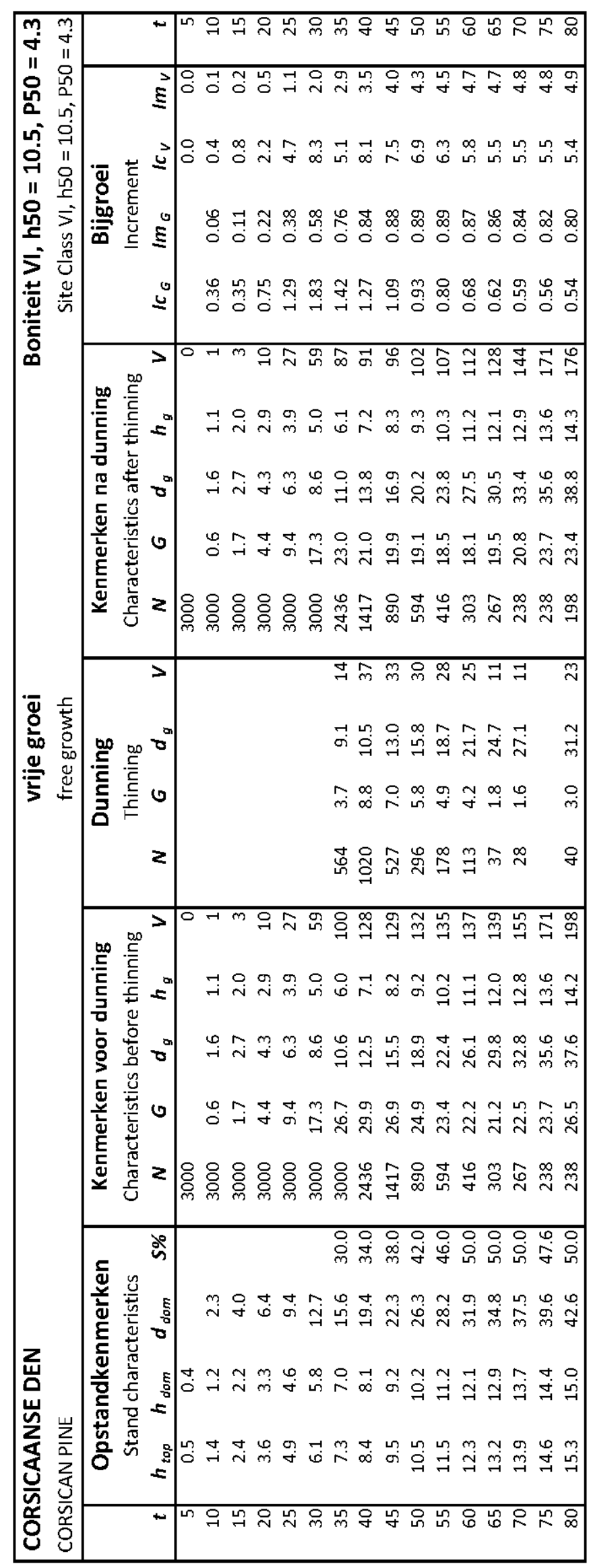




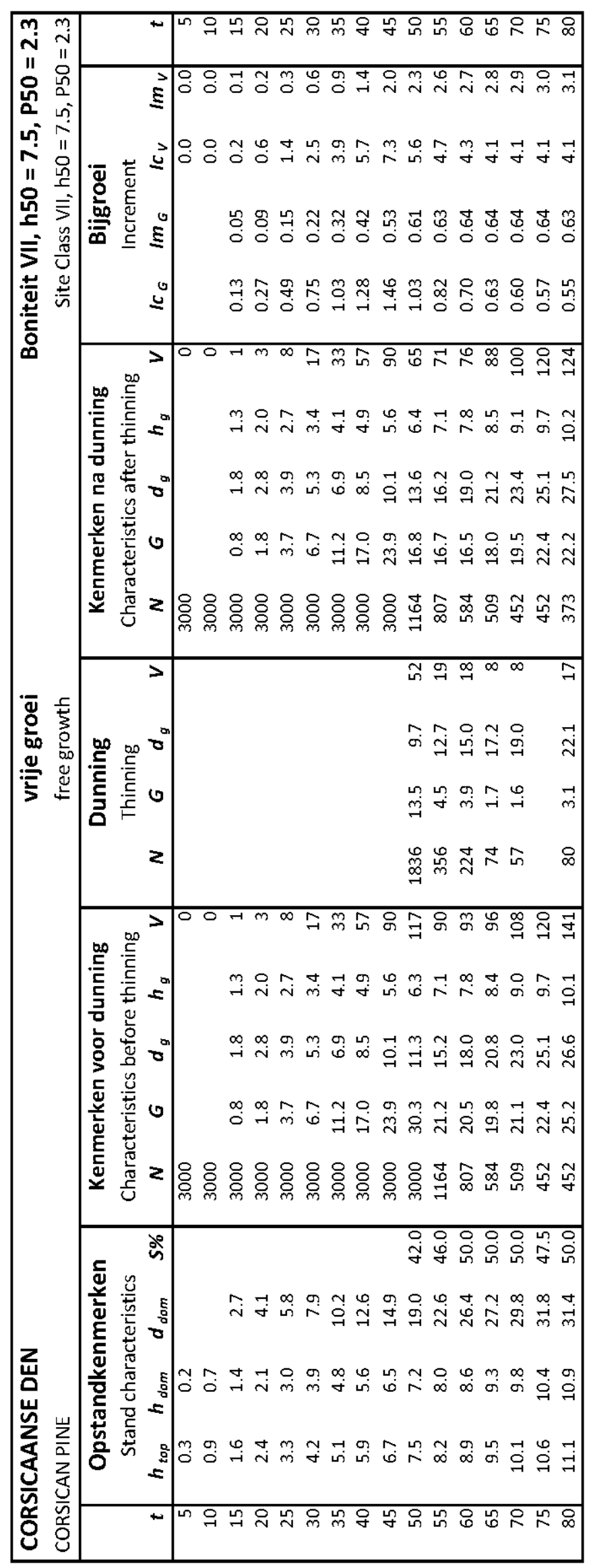

